\title{
Axially Chiral Stable Radicals: Resolution and Characterization of Blatter Radical Atropisomers
}

\author{
Agnieszka Bodzioch,${ }^{\dagger *}$ Anna Pietrzak,${ }^{\perp}$ and Piotr Kaszyński ${ }^{\dagger \$}{ }^{* *}$ \\ † Centre of Molecular and Macromolecular Studies, Polish Academy of Sciences, 90-363 Łódź, Poland \\ Faculty of Chemistry, Łódź University of Technology, Żeromskiego 116, 90-024, Łódź, Poland \\ ${ }^{\sharp}$ Faculty of Chemistry, University of Łódź, 91-403 Łódź, Poland. \\ ${ }^{\S}$ Department of Chemistry, Middle Tennessee State University, Murfreesboro, TN, 37132, USA
}

\section{Table of contents}

Page

1. Synthetic and characterization details $\quad$......S2

2. NMR spectra $\quad \ldots . .$. S6

3. IR spectra $\quad \ldots . . . \mathrm{S} 10$

4. XRD data $\quad \ldots . . . \mathrm{S} 11$

5. UV-vis spectroscopy _....S14

6. EPR spectroscopy _....S15

7. Electrochemical results $\quad \ldots . . . \mathrm{S} 17$

8. Chiral HPLC analysis and resolution $\quad$......S19

9. Optical rotation $\quad \ldots . . . \mathrm{S} 21$

10. Electronic circular dichroism spectroscopy $\quad$.....S21

11. Determination of absolute configuration of the atropisomers $\quad \ldots .$. S23

12. Kinetic analysis of racemization $\quad$.....S27

13. Computational details $\quad$......S34

14. Partial output from TD-DFT calculations $\quad$.....S34

15. Archive for DFT calculations $\quad$.....S40

16. References $\quad$......S44 


\section{Synthetic and characterization details}

Reagents and solvents were obtained commercially.

Heat in reactions involving elevated temperatures was supplied using oil baths, and reported temperature refers to that of the bath.

NMR spectra were obtained at $400\left({ }^{1} \mathrm{H}\right)$ and $100 \mathrm{MHz}\left({ }^{13} \mathrm{C}\right)$ in $\mathrm{CDCl}_{3}$ or DMSO- $d_{6}$. Chemical shifts were referenced to the solvent $\left({ }^{1} \mathrm{H}\right.$ and ${ }^{13} \mathrm{C}: 7.26$ and $77.16 \mathrm{ppm}$ for $\mathrm{CDCl}_{3}$, and 2.50 and $39.52 \mathrm{ppm}$ for DMSO- $d_{6}$, respectively). ${ }^{1}$ Melting points were determined on a Melt-Temp II apparatus in capillaries, and they are uncorrected. The ESI-MS spectra were obtained using a Varian 500 MS LS Ion Trap spectrometer. IR spectra were measured in KBR pellets.

\section{Preparation of racemic radicals rac-1. A general procedure.}

A solution of an organolithium reagent (generated from $1.3 \mathrm{mmol}$ of appropriate bromonaphthalene and $2.6 \mathrm{mmol} t$-BuLi) in THF $(3 \mathrm{~mL})$ was added dropwise at $-78{ }^{\circ} \mathrm{C}$ to a stirred solution of corresponding benzo[e][1,2,4]triazine $2(1.0 \mathrm{mmol})$ in dry THF $(3 \mathrm{~mL})$. The resulting mixture was stirred for $20 \mathrm{~min}$ at $-78{ }^{\circ} \mathrm{C}$ and at $\mathrm{rt}$ for $30 \mathrm{~min}$. Then it was opened to air and stirred overnight at rt. Water and $\mathrm{CH}_{2} \mathrm{Cl}_{2}$ were added and the organic phase was separated, washed with water and dried $\left(\mathrm{Na}_{2} \mathrm{SO}_{4}\right)$. After evaporation of solvent the resulting crude product was purified by column chromatography $\left(\mathrm{SiO}_{2}\right.$ passivated with $1 \% \mathrm{Et}_{3} \mathrm{~N}$ in hexane, hexane/AcOEt) to afford radicals $r a c-1$. Analytically pure radicals were obtained by recrystallization from $n$-heptane.

3-Phenyl-1-(8-phenylnaphth-1-yl)-1,4-dihydrobenzo[e][1,2,4]triazin-4-yl (rac-1aA). Radical rac-1aA (161 mg, $0.392 \mathrm{mmol}, 62 \%$ yield) was obtained from 3-phenylbenzo[e][1,2,4]triazine ${ }^{2}$ (2a, $131 \mathrm{mg}, 0.632 \mathrm{mmol}$ ) and 1-bromo-8-phenylnaphthalene (3A , $224 \mathrm{mg}, 0.794 \mathrm{mmol})$ as a dark brown solid. Recrystallization from $n$-heptane gave the analytically pure microcrystalline product in 44\% yield: $\mathrm{mp} 179-180{ }^{\circ} \mathrm{C}$ ( $n$-heptane); IR $v$ 3047, 1484, 1391, 831, 770, $695 \mathrm{~cm}^{-1}$; UV-vis $\left(\mathrm{CH}_{2} \mathrm{Cl}_{2}\right) \lambda_{\text {max }}(\log \varepsilon) 231$ (4.69), 270 (4.48), 370 (3.56), 487 (3.15), 543 (2.81) nm; ESI-MS, $m / z$ $411\left(100,[\mathrm{M}+\mathrm{H}]^{+}\right)$; HRMS (ESI-TOF) $\mathrm{m} / z \cdot[\mathrm{M}+\mathrm{H}]^{+}$calcd for $\mathrm{C}_{29} \mathrm{H}_{21} \mathrm{~N}_{3} 411.1735$, found 411.1719. Anal. Calcd for $\mathrm{C}_{29} \mathrm{H}_{20} \mathrm{~N}_{3}: \mathrm{C}, 84.85 ; \mathrm{H}, 4.91 ; \mathrm{N}, 10.24$. Found: C, 84.72; H, 4.82; N, 10.25. Chiral HPLC: $\mathrm{t}_{\mathrm{R} 1}=14.45 \min (+), \mathrm{t}_{\mathrm{R} 2}=16.79 \min (-)$.

1-[8-(4-tert-Butylphenyl)naphth-1-yl)-3-phenyl-1,4-dihydrobenzo[e][1,2,4]triazin-4-yl ( rac1aB). Racemic radical rac-1aB (51.0 mg, $0.109 \mathrm{mmol}, 29 \%$ yield) was obtained from 3phenylbenzo[e][1,2,4]triazine ${ }^{2} \quad(\mathbf{2 a}, \quad 78.0 \quad \mathrm{mg}, \quad 0.377 \quad \mathrm{mmol})$ and 1-bromo-8-(4-tertbutylphenyl)naphthalene (3B, $141 \mathrm{mg}, 0.416 \mathrm{mmol})$ as a dark brown powder: $\mathrm{mp} 108-109{ }^{\circ} \mathrm{C}(n$ - 
heptane); IR $v$ 3057, 2961, 1485, 1392, 834, 756, $696 \mathrm{~cm}^{-1}$; UV-vis $\left(\mathrm{CH}_{2} \mathrm{Cl}_{2}\right) \lambda_{\max }(\log \varepsilon) 229$ (4.75), 269 (4.60), 373 (3.65), 444 (3.40), 490 (3.27) nm; ESI-MS, m/z 467 (100, [M+H]+); HRMS (ESI-TOF) $m / z$ [M+H] $]^{+}$calcd for $\mathrm{C}_{33} \mathrm{H}_{29} \mathrm{~N}_{3}$ : 467.2361, found 467.2357. Anal. Calcd for $\mathrm{C}_{33} \mathrm{H}_{28} \mathrm{~N}_{3}$ : C, 84.95; H, 6.05; $\mathrm{N}, 9.01$. Found: C, 85.01; H, 5.99; $\mathrm{N}, 9.08$. Chiral HPLC: $\mathrm{t}_{\mathrm{R} 1}=9.85 \mathrm{~min}(+), \mathrm{t}_{\mathrm{R} 2}$ $=11.47 \min (-)$.

3-tert-Butyl-1-(8-phenylnaphth-1-yl)-1,4-dihydrobenzo[e][1,2,4]triazin-4-yl

(rac-1bA).

Radical rac-1bA $\quad(49.0 \mathrm{mg}, \quad 0.126,45 \%$ yield) was obtained from 3-(tertbutyl)benzo[ $e][1,2,4]$ triazine $(\mathbf{2 b}, 29.0 \mathrm{mg}, 0.155 \mathrm{mmol})$ and 1-bromo-8-phenylnaphthalene (3A , $53.0 \mathrm{mg}, 0.188 \mathrm{mmol}$ ) as a dark brown solid. Recrystallization from $n$-heptane gave the analytically pure microcrystalline product in $11 \%$ yield: $\mathrm{mp} 177-178{ }^{\circ} \mathrm{C}$ ( $n$-heptane); IR $v 3058$, 2954, 1481, 1400, 832, 770, $699 \mathrm{~cm}^{-1}$; UV-vis $\left(\mathrm{CH}_{2} \mathrm{Cl}_{2}\right) \lambda_{\max }(\log \varepsilon) 233$ (4.69), 296 (3.96), 346 (3.60), 442 (3.33), 544 (2.90) nm; ESI-MS, m/z $391\left(90,[\mathrm{M}+\mathrm{H}]^{+}\right), 390\left(100, \mathrm{M}^{+}\right)$; HRMS (ESITOF) $m / z[M+H]^{+}$calcd for $\mathrm{C}_{27} \mathrm{H}_{25} \mathrm{~N}_{3} 391.2048$, found 391.2032. Anal. Calcd for $\mathrm{C}_{27} \mathrm{H}_{24} \mathrm{~N}_{3}: \mathrm{C}$, 83.04; H, 6.19; $\mathrm{N}, 10.76$. Found: $\mathrm{C}, 83.02 ; \mathrm{H}, 6.07 ; \mathrm{N}, 10.82$. Chiral HPLC: $\mathrm{t}_{\mathrm{R} 1}=11.55 \mathrm{~min}(+), \mathrm{t}_{\mathrm{R} 2}$ $=12.77 \min (-)$.

3-(tert-Butyl)benzo[e $][1,2,4]$ triazine $(\mathbf{2 b})$. $^{3}$ Following the method of Koutentis, ${ }^{4} N^{\prime}-(2-$ nitrophenyl)pivalohydrazide $(5,1.15 \mathrm{~g}, 4.85 \mathrm{mmol})$ was dissolved in glacial acetic acid (40 $\mathrm{mL})$, Sn powder (2.30 g, $19.4 \mathrm{mmol})$ was added, and the solution was left stirring vigorously at room temperature for $1 \mathrm{~h}$. The reaction was then heated at $120{ }^{\circ} \mathrm{C}$ for $20 \mathrm{~min}$ and cooled. Then, AcOEt $(100 \mathrm{~mL})$ and water $(200 \mathrm{~mL})$ were added, and the resulting biphasic mixture was passed through a layer of Cellite. The organic layer was separated, and the aqueous layer was extracted with AcOEt $(2 \times 100 \mathrm{~mL})$. The combined organic extracts were washed with sat. $\mathrm{NaHCO}_{3}$ and dried $\left(\mathrm{Na}_{2} \mathrm{SO}_{4}\right)$. The solvent was removed and the solid residue was dissolved in a $\mathrm{MeOH} / \mathrm{CH}_{2} \mathrm{Cl}_{2}$ mixture $(1: 1,20 \mathrm{~mL})$, and solid $\mathrm{NaIO}_{4}(1.16 \mathrm{~g}, 5.42 \mathrm{mmol})$ was added. The mixture was stirred until the initial dihydro derivative was no longer observed by TLC (about $30 \mathrm{~min}$ ). Inorganic salts were filtered, solvents were evaporated, and the resulting yellow solid residue was passed through a short $\mathrm{SiO}_{2}$ column (petroleum eter/AcOEt) giving $0.659 \mathrm{~g}$ (3.52 mmol, 73\% yield) of 3-(tertbutyl)benzo[e][1,2,4]triazine (2b) as a yellow microcrystalline solid: mp $72-73{ }^{\circ} \mathrm{C}(\mathrm{EtOH}) ;{ }^{1} \mathrm{H}$ NMR $\left(\mathrm{CDCl}_{3}, 500 \mathrm{MHz}\right) \delta 8.49(\mathrm{~d}, J=8.4 \mathrm{~Hz}, 1 \mathrm{H}), 8.02(\mathrm{~d}, J=8.5 \mathrm{~Hz}, 1 \mathrm{H}), 7.93$ (t, $J=8.2 \mathrm{~Hz}$, $1 \mathrm{H}), 7.80(\mathrm{t}, J=7.8 \mathrm{~Hz}, 1 \mathrm{H}), 1.63(\mathrm{~s}, 9 \mathrm{H}) ;{ }^{13} \mathrm{C}\left\{{ }^{1} \mathrm{H}\right\} \mathrm{NMR}\left(\mathrm{CDCl}_{3}, 125 \mathrm{MHz}\right) \delta 172.3,145.9$, 140.7, 135.0, 129.9, 129.5, 129.1, 39.2, 29.8. Anal. Calcd for $\mathrm{C}_{11} \mathrm{H}_{13} \mathrm{~N}_{3}$ : C, 70.56; H, 7.00; N, 22.44. Found: C, 70.49; H, 7.28; N, 22.26. 


\section{Preparation of 8-substituted-1-bromonaphthalenes 3. A general procedure.}

Following a literature procedure, ${ }^{5}$ 1,8-dibromonaphthalene $(715 \mathrm{mg}, 2.50 \mathrm{mmol})$, arylboronic acid (2.53 mmol, 1.01 eqiv), $\mathrm{Pd}\left(\mathrm{PPh}_{3}\right)_{4}(144 \mathrm{mg}, 0.125,5 \mathrm{~mol} \%)$ were dissolved in deoxygenated 1,2dimethoxyethane $(15 \mathrm{~mL})$. Then, the solution of $\mathrm{Na}_{2} \mathrm{CO}_{3}(795 \mathrm{mg}, 7.5 \mathrm{mmol}, 3$ equiv) in water (7 $\mathrm{mL}$ ), which was previously purged with argon for $15 \mathrm{~min}$, was added. The reaction mixture was refluxed overnight, cooled to room temperature, treated with water $(15 \mathrm{~mL})$ and extracted with $\mathrm{CH}_{2} \mathrm{Cl}_{2}(2 \times 20 \mathrm{~mL})$. The extract was dried $\left(\mathrm{Na}_{2} \mathrm{SO}_{4}\right)$, filtered and concentrated to dryness. The resulting residue was purified by column chromatography $\left(\mathrm{SiO}_{2}\right.$, pentane) giving 8-substituted-1bromonaphthalenes $\mathbf{3}$.

1-Bromo-8-phenylnaphthalene $\quad \mathbf{( 3 A}) .^{6}$ Following the procedure above, 1-bromo-8phenylnaphthalene (3A, $246 \mathrm{mg}, 0.872 \mathrm{mmol}, 35 \%$ yield) was obtained as a light yellow microcrystalline solid from 1,8-dibromonaphthalene $(715 \mathrm{mg}, 2.50 \mathrm{mmol})$ and phenylboronic acid (309 mg, $2.53 \mathrm{mmol}): \mathrm{mp} 37-38{ }^{\circ} \mathrm{C}$ (n-pentane); ${ }^{1} \mathrm{H} \mathrm{NMR}\left(\mathrm{CDCl}_{3}, 400 \mathrm{MHz}\right) \delta 7.89-7.90(\mathrm{~m}$, 2H), $7.80(\mathrm{~d}, J=7.4 \mathrm{~Hz}, 1 \mathrm{H}), 7.52$ (t, $J=7.3 \mathrm{~Hz}, 1 \mathrm{H}), 7.45$ (d, $J=7.0 \mathrm{~Hz}, 1 \mathrm{H}), 7.40-7.41$ (m, 3H), 7.36-7.37 (m, 2H), $7.30(\mathrm{t}, J=7.9 \mathrm{~Hz}, 1 \mathrm{H}) ;{ }^{13} \mathrm{C}\left\{{ }^{1} \mathrm{H}\right\} \mathrm{NMR}\left(\mathrm{CDCl}_{3}, 100 \mathrm{MHz}\right) \delta 143.0$, $140.5,136.2$, 133.9, 131.3, 130.3, 129.7, 129.03, 128.98, 127.5, 127.0, 126.2, 125.4, 120.3; MS (EI) $\mathrm{m} / z .203\left(100,[\mathrm{M}]^{+}\right)$. Anal. Calcd for $\mathrm{C}_{16} \mathrm{H}_{11} \mathrm{Br}$ : C, 67.87; H, 3.92. Found: C, 67.78; H, 4.02.

1-Bromo-8-(4-tert-butylphenyl)naphthalene (3B). Following the procedure above, 1-bromo-8(4-tert-butylphenyl)naphthalene (3B, $858 \mathrm{mg}, 2.53 \mathrm{mmol}, 51 \%$ yield) was obtained as a white microcrystalline solid from 1,8-dibromonaphthalene $(1.410 \mathrm{~g}, 4.93 \mathrm{mmol})$ and 4-tertbutylphenylboronic acid (885 mg, $4.97 \mathrm{mmol}): \mathrm{mp} 61-62{ }^{\circ} \mathrm{C}(\mathrm{EtOH}) ;{ }^{1} \mathrm{H} \mathrm{NMR}\left(\mathrm{CDCl}_{3}, 400 \mathrm{MHz}\right)$ $\delta 7.95(\mathrm{~d}, J=7.4 \mathrm{~Hz}, 1 \mathrm{H}), 7.82-7.89(\mathrm{~m}, 2 \mathrm{H}), 7.78(\mathrm{~d}, J=7.4 \mathrm{~Hz}, 1 \mathrm{H}), 7.40-7.51(\mathrm{~m}, 4 \mathrm{H}), 7.24$ $7.30(\mathrm{~m}, 2 \mathrm{H}), 1.39$ (s, 9H); ${ }^{13} \mathrm{C}\left\{{ }^{1} \mathrm{H}\right\} \mathrm{NMR}\left(\mathrm{CDCl}_{3}, 100 \mathrm{MHz}\right) \delta 150.2,140.6,139.8,136.2,133.8$, $131.3,129.9,129.0,128.8,126.8,126.1,125.5,124.4,120.3,34.7,31.7$; MS (EI) $\mathrm{m} / z 338$ (40, [M ]$^{+}$). Anal. Calcd for $\mathrm{C}_{20} \mathrm{H}_{19} \mathrm{Br}$ : C, 70.80; H, 5.64. Found: C, 70.95; H, 5.39.

$N^{\prime}$-(2-Nitrophenyl)pivalohydrazide (5). A solution of 1-fluoro-2-nitrobenzene (1.13 g, 9.94 mmol) and pivalohydrazide (1.41 g, $10.0 \mathrm{mmol}, 1.01 \mathrm{eqiv})$ in dry DMSO (3 mL) was stirred at 70 ${ }^{\circ} \mathrm{C}$ for 2 days. After cooling AcOEt $(50 \mathrm{~mL})$ followed by $\mathrm{H}_{2} \mathrm{O}(70 \mathrm{~mL})$ were added to the reaction mixture and the organic layer was separated. The aqueous layer was extracted twice with small portions of AcOEt. The combined organic layers were dried $\left(\mathrm{Na}_{2} \mathrm{SO}_{4}\right)$, the solvent was evaporated, and the solid residue was recrystallized (EtOH) giving $1.15 \mathrm{~g}$ (4.85 mmol, 61\% yield) 
of hydrazide 5 as yellow microcrystalline solid: mp 143-145 ${ }^{\circ} \mathrm{C}(\mathrm{EtOH}) ;{ }^{1} \mathrm{H}$ NMR (DMSO- $d_{6}$, $500 \mathrm{MHz}) \delta 9.93(\mathrm{~s}, 1 \mathrm{H}), 9.12(\mathrm{~s}, 1 \mathrm{H}), 8.09$ (d, $J=8.5 \mathrm{~Hz}, 1 \mathrm{H}), 7.59$ (t, $J=7.8 \mathrm{~Hz}, 1 \mathrm{H}), 7.02(\mathrm{~d}, J$ $=8.6 \mathrm{~Hz}, 1 \mathrm{H}), 6.86(\mathrm{t}, J=7.8 \mathrm{~Hz}, 1 \mathrm{H}), 1.22(\mathrm{~s}, 9 \mathrm{H}) ;{ }^{13} \mathrm{C}\left\{{ }^{1} \mathrm{H}\right\}$ NMR (DMSO- $\left.d_{6}, 125 \mathrm{MHz}\right) \delta$ 176.9, 145.9, 136.4, 131.8, 125.8, 117.8, 114.6, 37.6, 27.1. Anal. Calcd for $\mathrm{C}_{11} \mathrm{H}_{15} \mathrm{~N}_{3} \mathrm{O}_{3}$ : C, 55.69; H, 6.37; N, 17.71. Found C, 55.63; H, 6.48; N, 17.74 . 


\section{NMR spectra}
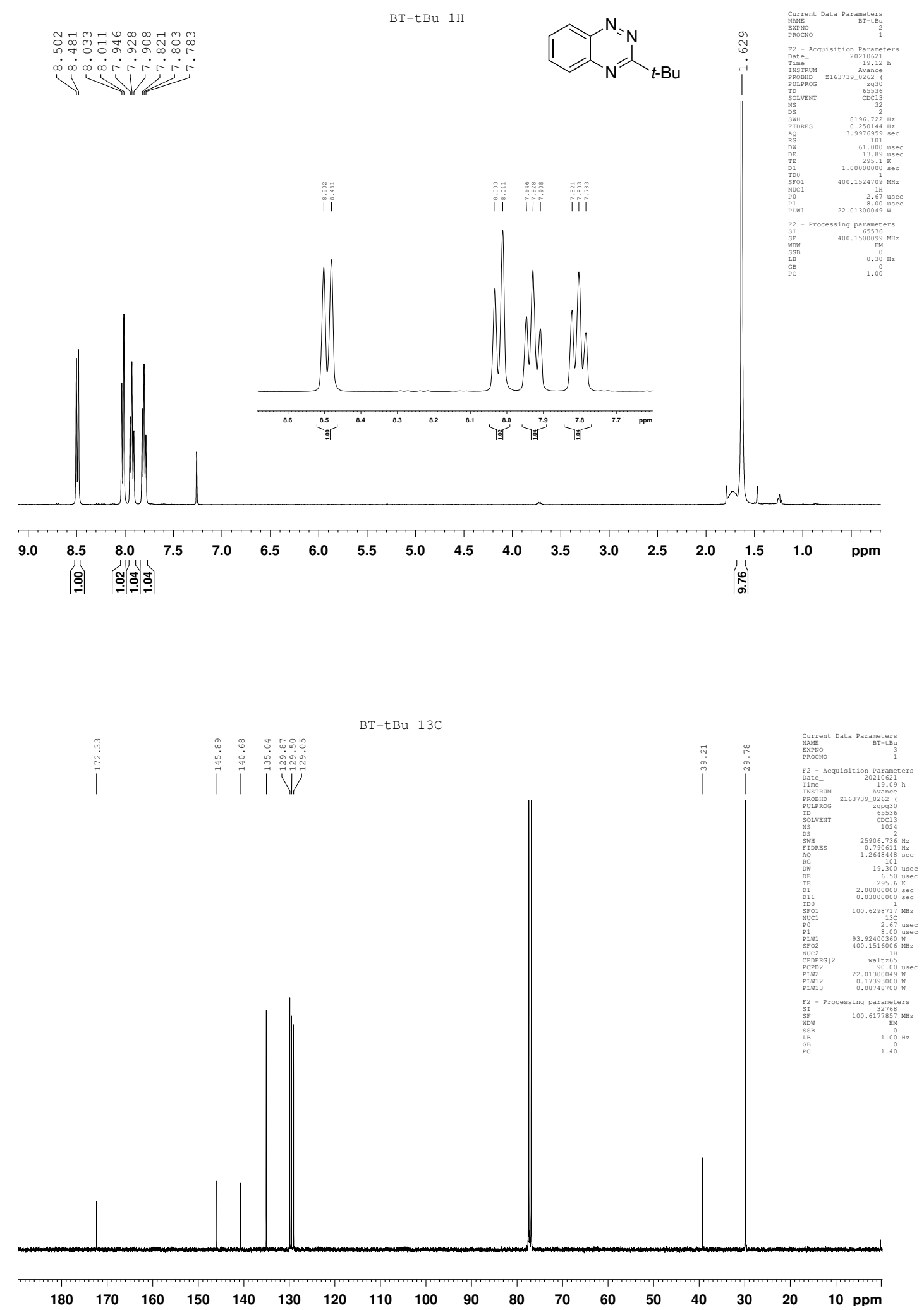

Figure S1. ${ }^{1} \mathrm{H}$ NMR $(400 \mathrm{MHz})$ and ${ }^{13} \mathrm{C}\left\{{ }^{1} \mathrm{H}\right\}$ NMR $(100 \mathrm{MHz})$ spectra of $\mathbf{2 b}\left(\mathrm{CDCl}_{3}\right)$. 

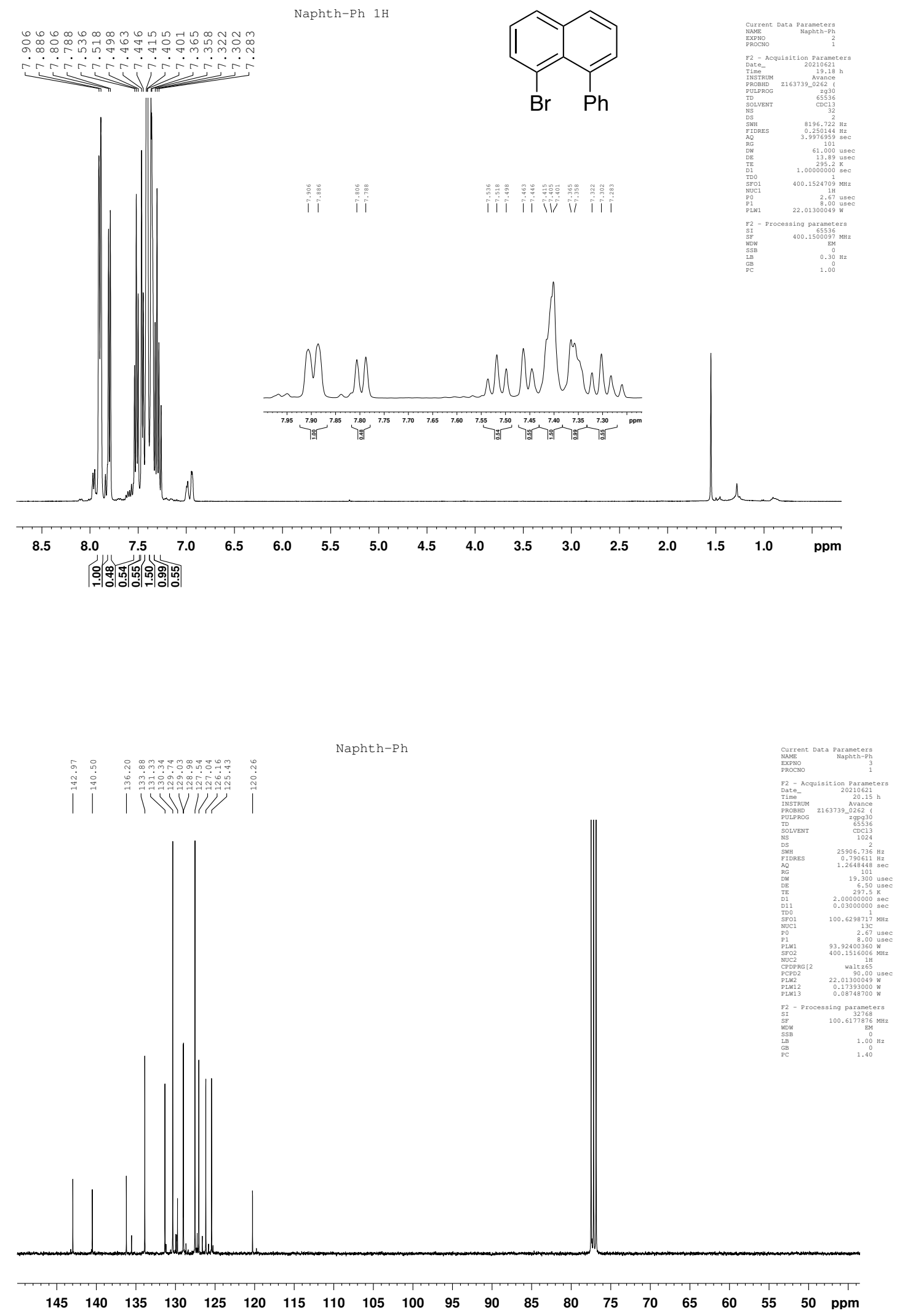

Figure S2. ${ }^{1} \mathrm{H}$ NMR $(400 \mathrm{MHz})$ and ${ }^{13} \mathrm{C}\left\{{ }^{1} \mathrm{H}\right\}$ NMR $(100 \mathrm{MHz})$ spectra of $\mathbf{3 A}\left(\mathrm{CDCl}_{3}\right)$. 

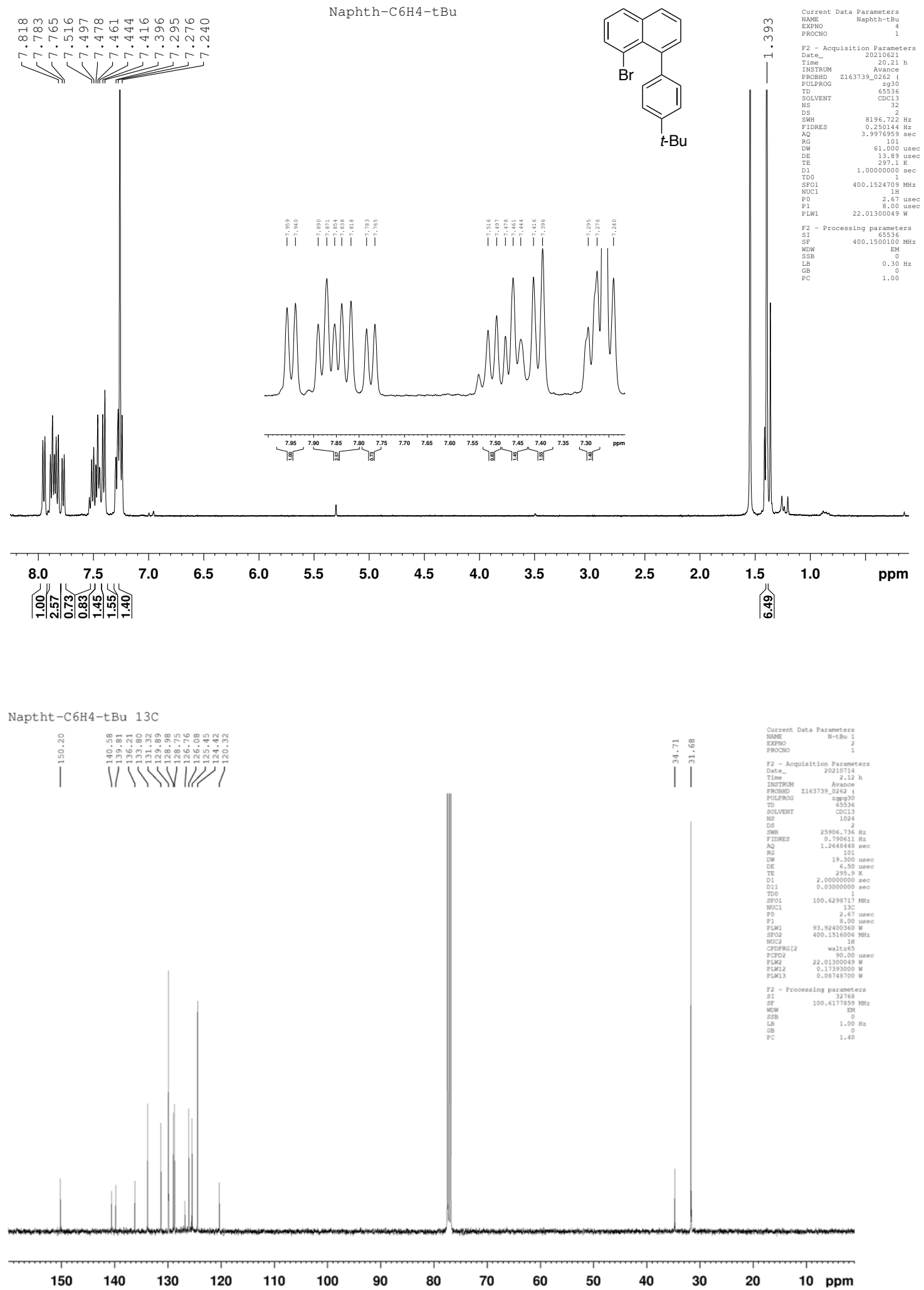

Figure S3. ${ }^{1} \mathrm{H}$ NMR $(400 \mathrm{MHz})$ and ${ }^{13} \mathrm{C}\left\{{ }^{1} \mathrm{H}\right\}$ NMR $(100 \mathrm{MHz})$ spectra of 3B $\left(\mathrm{CDCl}_{3}\right)$. 

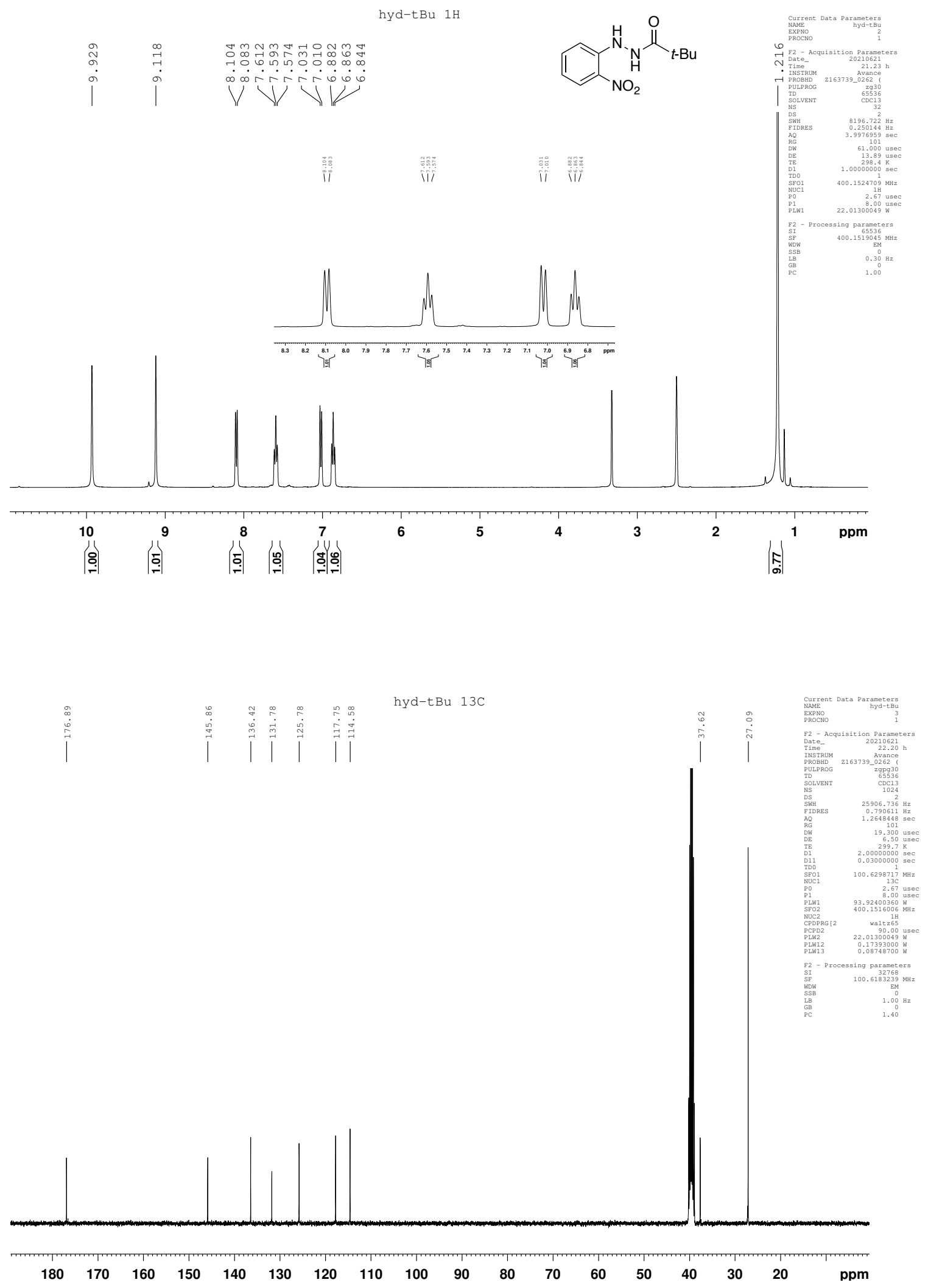

Figure S4. ${ }^{1} \mathrm{H}$ NMR (400 MHz) and ${ }^{13} \mathrm{C}\left\{{ }^{1} \mathrm{H}\right\}$ NMR $(100 \mathrm{MHz})$ spectra of 5 (DMSO- $d_{6}$ ). 


\section{IR spectra}

FT-IR spectra were recorded in $\mathrm{KBr}$ pellets.
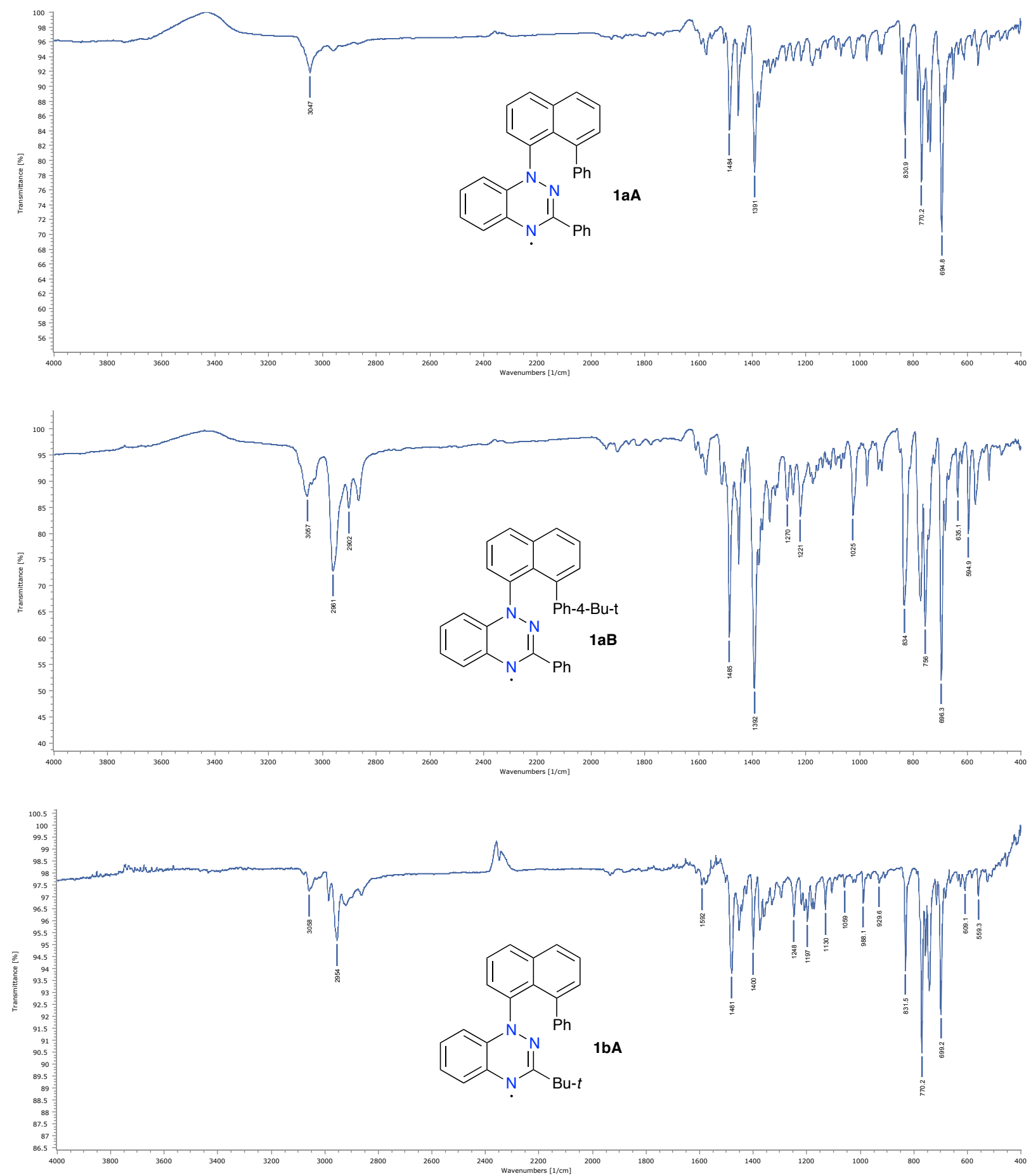

Figure S5. IR spectra for rac-1 recorded in $\mathrm{KBr}$. 


\section{XRD data collection and refinement}

Crystals of rac-1aA suitable for single crystal X-ray diffraction investigation were grown by slow evaporation of EtOH solutions and were analysed using a Rigaku XtaLAB Synergy, Dualflex, Pilatus $300 \mathrm{~K}$ diffractometer. The crystal was kept at 100.0(2) K during data collection and measurement was conducted using the $\mathrm{CuK \alpha}$ radiation $(\lambda=1.54184 \AA)$. The data were integrated using CrysAlisPro program. ${ }^{7}$ Intensities for absorption were corrected using SCALE3 ABSPACK scaling algorithm implemented in CrysAlisPro program. ${ }^{7}$ Structure was solved with the ShelXT structure solution program ${ }^{8}$ using Intrinsic Phasing and refined in the ShelXle by the full-matrix least-squares minimization on $F^{2}$ with the ShelXL refinement package. ${ }^{9}$ All nonhydrogen atoms were refined anisotropically. All hydrogen atoms were generated geometrically and refined isotropically using the riding model.

The crystal data and structure refinement descriptors are presented in Table S1, selected interatomic distances and angles are presented in Table S2, while thermal ellipsoid diagrams for single molecule of 1aA, unit cell, and partial packing are shown in Figures S6.

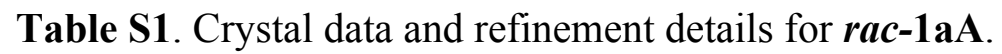

\begin{tabular}{ll}
\hline CDDC \# & 2087259 \\
Empirical formula & $\mathrm{C}_{29} \mathrm{H}_{20} \mathrm{~N}_{3}$ \\
Formula weight & 410.48 \\
Crystal system & Triclinic \\
Space group & $P-1$ \\
$a / \AA$ & $9.5989(2)$ \\
$b / \AA$ & $11.1996(3)$ \\
$c / \AA$ & $11.5498(3)$ \\
$\alpha /^{\circ}$ & $72.286(2)$ \\
$\beta /{ }^{\circ}$ & $71.372(2)$ \\
$\gamma /{ }^{\circ}$ & $65.984(2)$ \\
Volume/ $\AA$ & $1056.78(5)$ \\
$Z$ & 2 \\
Goodness-of-fit on $\mathrm{F}^{2}$ & 1.085 \\
Final $R$ indexes $[I>=2 \sigma(I)]$ & $R_{1}=0.0337, \mathrm{w} R_{2}=0.0945$ \\
Final $R$ indexes $[$ all data $]$ & $R_{1}=0.0399, \mathrm{w} R_{2}=0.0985$ \\
\hline
\end{tabular}


Table S2. Selected interatomic distances and angles for radical $\mathbf{r a c}-\mathbf{1 a A}{ }^{a}$

\begin{tabular}{llll}
\hline $\mathrm{N}(1)-\mathrm{Naphth}$ & $1.440(2)$ & $\mathrm{C}(7)-\mathrm{C}(8)$ & $1.373(2)$ \\
$\mathrm{N}(1)-\mathrm{N}(2)$ & $1.365(1)$ & $\mathrm{C}(8)-\mathrm{C}(8 \mathrm{a})$ & $1.392(2)$ \\
$\mathrm{N}(2)-\mathrm{C}(3)$ & $1.336(2)$ & $\mathrm{C}(8 \mathrm{a})-\mathrm{N}(1)$ & $1.383(1)$ \\
$\mathrm{C}(3)-\mathrm{N}(4)$ & $1.333(1)$ & $\mathrm{C}(8 \mathrm{a})-(\mathrm{C} 4 \mathrm{a})$ & $1.414(2)$ \\
$\mathrm{N}(4)-\mathrm{C}(4 \mathrm{a})$ & $1.372(2)$ & $\mathrm{C}(3)-\mathrm{Ph}$ & $1.489(2)$ \\
$\mathrm{C}(4 \mathrm{a})-\mathrm{C}(5)$ & $1.396(1)$ & $\mathrm{N}(1)-\mathrm{N}(2)-\mathrm{C}(3)$ & $115.44(9)$ \\
$\mathrm{C}(5)-\mathrm{C}(6)$ & $1.372(2)$ & $\mathrm{N}(2)-\mathrm{C}(3)-\mathrm{N}(4)$ & $127.7(1)$ \\
$\mathrm{C}(6)-\mathrm{C}(7)$ & $1.392(2)$ & & \\
\hline
\end{tabular}

${ }^{a}$ The numbering system according to the chemical nomenclature. 


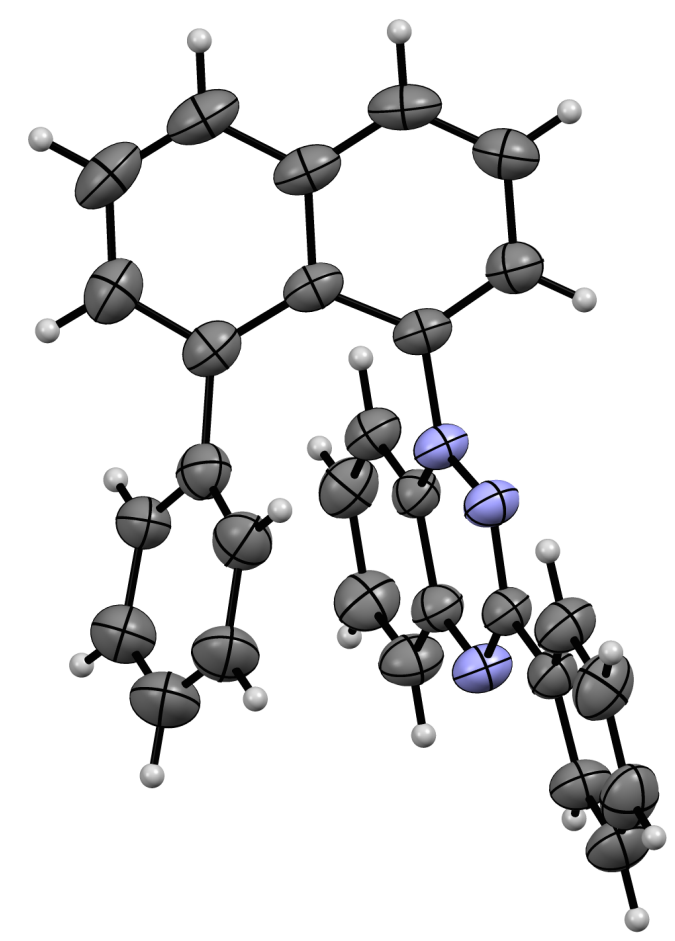

a)

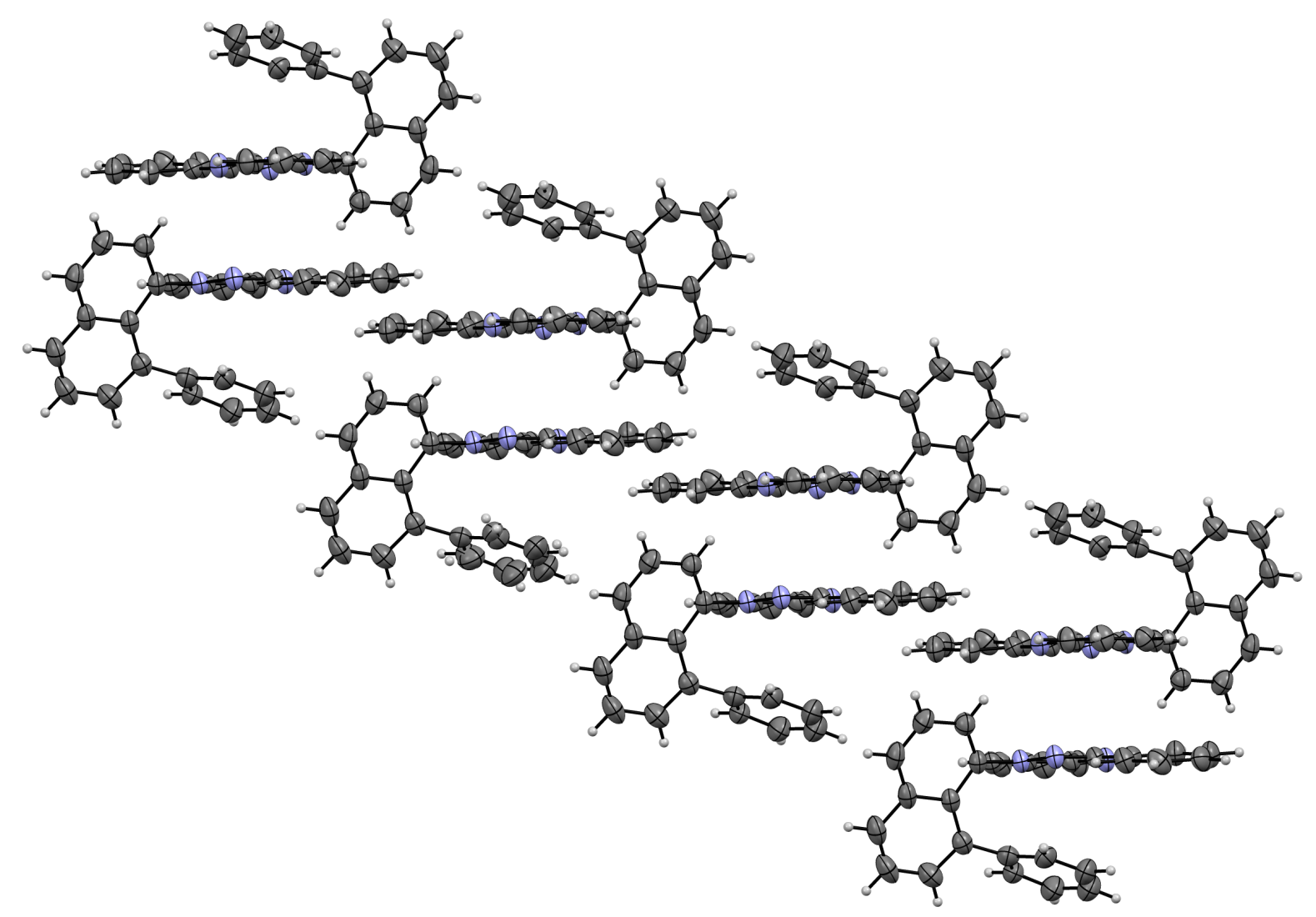

Figure S6. Clockwise: a) thermal ellipsoid diagram for one molecule of $\boldsymbol{r a c - 1 a A}$; b) The unit cell packing diagram for $\boldsymbol{r a c - 1 a A}$ (hydrogen atoms are omitted for clarity); c) partial packing diagram for rac-1aA. Thermal ellipsoids at 50\% probability level. 


\section{UV-vis spectroscopy}

Electronic absorption spectra for racemic radicals rac-1 were recorded on Jasco V-770 UV-Vis-NIR spectrometer in spectroscopic grade $\mathrm{CH}_{2} \mathrm{Cl}_{2}$ at concentrations in a range $1.5-10 \times 10^{-5}$ mol/L and fitted to the Beer-Lambert law. Results are shown in Figures S7-S9.
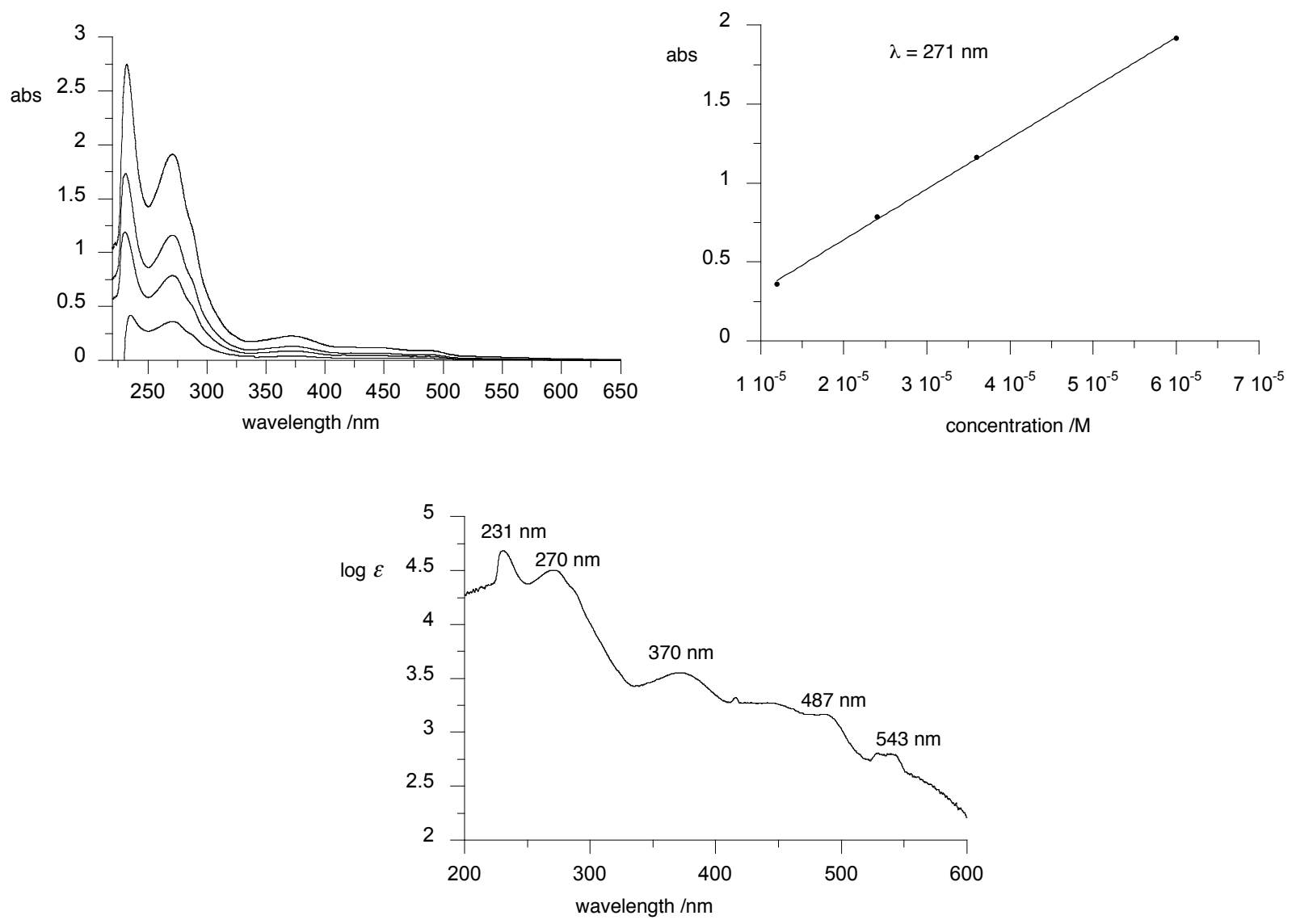

Figure S7. Clockwise: electronic absorption spectra for rac-1aA $(\mathrm{R}=\mathrm{Ph}, \mathrm{X}=\mathrm{Ph})$ in $\mathrm{CH}_{2} \mathrm{Cl}_{2}$ for four concentrations, determination of molar extinction coefficient $\varepsilon$ at $\lambda=271 \mathrm{~nm}$ (best fit line: $\varepsilon=$ $32057 \times$ conc, $\left.r^{2}=0.9992\right)$, and a molar extinction $\log (\varepsilon)$ plot.
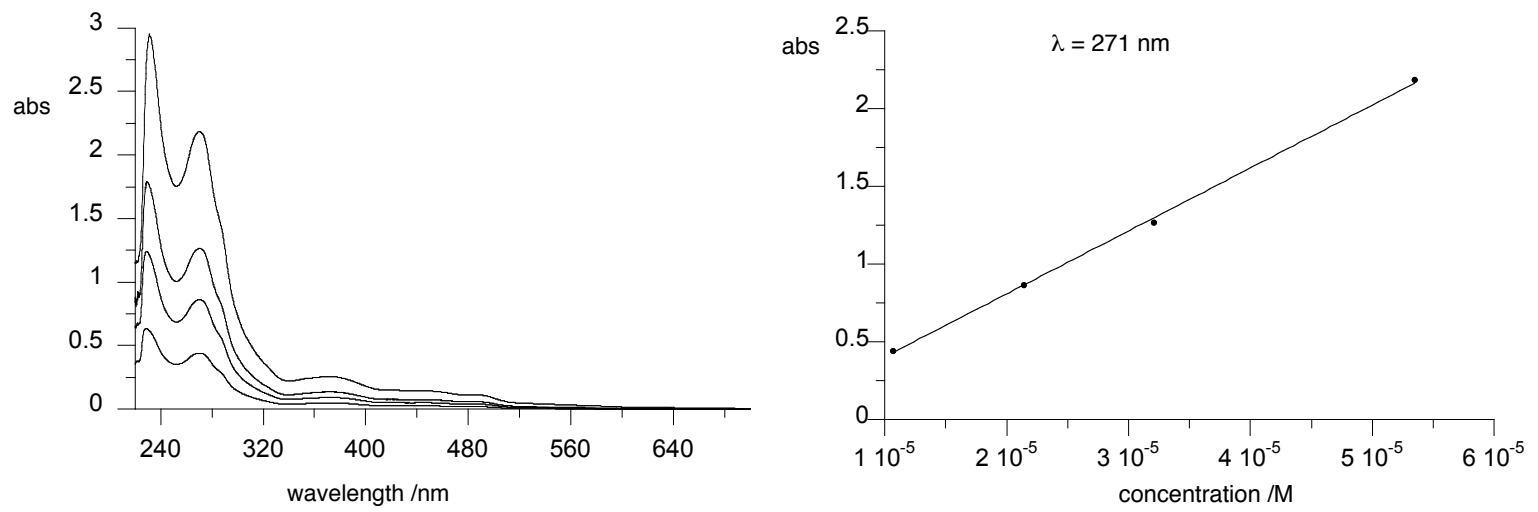


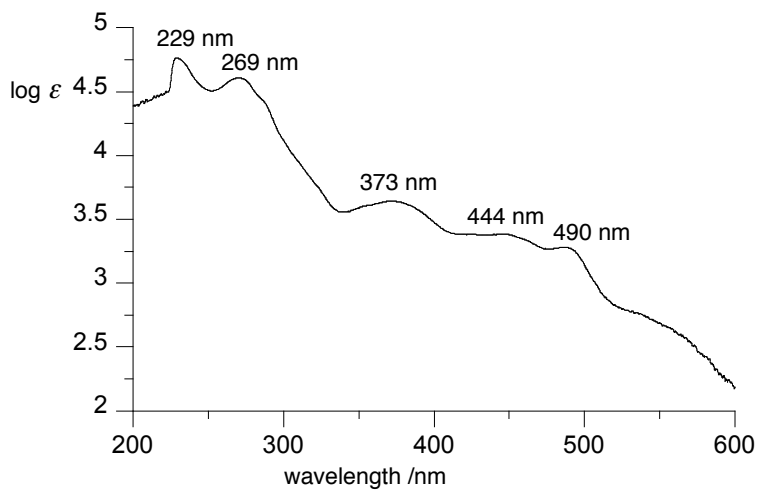

Figure S8. Clockwise: electronic absorption spectra for $\boldsymbol{r a c}-\mathbf{1 a B}\left(\mathrm{R}=\mathrm{Ph}, \mathrm{X}=4-t-\mathrm{Bu}-\mathrm{C}_{6} \mathrm{H}_{4}\right)$ in $\mathrm{CH}_{2} \mathrm{Cl}_{2}$ for four concentrations, determination of molar extinction coefficient $\varepsilon$ at $\lambda=271 \mathrm{~nm}$ (best fit line: $\varepsilon=40436 \times$ conc, $\left.r^{2}=0.9991\right)$, and a molar extinction $\log (\varepsilon)$ plot.
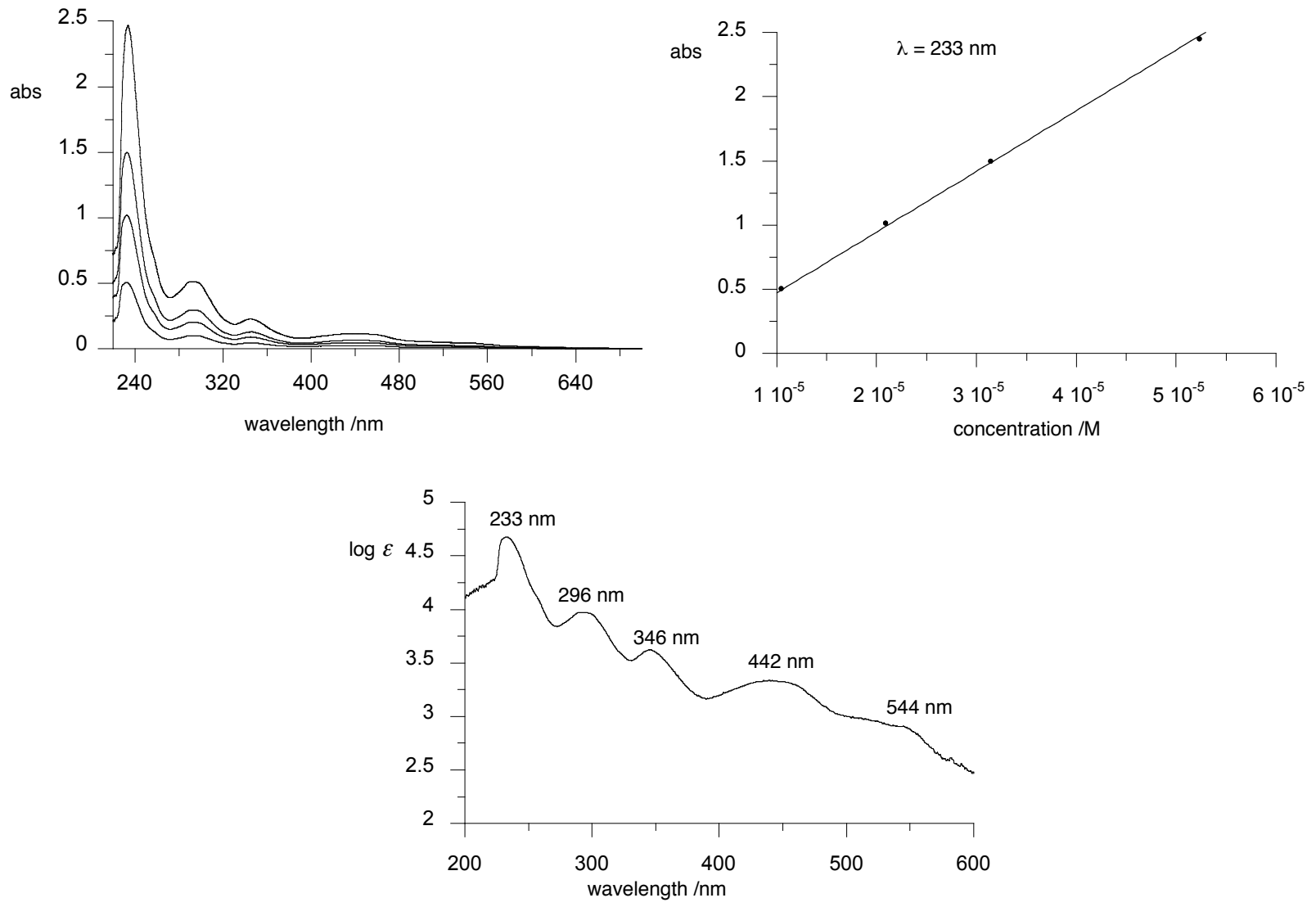

Figure S9. Clockwise: electronic absorption spectra for $\boldsymbol{r a c}-\mathbf{1 b A}(\mathrm{R}=t-\mathrm{Bu}, \mathrm{X}=\mathrm{Ph})$ in $\mathrm{CH}_{2} \mathrm{Cl}_{2}$ for four concentrations, determination of molar extinction coefficient $\varepsilon$ at $\lambda=233 \mathrm{~nm}$ (best fit line: $\varepsilon=$ $47314 \times$ conc, $\left.r^{2}=0.9992\right)$, and a molar extinction $\log (\varepsilon)$ plot.

\section{EPR spectroscopy}

EPR spectra for racemic radicals rac-1 were recorded on an X-band EMX-Nano EPR spectrometer at room temperature on dilute and degassed solutions in benzene. The microwave 
power was in a range of 5-15 $\mathrm{mW}$ (established with the Power Sweep program below the saturation of the signal) with a modulation frequency of $100 \mathrm{kHz}$, modulation amplitude of $0.5 \mathrm{G}_{\mathrm{pp}}$ and spectral width of $100 \mathrm{G}$. Accurate g-values were obtained using TEMPO as EMX-Nano internal standard. Simulations of the spectra were performed with the EMX-Nano software using DFT results (vide infra) as the starting point including all nitrogen and up to 4 hydrogen atoms. The resulting $h f c c$ values were perturbed several times until a global minimum for the fit was achieved. Experimental and simulated spectra are shown in Figures S10-S12 and final $h f c c$ are listed in Table S3.
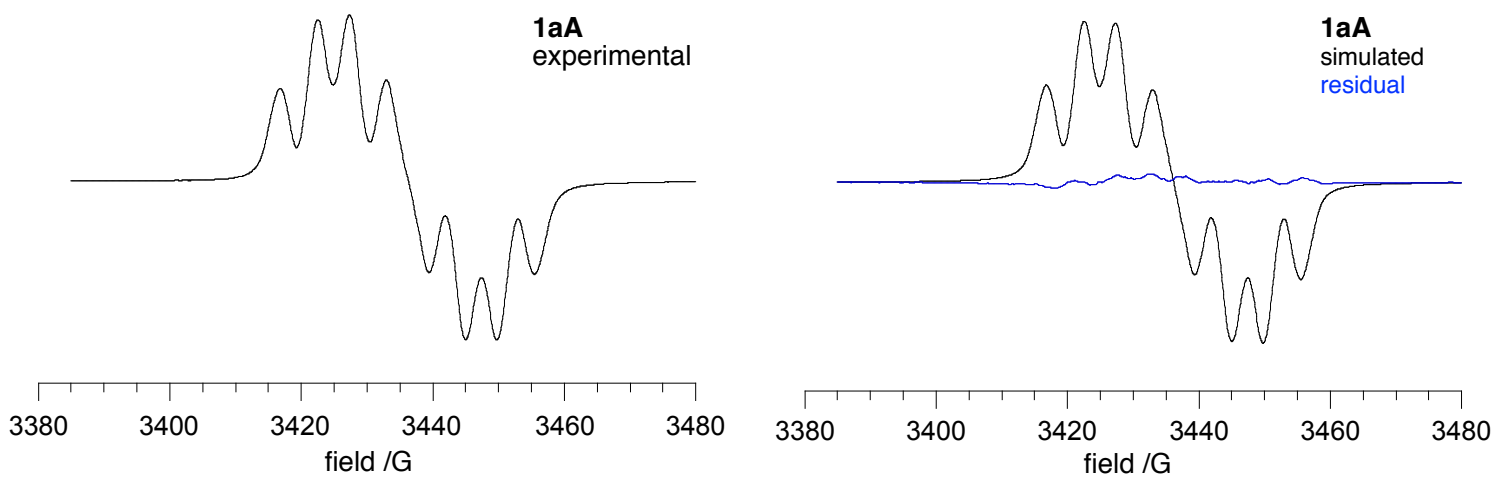

Figure S10. Experimental, simulated and difference spectra for Blatter radical $r a c-1 a A(R=P h, X$ $=\mathrm{Ph})$.
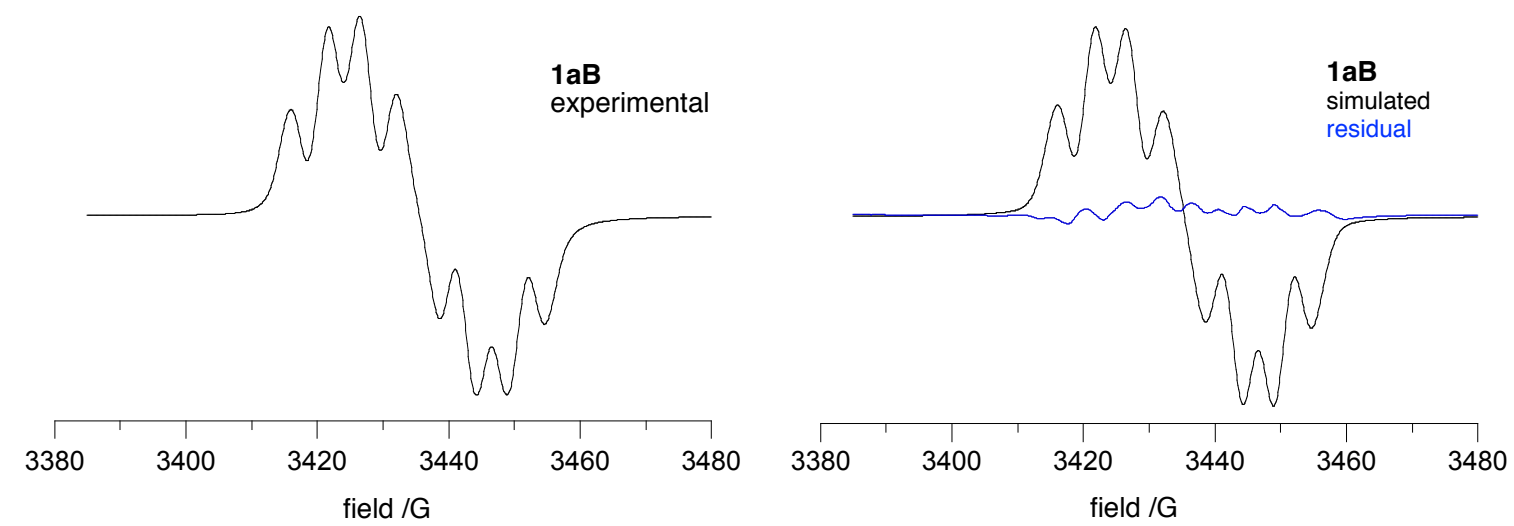

Figure S11. Experimental, simulated and difference spectra for Blatter radical $\mathbf{r a c}-\mathbf{1 a B}(\mathrm{R}=\mathrm{Ph}, \mathrm{X}$ $\left.=4-t-\mathrm{Bu}-\mathrm{C}_{6} \mathrm{H}_{4}\right)$. 

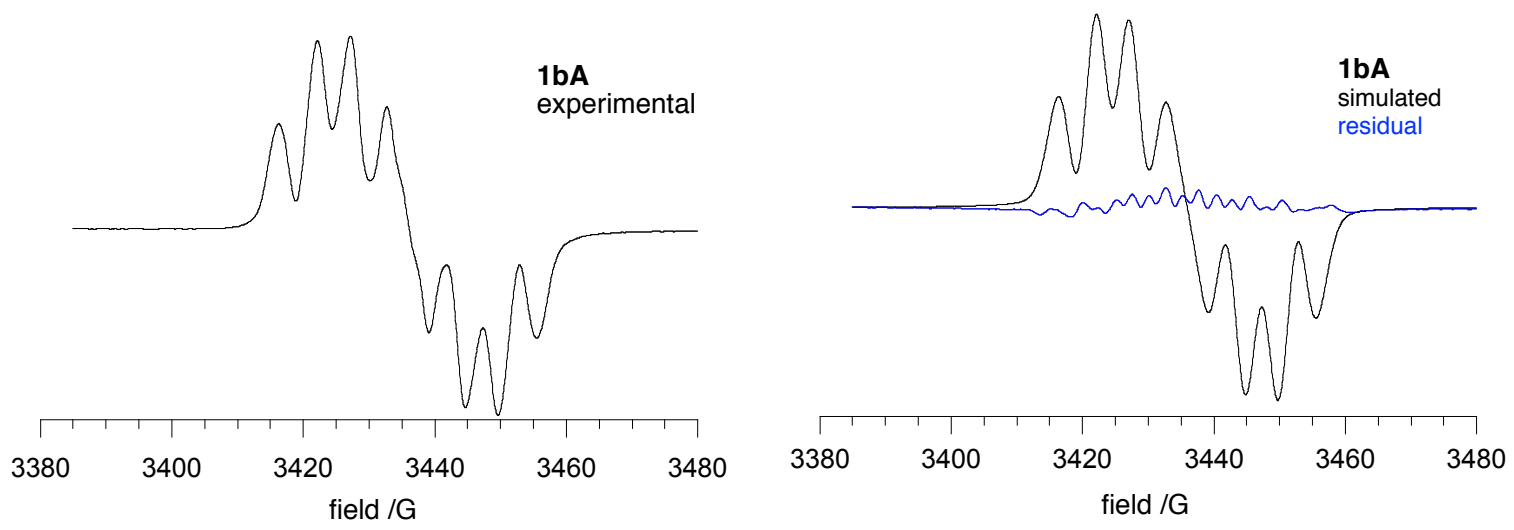

Figure S12. Experimental, simulated and difference spectra for Blatter radical $r a c-1 b A(R=t-B u$, $\mathrm{X}=\mathrm{Ph})$.

Table S3. Summary of hyperfine coupling constants $(\mathrm{G})$ for radicals $\boldsymbol{r a c}-1{ }^{a}$<smiles>[Y]c1cccc2cccc(N3N=C(P)Nc4ccccc43)c12</smiles>

\begin{tabular}{lrrrrrrrr}
\hline \multicolumn{1}{c}{ Compound } & $\mathrm{a}_{\mathrm{N} 1}$ & $\mathrm{a}_{\mathrm{N} 2}$ & $\mathrm{a}_{\mathrm{N} 4}$ & $\mathrm{a}_{\mathrm{H}}$ & $\mathrm{a}_{\mathrm{H}}$ & $\mathrm{a}_{\mathrm{H}}$ & $\mathrm{a}_{\mathrm{H}}$ & $g^{b}$ \\
\hline Blatter $^{c}$ & 7.56 & 4.92 & 4.94 & 1.34 & 0.83 & 0.68 & 0.59 & 2.0036 \\
$\operatorname{rac-1aA}, \mathrm{X}=\mathrm{Ph}, \mathrm{Y}=\mathrm{Ph}$ & 7.50 & 4.88 & 5.03 & 1.52 & 1.15 & 1.87 & 0.73 & 2.0035 \\
$\operatorname{rac-1aB}, \mathrm{X}=t$ - $\mathrm{Bu}, \mathrm{Y}=\mathrm{Ph}$ & 7.58 & 4.90 & 5.22 & - & - & - & - & 2.0037 \\
$\operatorname{rac-1bA}, \mathrm{X}=\mathrm{Ph}, \mathrm{Y}=4-t-\mathrm{Bu}_{-} \mathrm{C}_{6} \mathrm{H}_{4}$ & 7.49 & 4.88 & 5.03 & 0.69 & 0.69 & 0.69 & 0.69 & 2.0035
\end{tabular}

${ }^{a}$ Assignments follow the previous EPR and ENDOR studies on ${ }^{15} \mathrm{~N}$-labeled derivatives $\left(\right.$ ref. $\left.{ }^{10}\right) .{ }^{b}$ Referenced to DPPH $(g=2.0036)$ as the internal standard. ${ }^{\mathrm{c}}$ Ref. ${ }^{11}$.

\section{Electrochemical results}

The electrochemical characterization of racemic radicals rac-1 was conducted using a Autolab PGSTAT $128 \mathrm{~N}$ potentiostat/galvanostat in dry and degassed $\mathrm{CH}_{2} \mathrm{Cl}_{2}$ (conc. $0.5 \mathrm{mM}$ ) in the presence of $\left[n-\mathrm{Bu}_{4} \mathrm{~N}\right]^{+}\left[\mathrm{PF}_{6}\right]^{-}$as an electrolyte (conc. $50 \mathrm{mM}$ ) using glassy carbon as the working electrode and $\mathrm{Ag} / \mathrm{AgCl}$ pseudo reference electrode with a scan rate of $50 \mathrm{mV} \mathrm{s}^{-1}$ at $20{ }^{\circ} \mathrm{C}$. At the end of each measurement ferrocene was added and the peak potentials were referenced to the $\mathrm{Fc} / \mathrm{Fc}^{+}$couple $(0.46 \mathrm{~V}$ vrs $\mathrm{SCE}) .^{12}$ 
CV plots are shown in Figures S13-S15 and numerical result are shown in Table 2 in the main text.

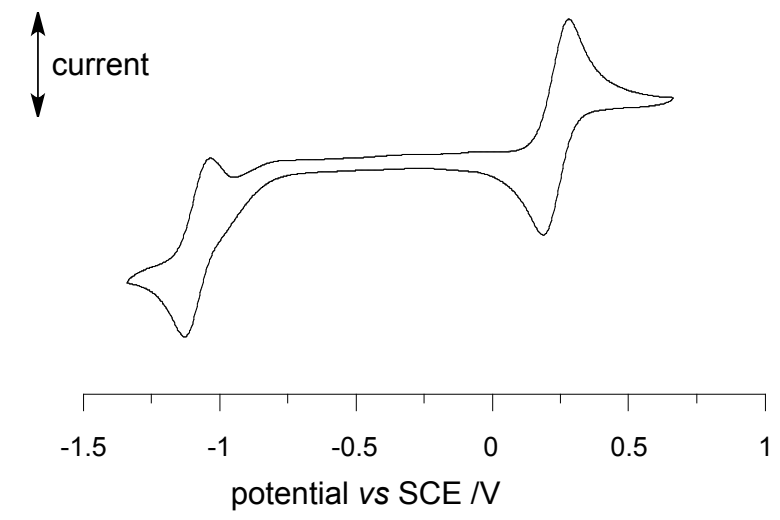

Figure S13. Cyclic voltammogram for $\operatorname{rac}-\mathbf{1 a A}(\mathrm{R}=\mathrm{Ph}, \mathrm{X}=\mathrm{Ph})$.

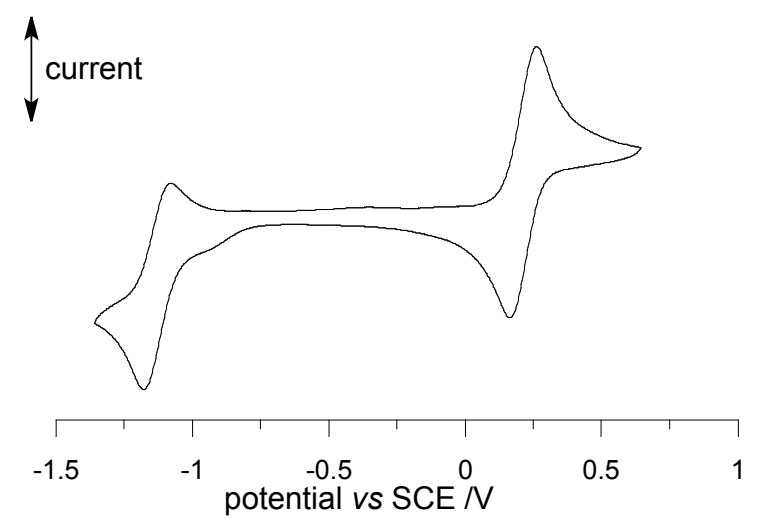

Figure S14. Cyclic voltammogram for $r a c-1 a B\left(R=P h, X=4-t-B_{1} C_{6} H_{4}\right)$.

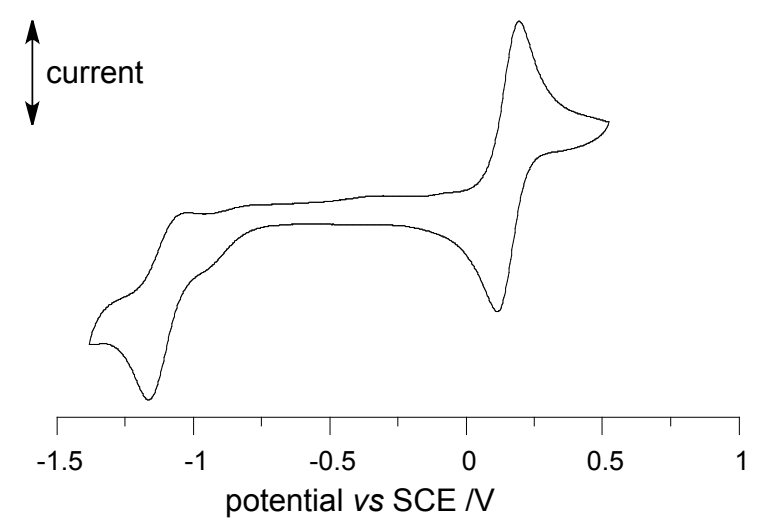

Figure S15. Cyclic voltammogram for $\boldsymbol{r a c}-\mathbf{1 b A}(\mathrm{R}=t-\mathrm{Bu}, \mathrm{X}=\mathrm{Ph})$. 


\section{Chiral HPLC analysis and resolution}

Chiral HPLC analyses were performed on Chiralcel OD-H $\mathrm{H}^{\star}$ analytical column (cellulose tris-3,5-dimethylphenylcarbamate, $250 \times 4.6 \mathrm{~mm})$ in hexane $/ i$-PrOH mixtures $(97: 3$ ratio for radicals $\mathbf{1 a A}$ and $\mathbf{1 a B}$, and 99:1 ratio for radical $\mathbf{1 b A}$ ) at $0.5 \mathrm{~mL} / \mathrm{min}$ flow and $\mathrm{UV}$ detection 254 $\mathrm{nm}$. Retention times $t_{R}$ are given in minutes. Separation of enantiomeric was accomplished on a chiral semipreparative column Lux Cellulose-1 (cellulose tris-3,5-dimethylphenylcarbamate, 250 $\times 10 \mathrm{~mm}$ ) using a hexane/ $i$-PrOH mixture (98:2 ratio) as the liquid phase with the flow of 3.0 $\mathrm{mL} / \mathrm{min}$ and UV detection at $254 \mathrm{~nm}$.

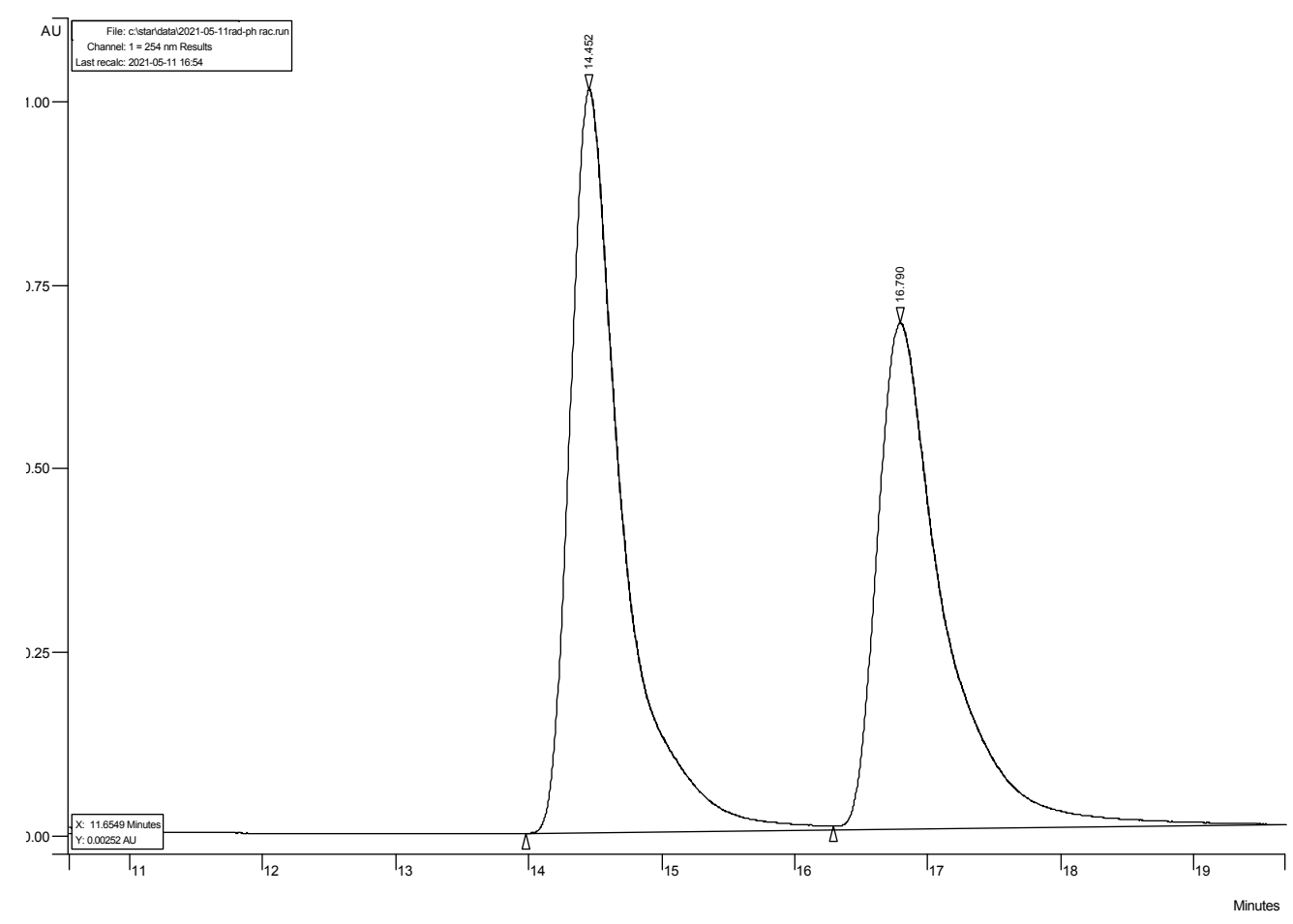

Figure S16. Chiral HPLC analysis of racemic radical rac-1aA $(\mathrm{R}=\mathrm{Ph}, \mathrm{X}=\mathrm{Ph})$ using Chiralcel OD-H® analytical column. Hexane/i-PrOH 97:3 ratio. 


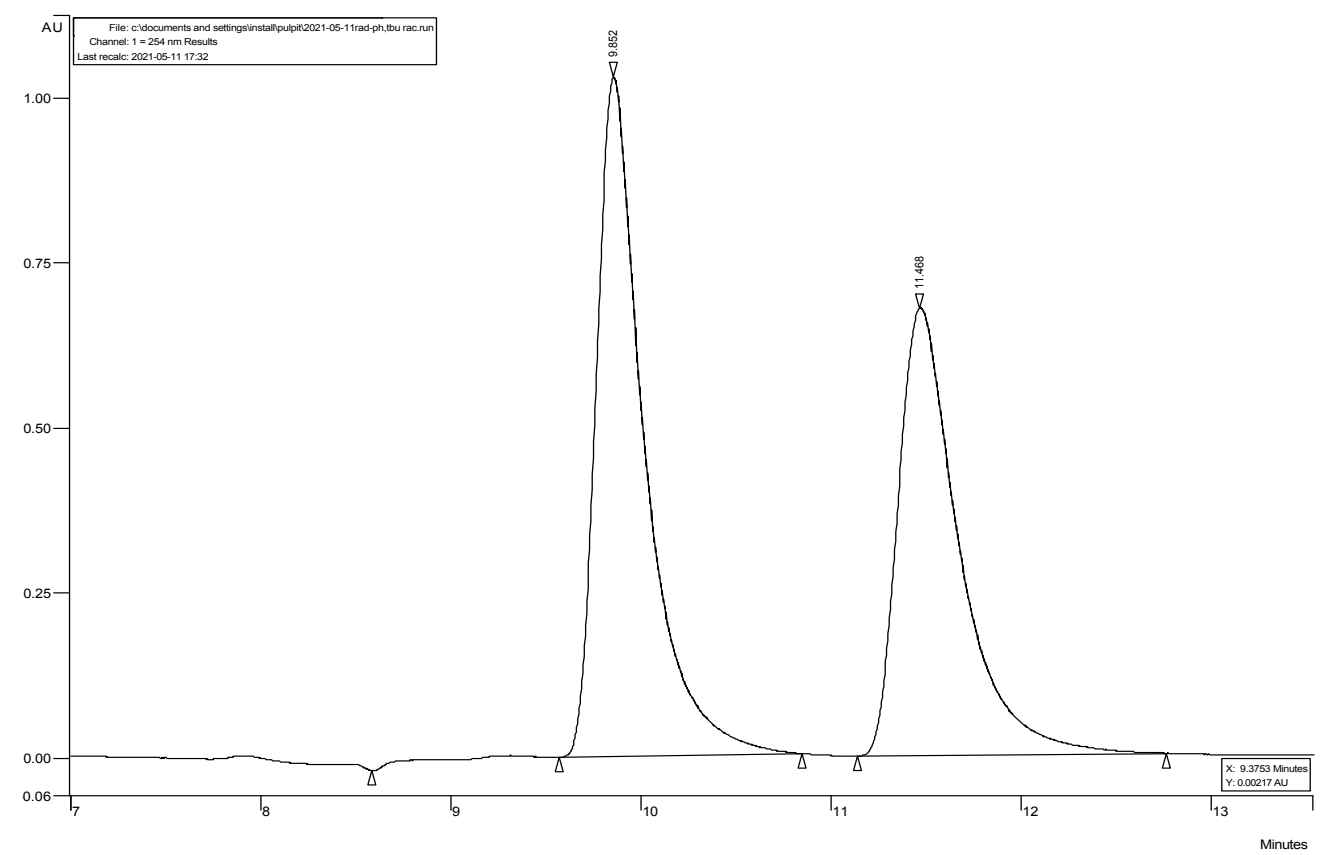

Figure S17. Chiral HPLC analysis of racemic radical rac-1aB $\left(\mathrm{R}=\mathrm{Ph}, \mathrm{X}=4-t-\mathrm{BuC}_{6} \mathrm{H}_{4}\right)$ using Chiralcel OD-H® analytical column. Hexane/i-PrOH 99:1 ratio.

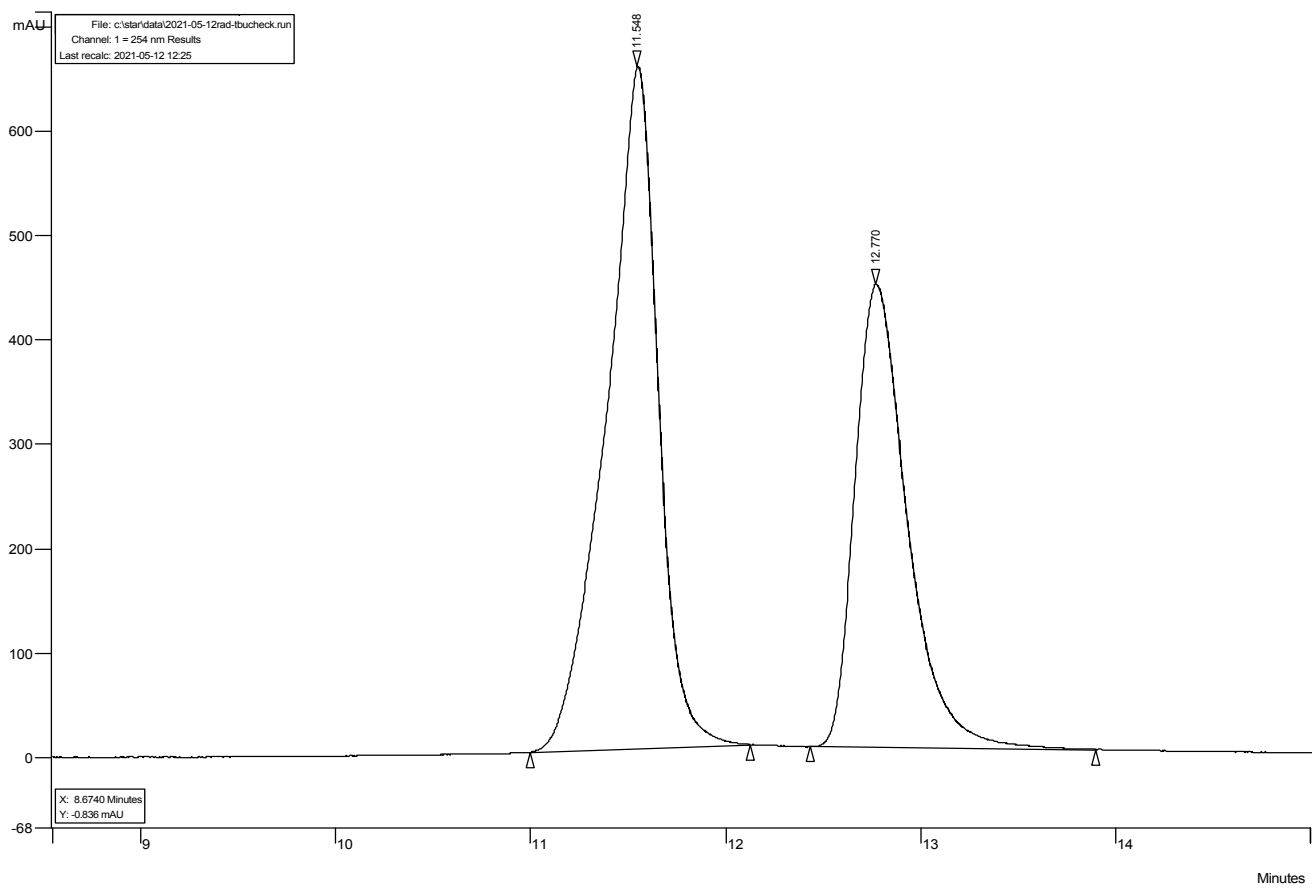

Figure S18. Chiral HPLC analysis of racemic radical rac-1bA $(\mathrm{R}=t$-Bu, $\mathrm{X}=\mathrm{Ph})$ using Chiralcel OD-H® analytical column. Hexane/i-PrOH 97:3 ratio. 


\section{Optical rotation}

Determination of specific rotation of individual atropisomers was attempted using Perkin Elmer 241MC polarimeter in $\mathrm{CH}_{2} \mathrm{Cl}_{2}$ solutions. High optical density of the solutions and consequently low concentrations of the analyte resulted in unreliable measurement in a range $550-800 \mathrm{~nm}$. The analysis gave only the sign of the optical rotation listed in Table S4.

Table S4. Optical rotation sign for atropisomers 1 in $\mathrm{CH}_{2} \mathrm{Cl}_{2}$.

\begin{tabular}{lcc}
\hline \multicolumn{1}{c}{ Compound } & \multicolumn{2}{c}{ Fraction } \\
\hline $\mathbf{1 a A} X=\mathrm{Ph}, \mathrm{Y}=\mathrm{Ph}$ & first $^{[a]}$ & second $^{[b}$ \\
$\mathbf{1 a B} \mathrm{X}=t-\mathrm{Bu}, \mathrm{Y}=\mathrm{Ph}$ & $(+)$ & $(-)$ \\
$\mathbf{1 b A}, \mathrm{X}=\mathrm{Ph}, \mathrm{Y}=4-t-\mathrm{Bu}_{-} \mathrm{C}_{6} \mathrm{H}_{4}$ & $(+)$ & $(-)$
\end{tabular}

${ }^{[a]}$ Shorter retention time. ${ }^{[b]}$ Longer retention time.

\section{Electronic circular dichroism spectroscopy}

Electronic circular dichroism spectra of individual atropisomers 1 were recorded on Jasco $\mathrm{J}-1500 \mathrm{CD}$ spectrometer in spectroscopic grade $\mathrm{CH}_{2} \mathrm{Cl}_{2}$, in 1.0 and $0.1 \mathrm{~cm}$ cuvettes, at concentrations in a range $2-3 \times 10^{-4} \mathrm{~mol} / \mathrm{L}$. Results are shown in Figures S19-S21. The notation first and second refers to the shorter and longer retention times, respectively, of the individual atropisomers. The sign was determined with polarimetric methods (vide supra).
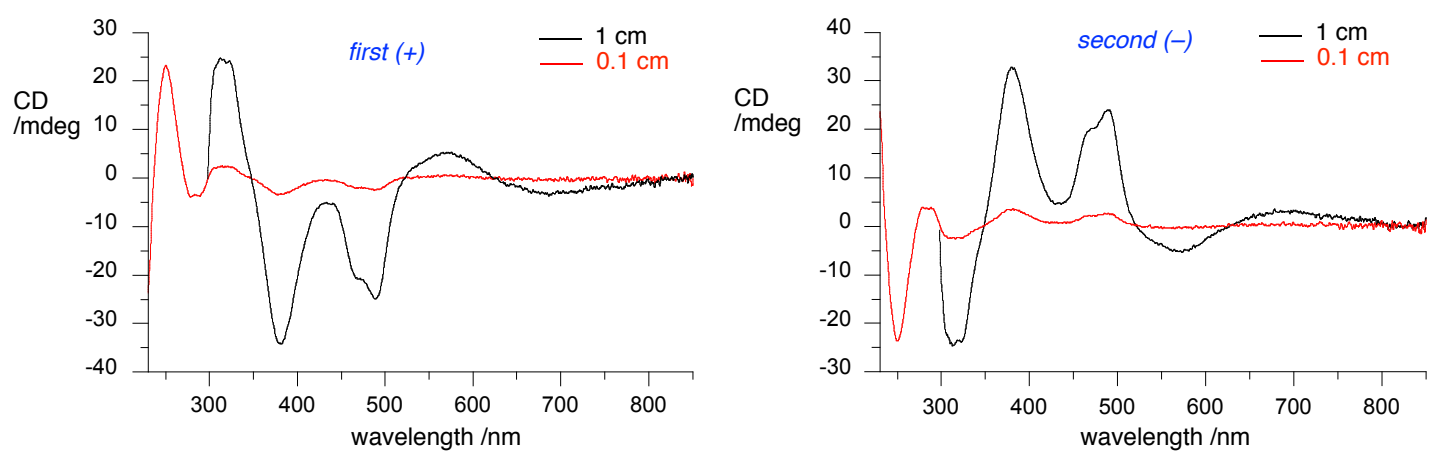


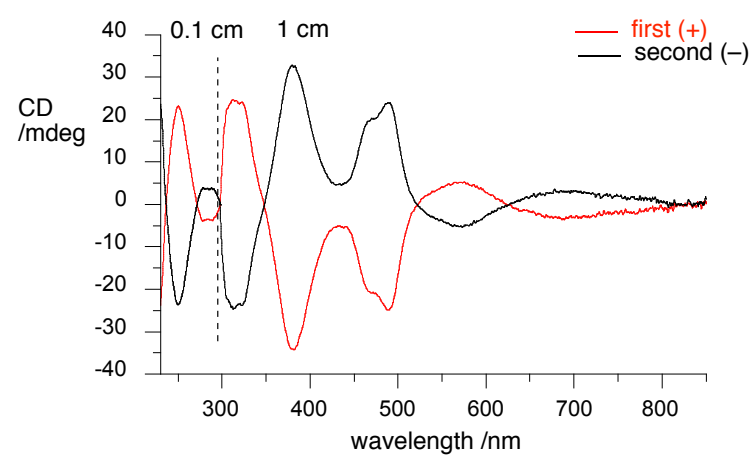

Figure S19. Clockwise: electronic circular dichroism spectra for the first $(+)\left(c=2.66 \times 10^{-4} \mathrm{~mol} \mathrm{~L}^{-}\right.$ $\left.{ }^{1}\right)$ and the second $(-)\left(c=2.64 \times 10^{-4} \mathrm{~mol} \mathrm{~L}^{-1}\right)$ atropisomers of radical $1 \mathrm{aA}(\mathrm{R}=\mathrm{Ph}, \mathrm{X}=\mathrm{Ph})$ in $\mathrm{CH}_{2} \mathrm{Cl}_{2}$ in $1 \mathrm{~cm}$ (black lines) and $0.1 \mathrm{~cm}$ (red lines) cuvettes, combined ECD spectra of both atropisomers.
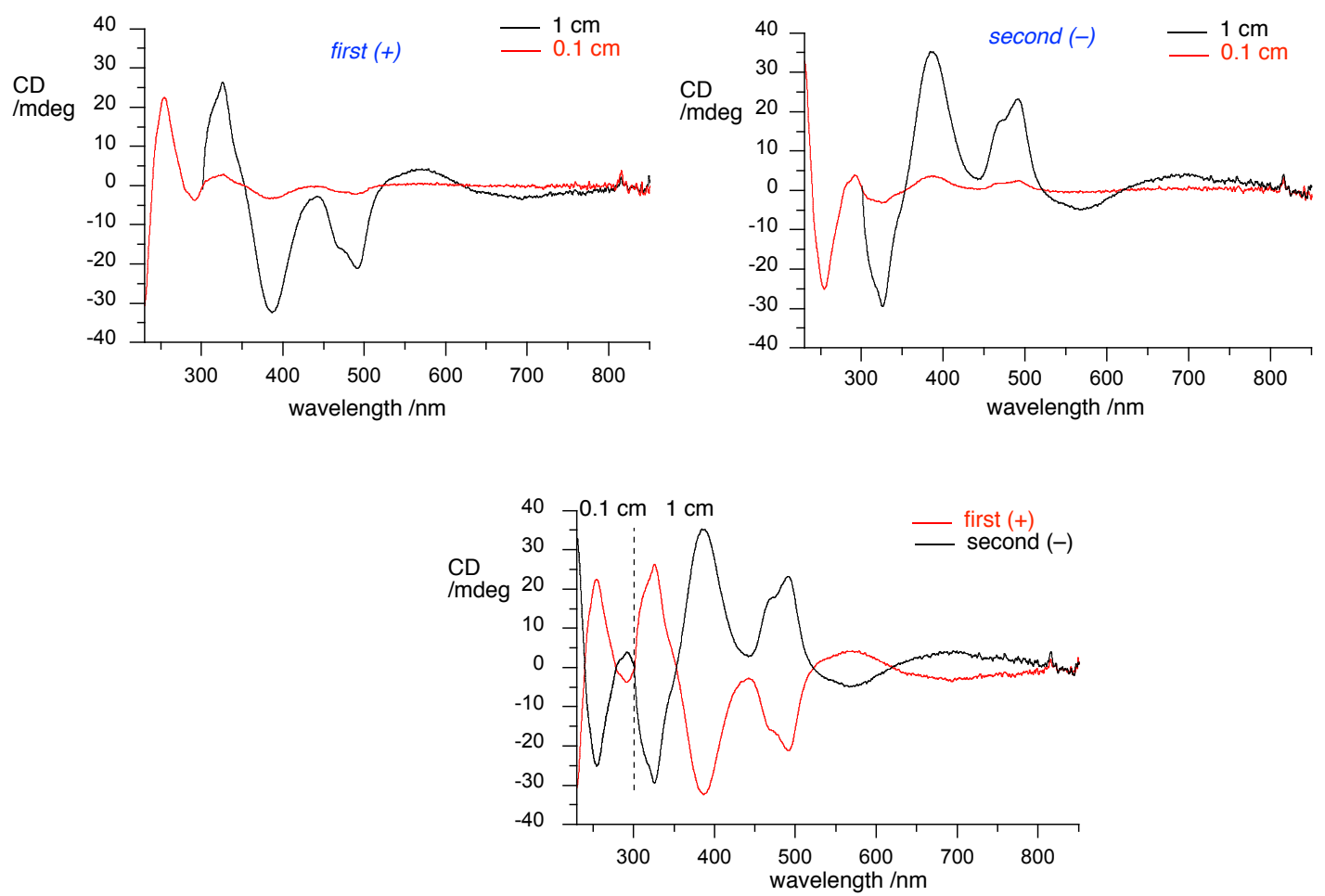

Figure S20. Clockwise: electronic circular dichroism spectra for the first $(+)\left(c=2.82 \times 10^{-4} \mathrm{~mol} \mathrm{~L}^{-}\right.$ $\left.{ }^{1}\right)$ and the second $(-)\left(c=2.77 \times 10^{-4} \mathrm{~mol} \mathrm{~L}^{-1}\right)$ atropisomers of radical $\mathbf{1 a B}(\mathrm{R}=\mathrm{Ph}, \mathrm{X}=4-t$ $\mathrm{BuC}_{6} \mathrm{H}_{4}$ ) in $\mathrm{CH}_{2} \mathrm{Cl}_{2}$ in $1 \mathrm{~cm}$ (black lines) and $0.1 \mathrm{~cm}$ (red lines) cuvettes, combined ECD spectra of both atropisomers. 


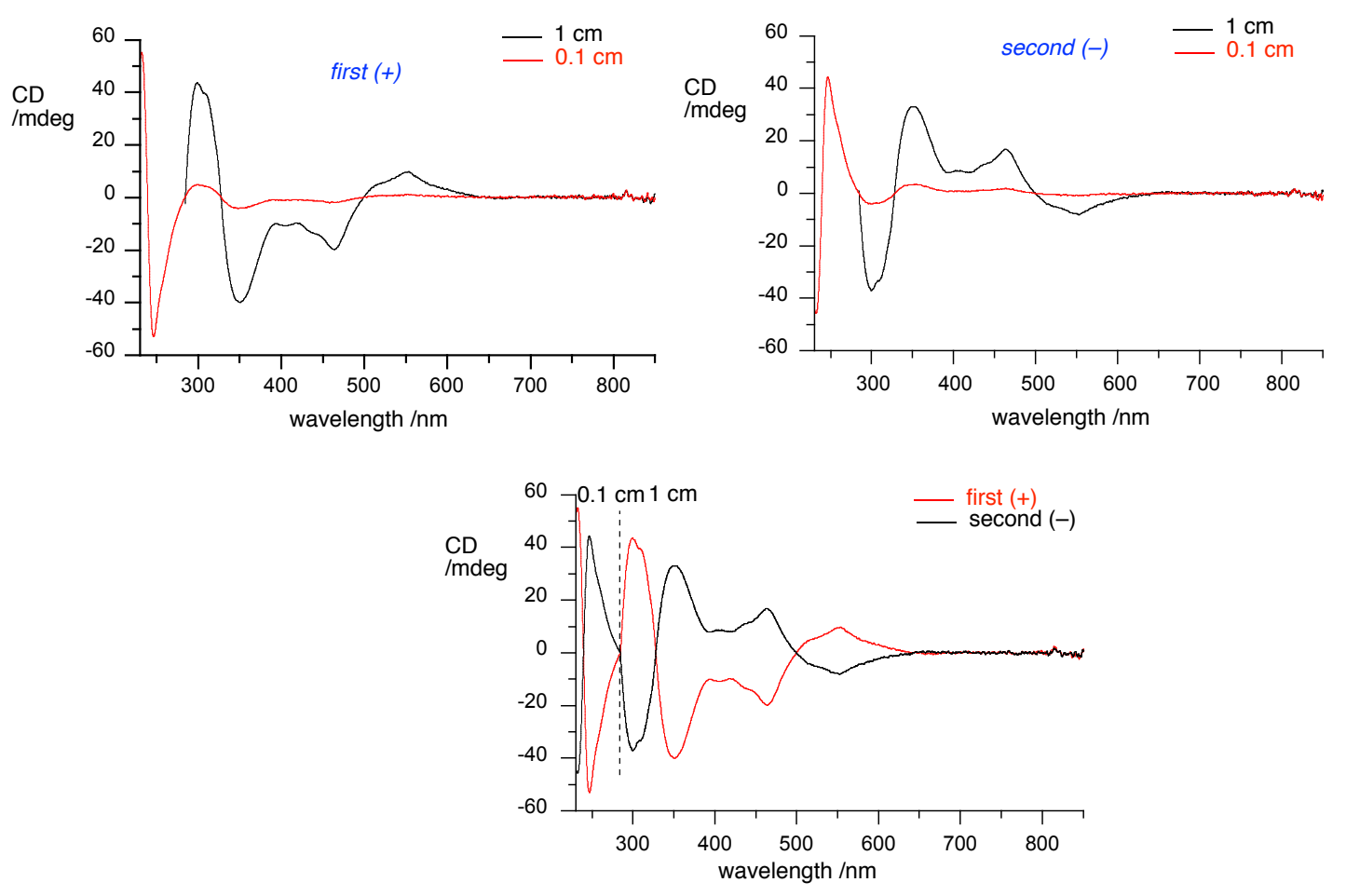

Figure S21. Clockwise: electronic circular dichroism spectra for the first $(+)\left(c=2.29 \times 10^{-4} \mathrm{~mol} \mathrm{~L}^{-}\right.$ $\left.{ }^{1}\right)$ and the second $(-)\left(c=2.25 \times 10^{-4} \mathrm{~mol} \mathrm{~L}^{-1}\right)$ atropisomers of radical $1 \mathbf{b A}(\mathrm{R}=t$-Bu, $\mathrm{X}=\mathrm{Ph})$ in $\mathrm{CH}_{2} \mathrm{Cl}_{2}$ in $1 \mathrm{~cm}$ (black lines) and $0.1 \mathrm{~cm}$ (red lines) cuvettes; combined ECD spectra of both atropisomers.

\section{Determination of absolute configuration of the atropisomers}

The absolute configuration was assigned to radical atropisomers $\mathbf{1}$ by comparison of experimental and DFT calculated electronic circular dichroism (ECD) spectra. Theoretical ECD spectra were obtained at the UCAM-B3LYP/Def2SVP // UB3LYP/Def2SVP level of theory in $\mathrm{CH}_{2} \mathrm{Cl}_{2}$ dielectric medium using the PCM model requested with SCRF(solvent=CH2CL2) keyword, with TD method and 45 or 50 states. Results are shown in Figures S22-S27.

ECD spectra were processed using UV peak half-width at high height set at $0.170 \mathrm{eV}$
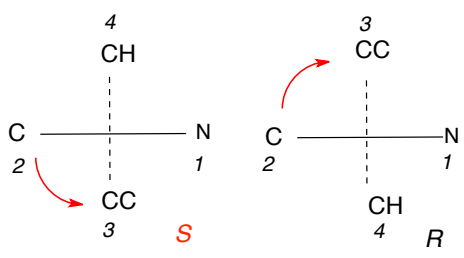

Figure S22. Left: a general scheme for assignment of absolute configuration in series 1. Right: $S$ and $R$ atropisomers of radical $\mathbf{1 a A}$.

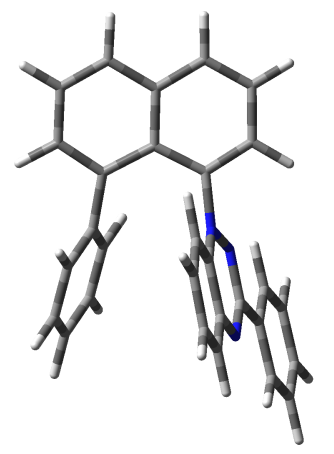

$S$ isomer

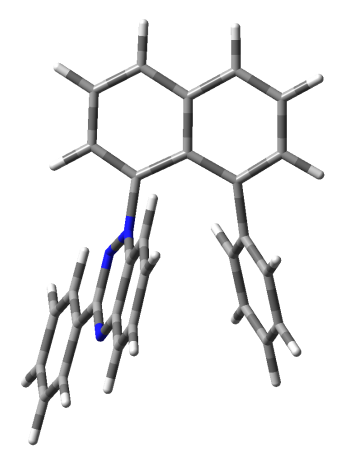

$R$ isomer 

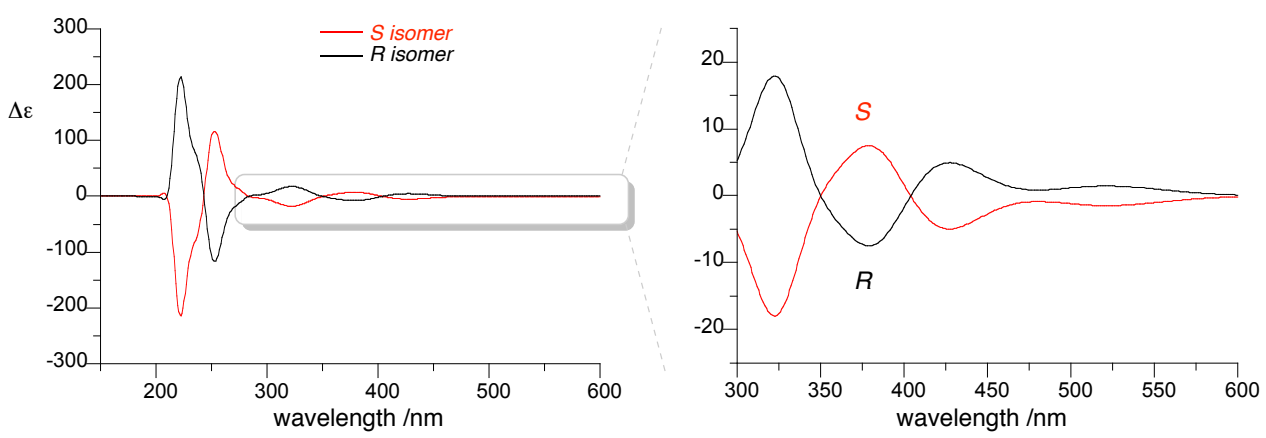

a)
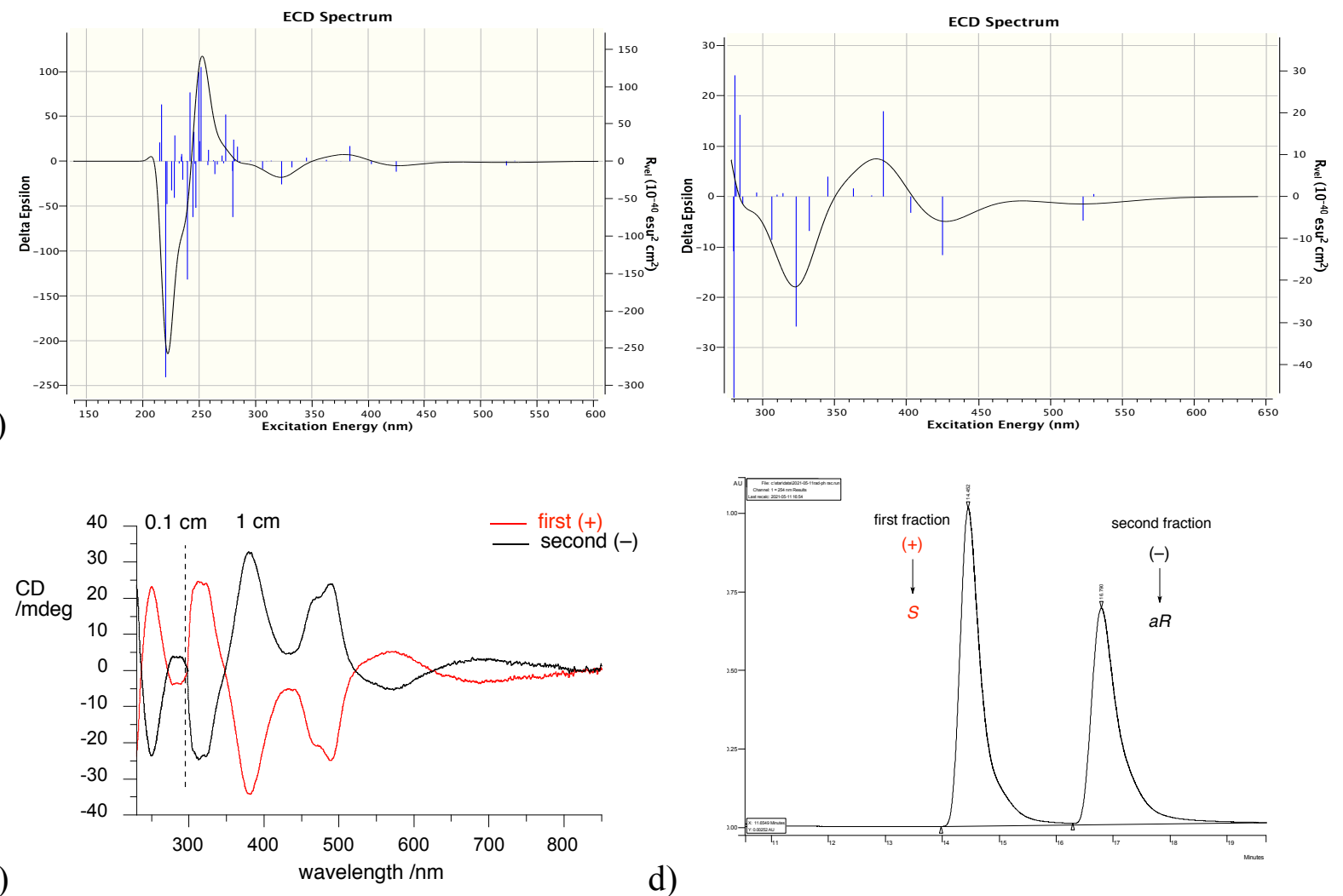

Figure S23. ECD spectra of 1aA atropisomers $R$ (black line) and $S$ (red line): a) TD-DFT calculated and b) measured in $\mathrm{CH}_{2} \mathrm{Cl}_{2}$; c) chiral HPLC analysis of radical rac-1aA and absolute configuration assignment.

Radical 1aB $\left(\mathrm{R}=\mathrm{Ph}, \mathrm{X}=4-t-\mathrm{Bu}-\mathrm{C}_{6} \mathrm{H}_{4}\right)$

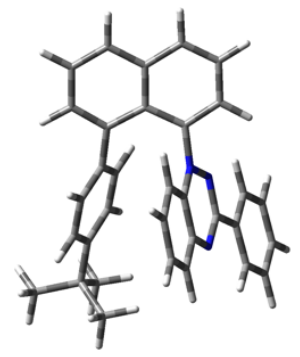

$\mathrm{S}$ isomer

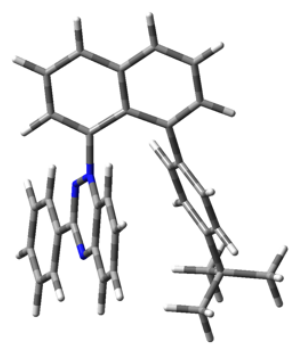

$\mathrm{R}$ isomer

Figure S24. Configuration of $S$ and $R$ atropisomers of radical $\mathbf{1 a B}$. 

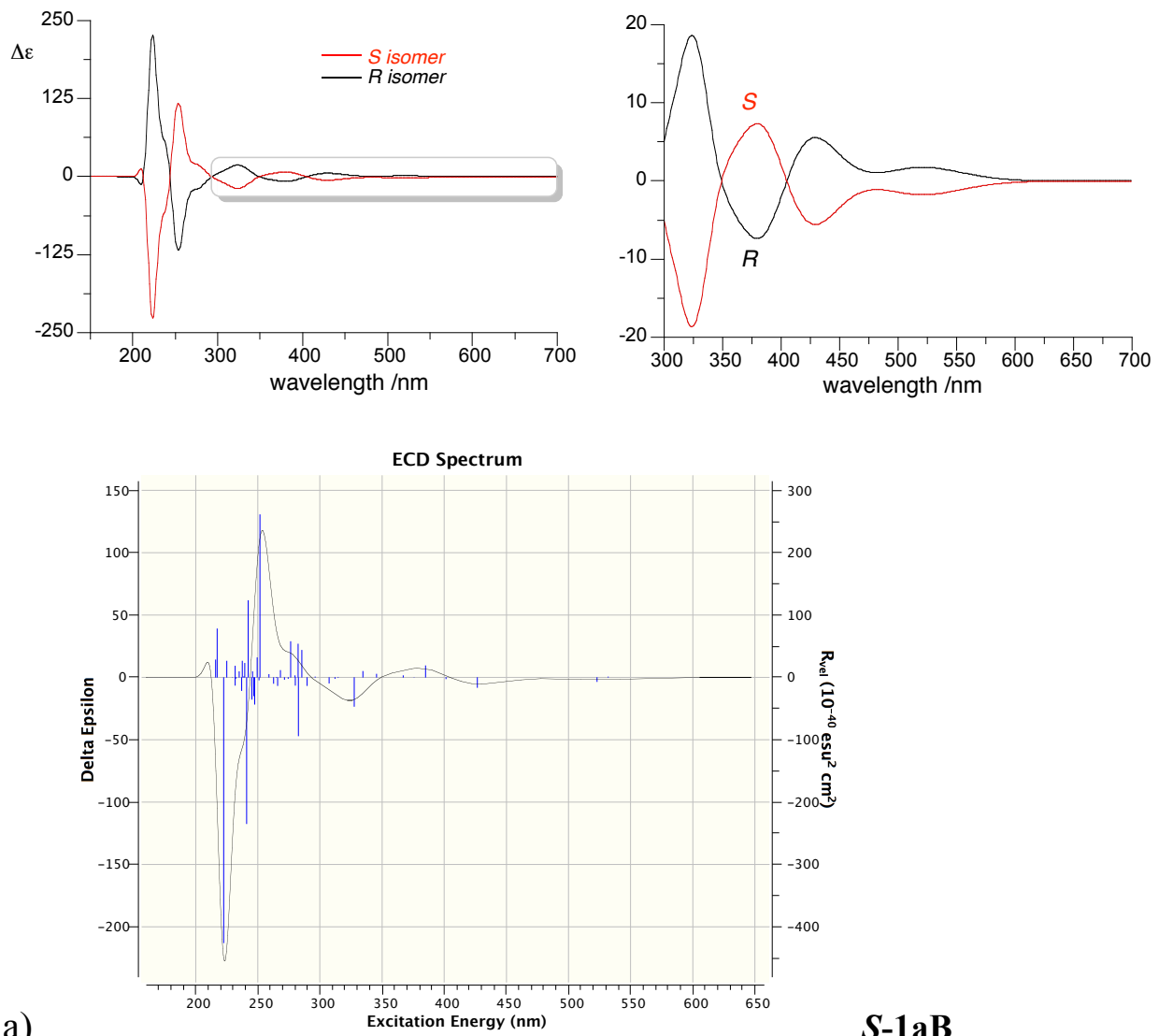

a)
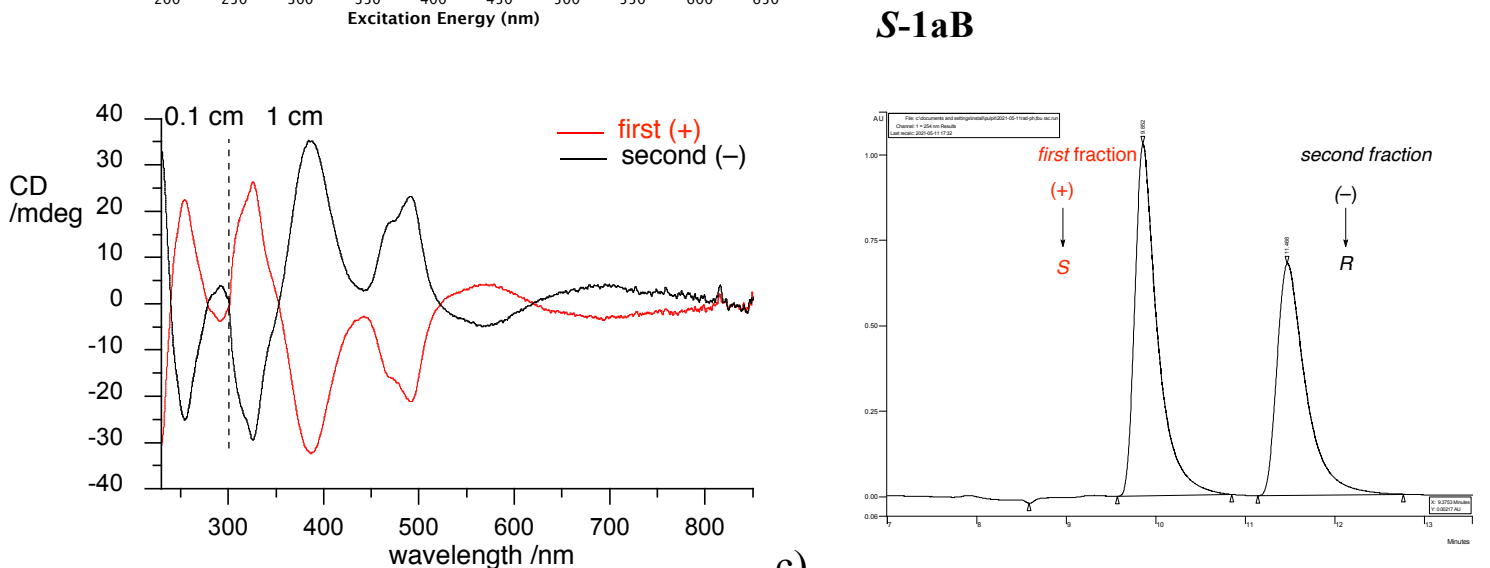

b)

c)

Figure S25. ECD spectra of $\mathbf{1 a B}$ atropisomers $R$ (black line) and $S$ (red line): a) TD-DFT calculated and b) measured in $\mathrm{CH}_{2} \mathrm{Cl}_{2}$; c) chiral HPLC analysis of radical rac-1aB and absolute configuration assignment. 
Radical 1bA $(\mathrm{R}=t$ - $\mathrm{Bu}, \mathrm{X}=\mathrm{Ph}) 45$ states,

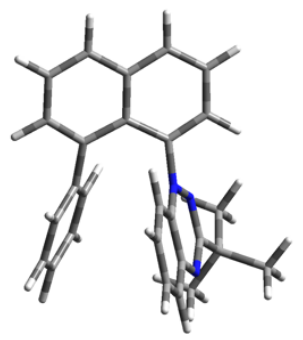

$S$ isomer

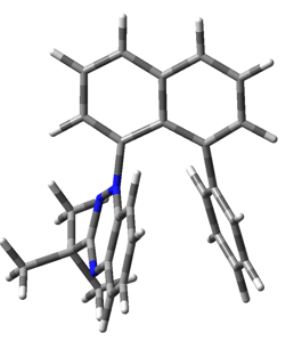

$R$ isomer

Figure S26. Configurations of $S$ and $R$ atropisomers of radical $\mathbf{1 b A}$.

a)
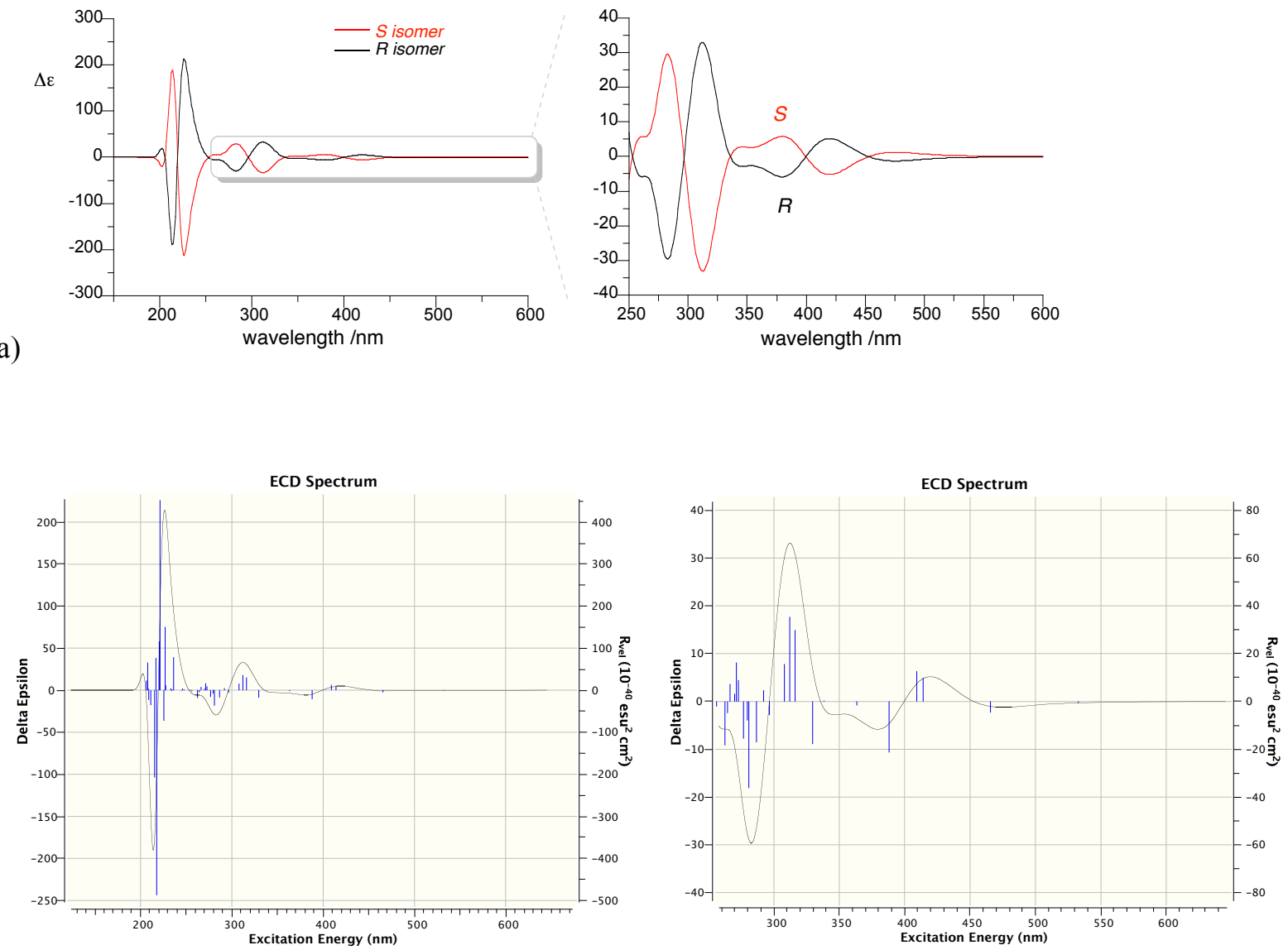

a) $R-1 b A$

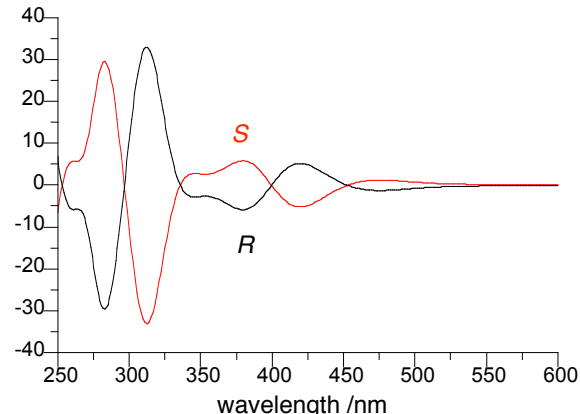

Exitation Energy $(\mathrm{nm})$ 

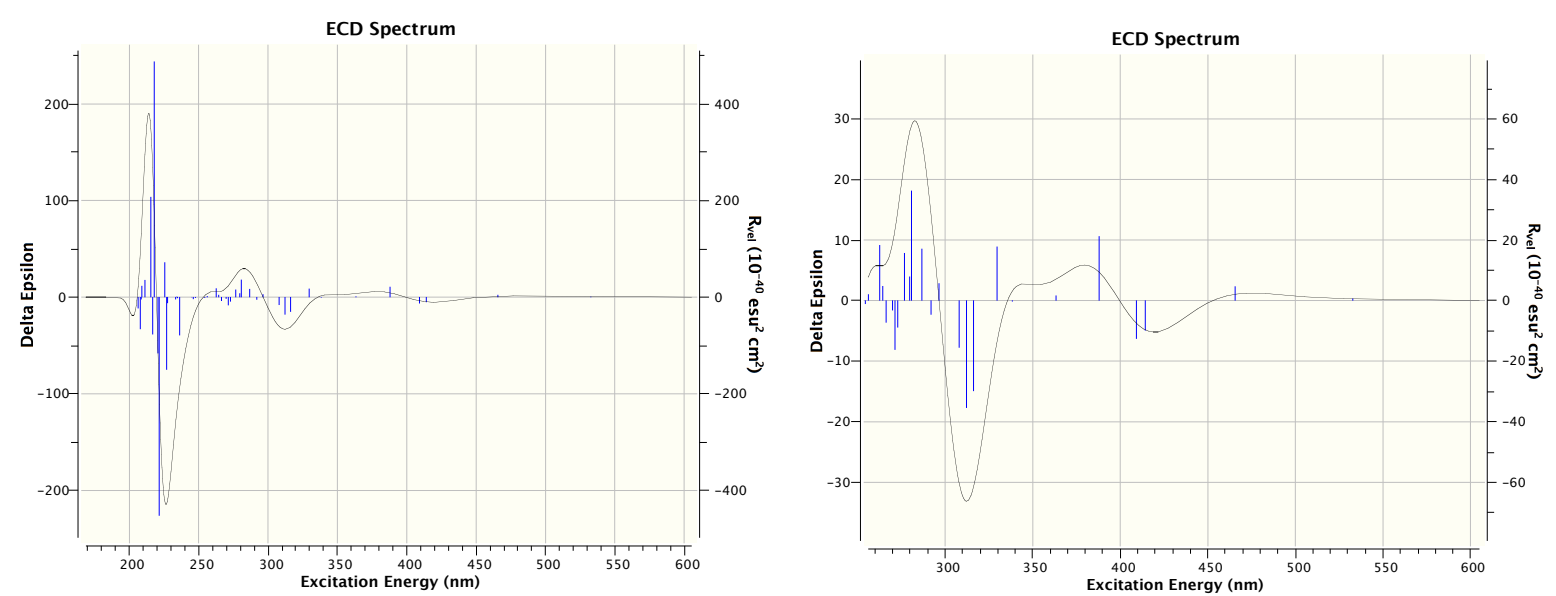

a) $S-1 \mathrm{bA}$
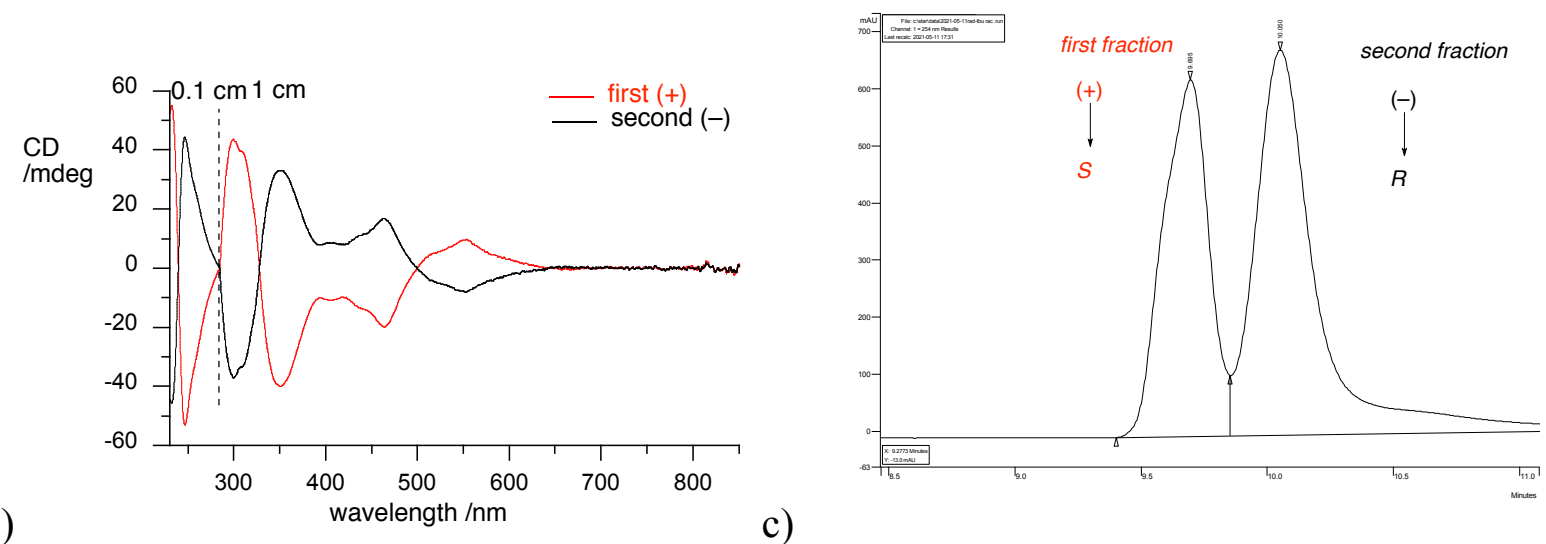

c)

Figure S27. ECD spectra of $\mathbf{1 b A}$ atropisomers $R$ (black line) and $S$ (red line): a) TD-DFT calculated and b) measured in $\mathrm{CH}_{2} \mathrm{Cl}_{2}$; c) chiral HPLC analysis of radical rac-1bA and absolute configuration assignment.

\section{Kinetics analysis of racemization}

All kinetic experiments were conducted in a closed vessel in 1,2-dichloroethane or cyclohexane. The temperature was controlled using Thermo Scientific dry bath thermostat. For kinetics experiments carried out in 1,2-dichloromethane, samples $(15 \mu \mathrm{L})$ were withdrawn at fixed time intervals $(5,10,15$ or $20 \mathrm{~min})$, diluted with hexane $(30 \mu \mathrm{L})$ and then cooled to $0{ }^{\circ} \mathrm{C}$. The $e e$ variation as a function of time was monitored by chiral HPLC (Chiralcel OD-H, hexane/i-PrOH, 97:3 ratio for radicals $\mathbf{1 a A}$ and $\mathbf{1 a B}$, and hexane/i-PrOH 99:1 ratio for radical $\mathbf{1 b A}$, flow 0.5 $\mathrm{mL} / \mathrm{min}$ ). For kinetic experiments carried out in cyclohexane, samples were withdrawn at fixed time intervals $(5,10,15$ or $20 \mathrm{~min})$, cooled to $0{ }^{\circ} \mathrm{C}$, and then analyzed by chiral HPLC as described above without dilution with hexane. The rate constant of enantiomerization, $k_{\mathrm{en}}$, was determined from first order kinetic line fitting according to equation $1:^{13}$ 


$$
\ln e e=-2 k_{e n} t+C
$$

eq 1

where $e e$ is an enantiomeric excess defined as $(1-\mathrm{R} / \mathrm{S}) /(1+\mathrm{R} / \mathrm{S}), k_{e n}$ is the rate constant of enantiomer interconversion $\left(\mathrm{s}^{-1}\right)$ and $t$ is the racemization time $(\mathrm{s})$.

For calculation of activation parameters frequently is used the racemization rate constant $k_{r a c}$, which is related to $k_{e n}$ by $k_{r a c}=2 \times k_{e n}{ }^{13}$ The constant $k_{r a c}$ is appropriate, however for irreversible processes, not for equilibrium processes, such as this one. Thus, further analyses were conducted using the enantiomer interconversion rate constant, $k_{e n}$. The use of the $k_{r a c}$ constant instead of $k_{e n}$ affects only the $\Delta S^{\neq}$by $+1.4 \mathrm{cal} \mathrm{mol}^{-1} \mathrm{~K}^{-1}$, which consequently lowers the $\Delta G_{298}^{\neq}$by $0.42 \mathrm{kcal} \mathrm{mol}^{-1}$.

The half-life of racemization, $t_{1 / 2 \text { rac }}$, the time during which the enantiomeric excess is reduces to $50 \%$, was calculated using equation 2 :

$$
t_{1 / 2 \text { rac }}=\frac{\ln 2}{2 k_{\text {en }}}=\frac{\ln 2}{k_{\text {rac }}}
$$

The experimentally obtained $k_{e n}$ values were analyzed using the Arrhenius equation 3:

$$
\ln k_{e n}=\ln A-\frac{E_{a}}{R T} \quad \text { eq } 3
$$

where $A$ is the frequency factor, $E_{a}$ is activation energy of enantiomerization, $R$ is the gas constant and $T$ absolute temperature. The value for $E_{a}$ and $\ln A$ were determined from a $\ln k_{e n}(1 / \mathrm{T})$ plot.

Temperature-independent thermodynamic parameters $\Delta H^{\neq}$and $\Delta S^{\neq}$were determined from the Eyring plot according to equation 4:

$$
\ln \left(\frac{k_{e n}}{T}\right)=-\frac{\Delta H^{\ddagger}}{R T}+\ln \left(\frac{k_{B}}{h}\right)+\frac{\Delta S^{\ddagger}}{R} \quad \text { eq } 4
$$

Finally, the apparent free energy barrier $\left(\Delta G_{T}{ }^{\neq}\right)$of enantiomer interconversion was calculated according to equation 5 :

$$
\Delta G_{T}^{\neq}=\Delta H^{\neq}-T \Delta S^{\neq}
$$

where $T$ is taken as standard temperature $(298 \mathrm{~K})$.

Confidence interval, CI, was determined for each parameter using equation 6 :

$$
C I=2 \times R \times z \frac{s t d}{\sqrt{n}}
$$

for which confidence $z$ was taken as $95 \%$ and $R$ is the gas constant. 
The first order kinetics data of racemization of enantiopure radicals $\mathbf{1}$ are shown at Figures S28S37 and resulting $k_{\mathrm{en}}$ and racemization activation parameters are presented in Tables S5 and S6.

Plotting and statistical analysis were performed with KaleidaGraph 4.5.0 software.

Kinetics data of racemization in 1,2-dichloroethane
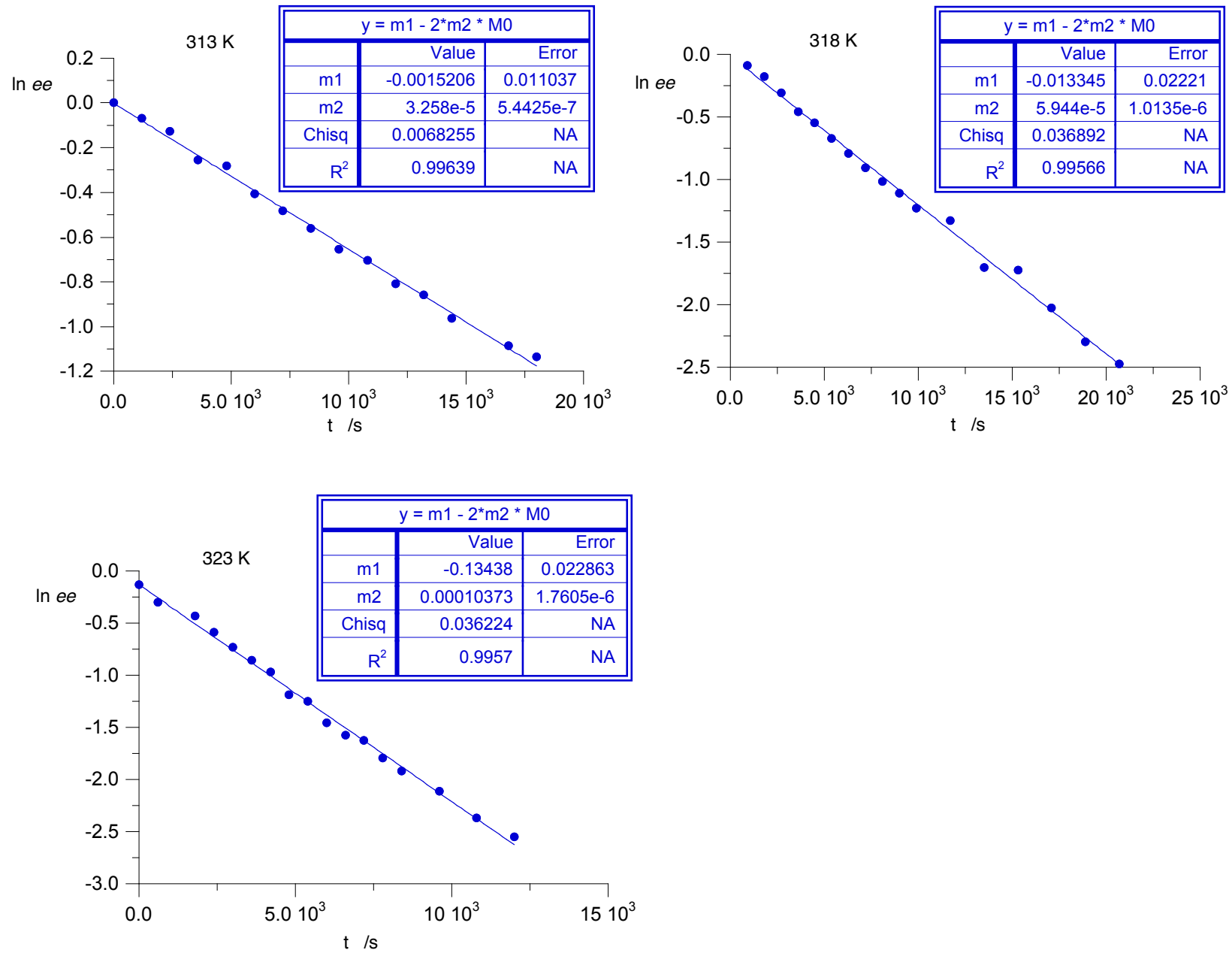

Figure S28. First order kinetics for racemization of radical $\mathbf{1 a A}$ in $\mathrm{ClCH}_{2} \mathrm{CH}_{2} \mathrm{Cl}$. 

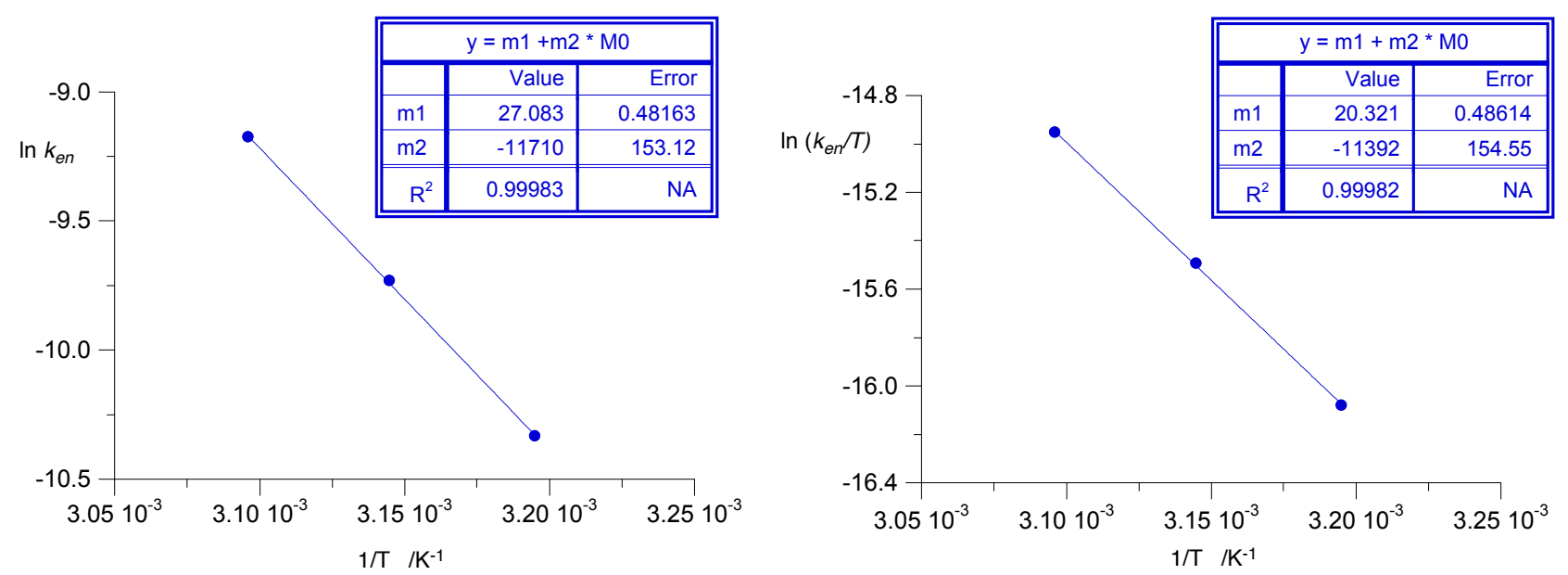

Figure S29. Arrhenius (left) and Eyring (right) plots for enantiomerization of radical $\mathbf{1 a A}$ in $\mathrm{ClCH}_{2} \mathrm{CH}_{2} \mathrm{Cl}$.
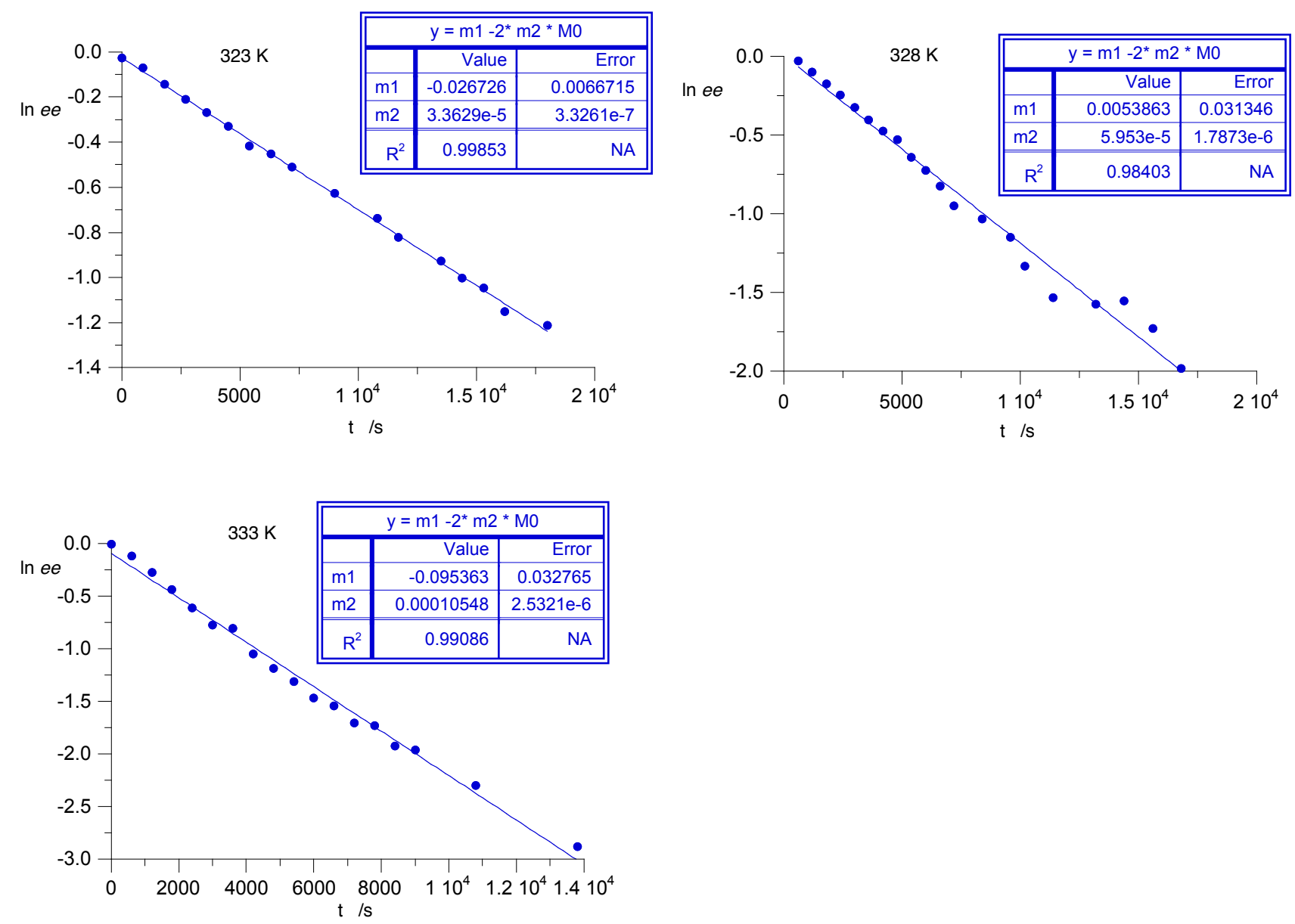

Figure S30. First order kinetics for racemization of radical $1 \mathrm{aB}$ in $\mathrm{ClCH}_{2} \mathrm{CH}_{2} \mathrm{Cl}$. 

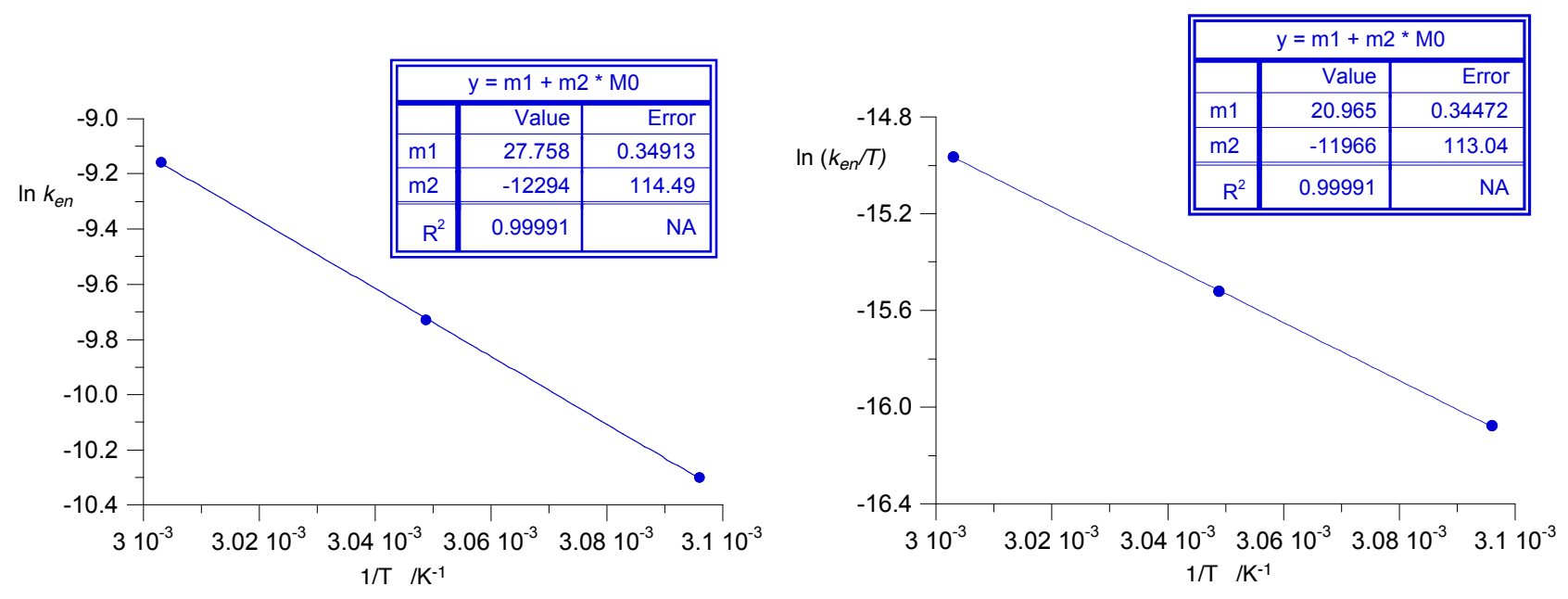

Figure S31. Arrhenius (left) and Eyring (right) plots for enantiomerization of radical $\mathbf{1 a B}$ in $\mathrm{ClCH}_{2} \mathrm{CH}_{2} \mathrm{Cl}$.
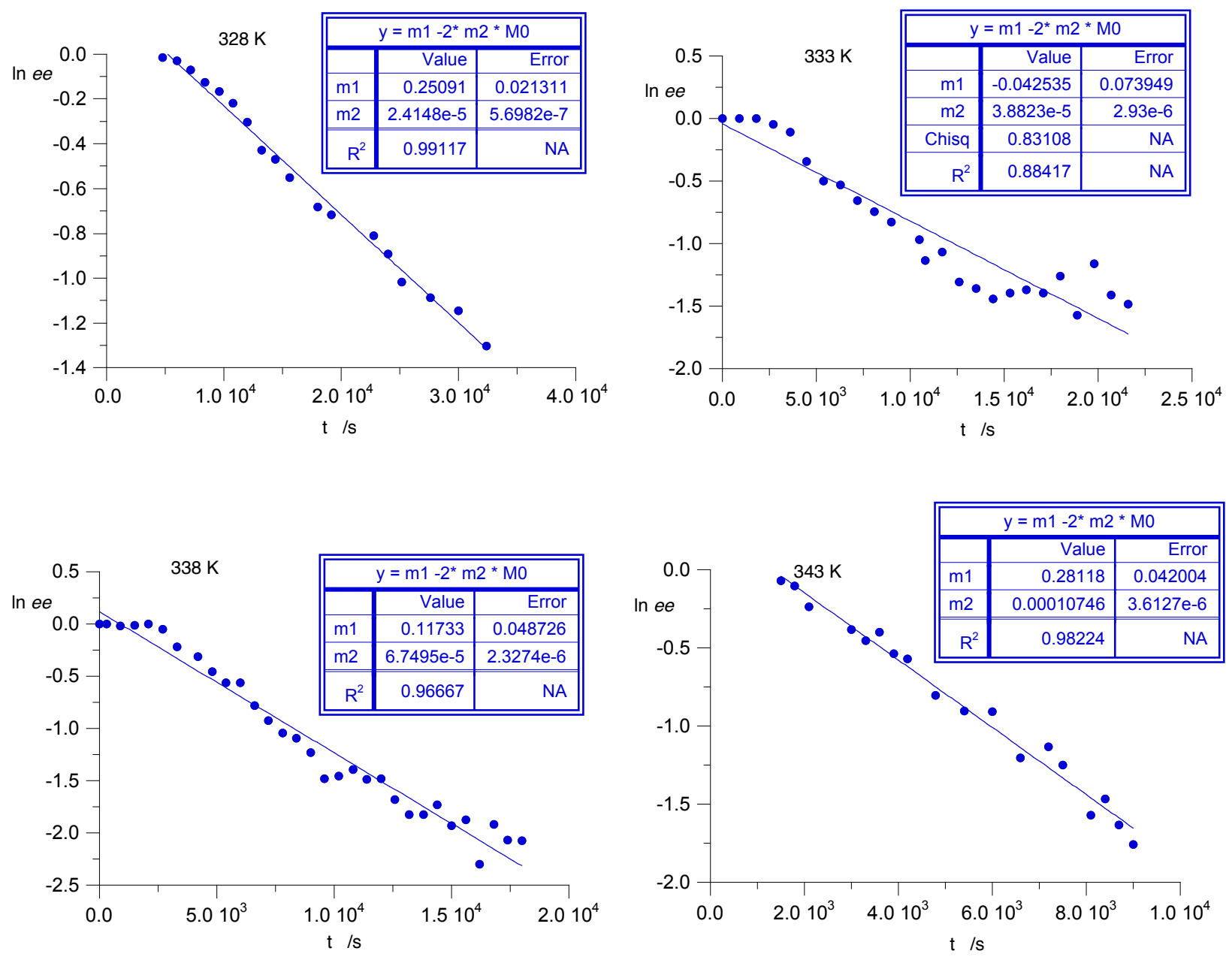

Figure S32. First order kinetics for racemization of radical $\mathbf{1 b A}$ in $\mathrm{ClCH}_{2} \mathrm{CH}_{2} \mathrm{Cl}$. 

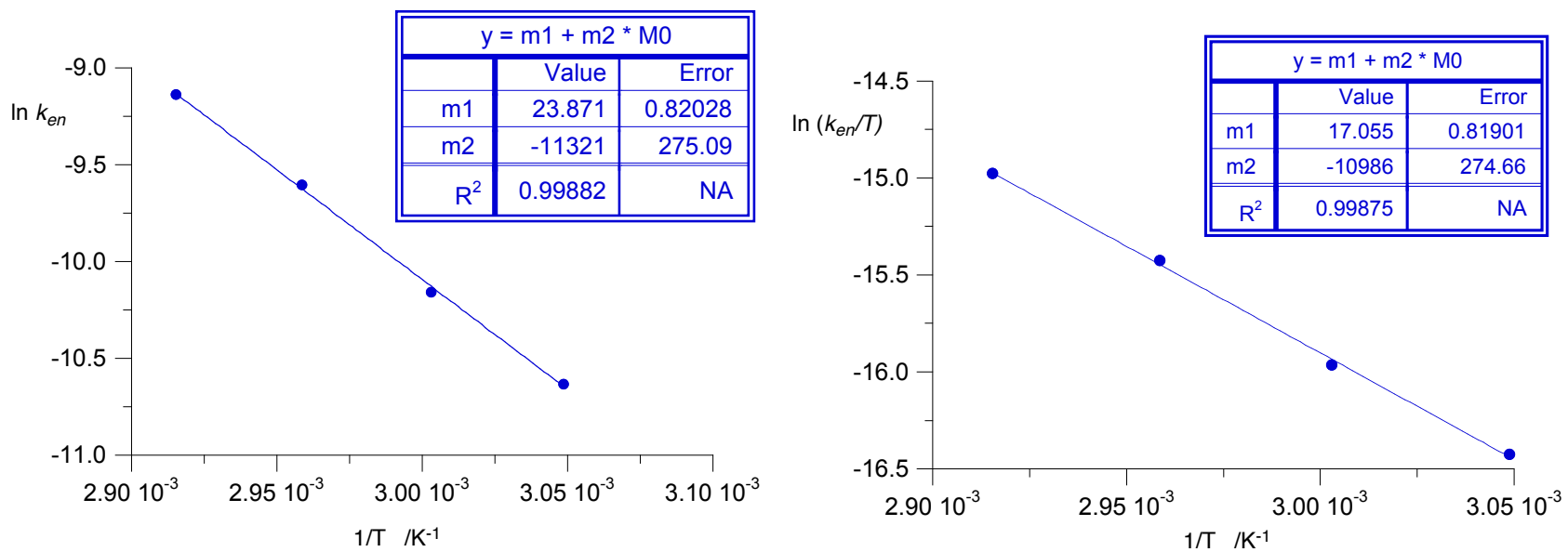

Figure S33. Arrhenius (left) and Eyring (right) plots for enantiomerization of radical $\mathbf{1 b A}$ in $\mathrm{ClCH}_{2} \mathrm{CH}_{2} \mathrm{Cl}$.

Table S5. Kinetic data for enantiomerization of radicals 1 in 1,2-dichloroethane obtained by integrations of HPLC signals and Arrhenius and Eyring analyses.

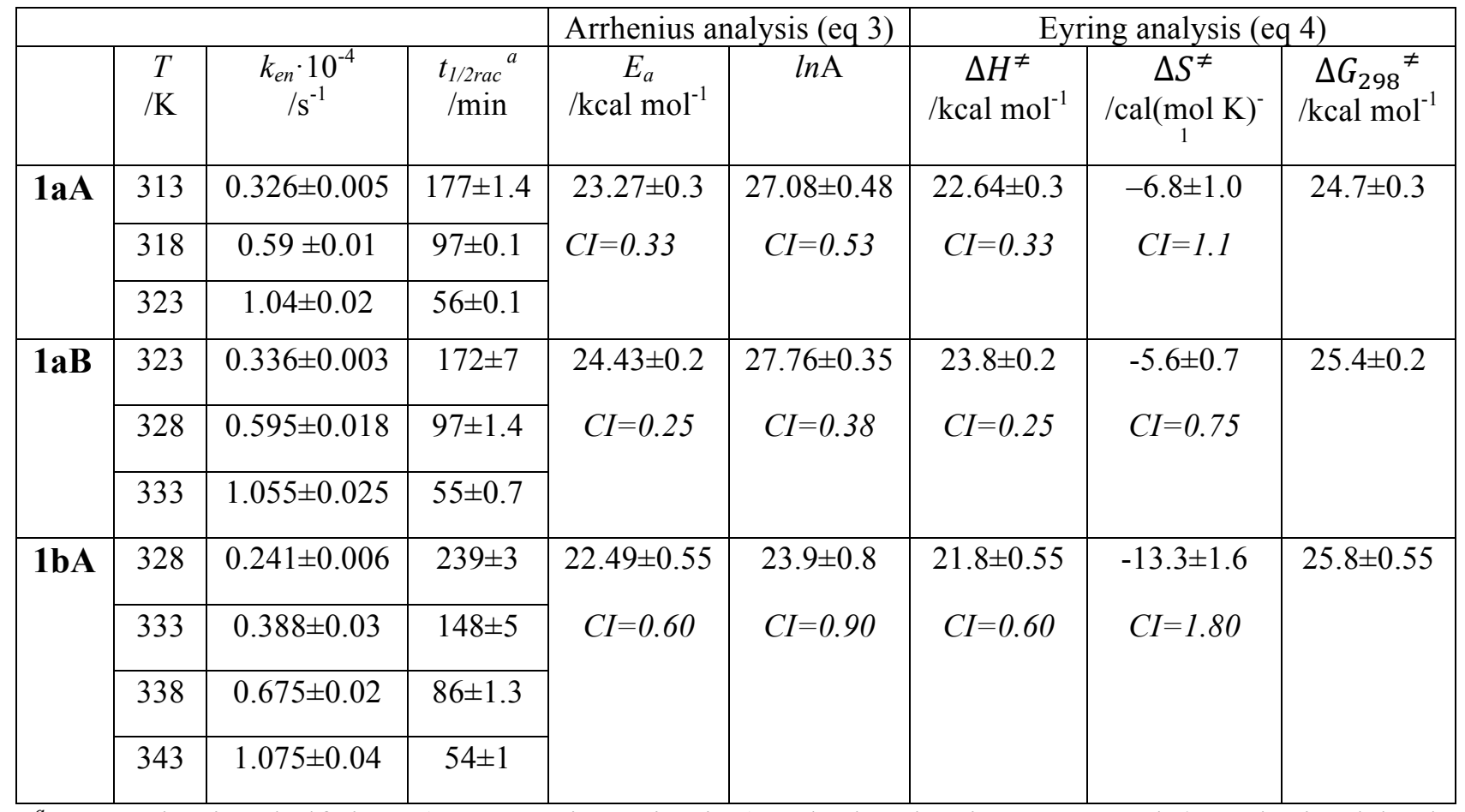

${ }^{a}$ Racemization half-time (not enantiomerization) calculated using eq 2 and $k_{\text {rac }}$ obtained back from the kinetic fitting line parameters (eq 3). Confidence integral CI calculated at confidence level of $95 \%$ according to eq. 6 . 
Kinetics data for racemization in cyclohexane
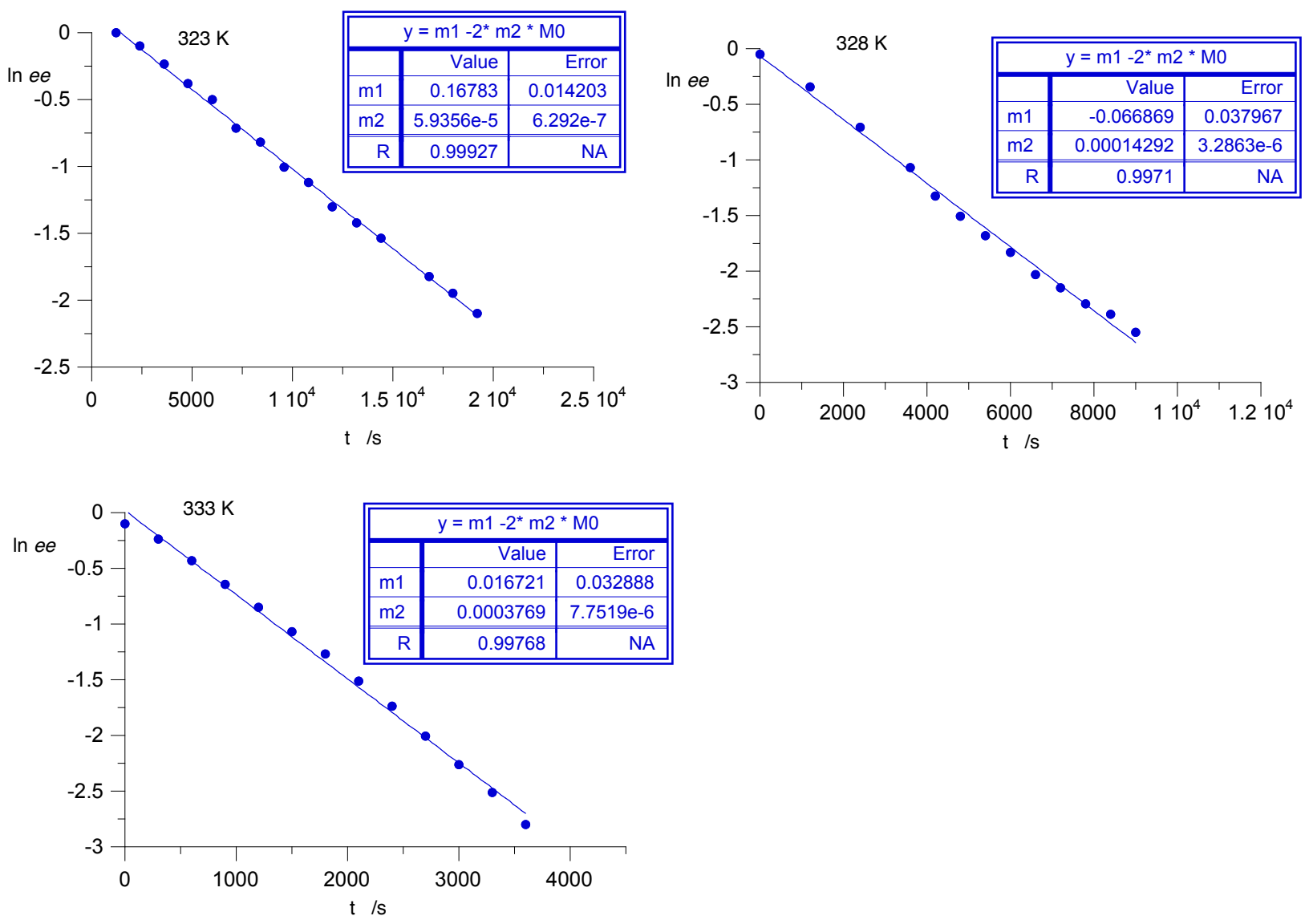

Figure S34. First order kinetics for enantiomerization of radical 1aA in cyclohexane.
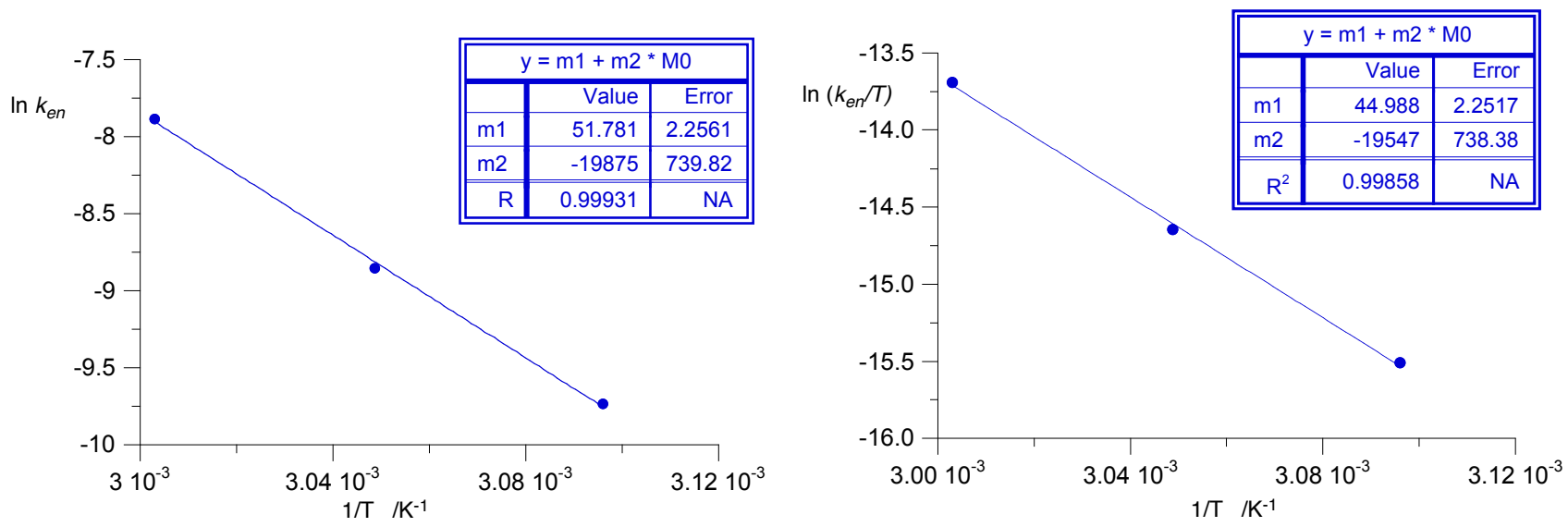

Figure S35. Arrhenius (left) and Eyring (right) plots for enantiomerization of radical 1aA in cyclohexane. 
Table S6. Kinetic data for enantiomerization of radicals 1 in cyclohexane obtained by integrations of HPLC signals and Arrhenius analysis.

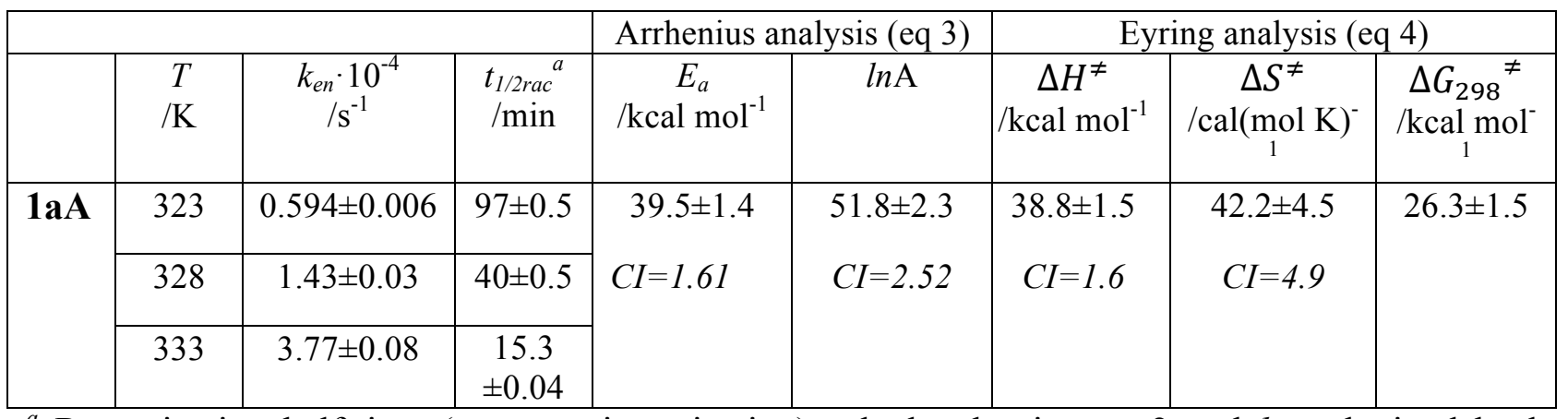

${ }^{a}$ Racemization half-time (not enantiomerization) calculated using eq 2 and $k_{\text {rac }}$ obtained back from the kinetic fitting line parameters (eq 3). Confidence integral CI calculated at confidence level of $95 \%$ according to eq. 6 .

\section{Computational details}

Quantum-mechanical calculations were carried out using Gaussian 09 suite of programs. ${ }^{14}$ Geometry optimizations were undertaken at the UB3LYP/Def2SVP level of theory using tight convergence limits. TD-DFT calculations were conducted at the UCAM-B3LYP/Def2SVP // UB3LYP/Def2SVP level of theory in $\mathrm{CH}_{2} \mathrm{Cl}_{2}$ dielectric medium using the PCM model requested with $\mathrm{SCRF}$ (solvent=CH2CL2) keyword, with TD method and 45 or 50 states.

\section{Partial output from TD-DFT calculations}

\begin{tabular}{|c|c|c|c|c|}
\hline \multicolumn{5}{|l|}{ s-1aA } \\
\hline Rotatory Stre & ths (R) in & cgs $(10 * *-40$ & erg-esu-cm & uss ) \\
\hline state & $\mathrm{XX}$ & YY & $\mathrm{ZZ}$ & $\mathrm{R}$ (length) \\
\hline 1 & 0.5133 & -1.2034 & 1.8455 & 0.3851 \\
\hline 2 & -2.9748 & -49.2836 & 32.5979 & -6.5535 \\
\hline 3 & 27.5801 & -23.7557 & -50.5580 & -15.5779 \\
\hline 4 & -0.7982 & -21.0566 & 12.7433 & -3.0372 \\
\hline 5 & 46.8218 & 12.5288 & 2.6754 & 20.6753 \\
\hline 6 & 12.4783 & 6.7407 & -19.8085 & -0.1965 \\
\hline 7 & 7.5707 & 0.7528 & -2.1152 & 2.0694 \\
\hline 8 & -21.9509 & 74.0979 & -36.0628 & 5.3614 \\
\hline 9 & -10.5751 & 39.4017 & -50.9173 & -7.3635 \\
\hline 10 & -62.8119 & 1.3229 & -33.1073 & -31.5321 \\
\hline 11 & -0.8347 & 2.3420 & 0.7710 & 0.7594 \\
\hline 12 & 10.2424 & 2.1961 & -10.9302 & 0.5028 \\
\hline 13 & -39.9648 & 31.0941 & -17.9127 & -8.9278 \\
\hline 14 & 11.0483 & 6.3176 & -12.6504 & 1.5718 \\
\hline 15 & 3.3160 & 38.6209 & -48.0856 & -2.0496 \\
\hline 16 & -0.9251 & 60.3141 & 0.7409 & 20.0433 \\
\hline 17 & -6.8562 & 15.8191 & -0.8499 & 2.7043 \\
\hline 18 & 1.1328 & 150.0041 & -68.6351 & 27.5006 \\
\hline 19 & -184.1382 & 8.4468 & -47.4470 & -74.3795 \\
\hline
\end{tabular}




$\begin{array}{rrrrr}20 & -43.1420 & 42.8513 & -37.5679 & -12.6195 \\ 21 & 96.8979 & 89.0340 & -2.7284 & 61.0678 \\ 22 & -3.2076 & -0.2693 & -4.9162 & -2.7977 \\ 23 & 19.6431 & 6.1934 & -1.2831 & 8.1845 \\ 24 & -7.6099 & 45.6161 & -51.6567 & -4.5501 \\ 25 & -19.0597 & -3.1200 & -30.1299 & -17.4366 \\ 26 & -35.2889 & 36.2107 & 2.7422 & 1.2213 \\ 27 & -51.6484 & 74.0560 & 25.3950 & 15.9342 \\ 28 & -0.5165 & -11.6171 & -2.0013 & -4.7116 \\ 29 & 14.2600 & 402.0719 & -25.3534 & 130.3262 \\ 30 & -4.0068 & 109.9438 & -23.9800 & 27.3190 \\ 31 & 124.9404 & 235.8284 & -1.6037 & 119.7217 \\ 32 & -106.1655 & -0.7834 & -79.7770 & -62.2420 \\ 33 & 4.8512 & 1.2238 & -17.4784 & -3.8011 \\ 34 & -1.3138 & 121.6686 & 1.4840 & 40.6129 \\ 35 & -60.9000 & 138.7981 & -307.3033 & -76.4684 \\ 36 & -5.2200 & 415.6012 & -138.4897 & 90.6305 \\ 37 & -210.9622 & -10.8450 & -265.7061 & -162.5044 \\ 38 & 3.7744 & -5.6019 & -0.7066 & -0.8447 \\ 39 & -13.6000 & 46.3105 & -111.6190 & -26.3028 \\ 40 & 39.6600 & -13.5934 & 6.0794 & 10.7153 \\ 41 & 24.3326 & 8.6651 & -10.5060 & 7.4972 \\ 42 & -57.2027 & 22.3557 & 32.8673 & -0.6599 \\ 43 & -2.1188 & 1.7784 & -4.1190 & -1.4865 \\ 44 & 33.4247 & 84.1474 & -3.6830 & 37.9630 \\ 45 & 22.8363 & 76.8294 & -248.4131 & -49.5825 \\ 46 & 10.0825 & 237.4273 & -374.7849 & -42.4251 \\ 47 & 147.7654 & 579.3100 & -900.5243 & -57.8163 \\ 48 & 472.4565 & 626.2200 & -1968.4808 & -289.9348 \\ 49 & -0.5027 & 391.9224 & -155.9675 & 78.4841 \\ 50 & 10.1720 & 77.8371 & -6.5763 & 27.1443\end{array}$

\section{R-1aA}

Rotatory Strengths ( $R$ )

in cgs $(10 * *-40$ erg-esu-cm/Gauss) tate

$\begin{array}{rr}1 & -0.5133 \\ 2 & 2.9752 \\ 3 & -27.5808 \\ 4 & 0.7983 \\ 5 & -46.8212 \\ 6 & -12.4784 \\ 7 & -7.5704 \\ 8 & 21.9508 \\ 9 & 10.5767 \\ 10 & 62.8097 \\ 11 & 0.8346 \\ 12 & -10.2423 \\ 13 & 39.9649 \\ 14 & -11.0481 \\ 15 & -3.3154 \\ 16 & 0.9255 \\ 17 & 6.8531 \\ 18 & -1.1344 \\ 19 & 184.1480 \\ 20 & 43.1360 \\ 21 & -96.8975 \\ 22 & 3.2076 \\ 23 & -19.6425\end{array}$

$$
\begin{array}{r}
Y Y \\
1.2030 \\
49.2845 \\
23.7522 \\
21.0591 \\
-12.5287 \\
-6.7410 \\
-0.7529 \\
-74.0971 \\
-39.4014 \\
-1.3225 \\
-2.3418 \\
-2.1967 \\
-31.0932 \\
-6.3177 \\
-38.6173 \\
-60.3166 \\
-15.8194 \\
-150.0039 \\
-8.4464 \\
-42.8502 \\
-89.0363 \\
0.2690 \\
-6.1930
\end{array}
$$

$-1.8451$

$-32.5996$

50.5587

$-12.7434$

$-2.6760$

19.8089

2.1152

36.0623

50.9176

33.1057

$-0.7710$

10.9311

17.9128

12.6502

48.0867

$-0.7414$

0.8488

68.6362

47.4498

37.5658

2. 7282

4. 9162

1.2831
$\mathrm{R}$ (length)

$-0.3851$

6.5534

15.5767

3.0380

$-20.6753$

0.1965

$-2.0694$

$-5.3613$

7.3643

31.5310

$-0.7594$

$-0.5026$

8.9282

$-1.5719$

2.0513

$-20.0442$

$-2.7059$

$-27.5007$

74.3838

12.6172

$-61.0686$

2.7976

$-8.1842$ 


$\begin{array}{lrrrr}24 & 7.6106 & -45.6170 & 51.6572 & 4.5503 \\ 25 & 19.0604 & 3.1200 & 30.1296 & 17.4367 \\ 26 & 35.2887 & -36.2102 & -2.7421 & -1.2212 \\ 27 & 51.6451 & -74.0545 & -25.3963 & -15.9352 \\ 28 & 0.5181 & 11.6170 & 2.0018 & 4.7123 \\ 29 & -14.2640 & -402.0811 & 25.3534 & -130.3306 \\ 30 & 4.0050 & -109.9462 & 23.9803 & -27.3203 \\ 31 & -124.9366 & -235.8197 & 1.6040 & -119.7175 \\ 32 & 106.1681 & 0.7833 & 79.7841 & 62.2451 \\ 33 & -4.8484 & -1.2242 & 17.4764 & 3.8013 \\ 34 & 1.3142 & -121.6772 & -1.4801 & -40.6144 \\ 35 & 60.8996 & -138.7788 & 307.2872 & 76.4693 \\ 36 & 5.2283 & -415.6151 & 138.4986 & -90.6294 \\ 37 & 210.9662 & 10.8491 & 265.7013 & 162.5055 \\ 38 & -3.7864 & 5.5997 & 0.7021 & 0.8384 \\ 39 & 13.6011 & -46.3058 & 111.6204 & 26.3052 \\ 40 & -39.6585 & 13.5933 & -6.0857 & -10.7170 \\ 41 & -24.3351 & -8.6670 & 10.4988 & -7.5011 \\ 42 & 57.2011 & -22.3505 & -32.8604 & 0.6634 \\ 43 & 2.1194 & -1.7787 & 4.1174 & 1.4860 \\ 44 & -33.4268 & -84.1461 & 3.6821 & -37.9636 \\ 45 & -22.8379 & -76.8306 & 248.4209 & 49.5842 \\ 46 & -10.0820 & -237.4119 & 374.7673 & 42.4245 \\ 47 & -147.7363 & -579.2336 & 900.3707 & 57.8003 \\ 48 & -472.4845 & -626.3002 & 1968.6572 & 289.9575 \\ 49 & 0.5019 & -391.9272 & 155.9785 & -78.4823 \\ 50 & -10.1726 & -77.8424 & 6.5767 & -27.1461\end{array}$

\section{s-1 aB}

Rotatory Strengths $(R)$ in cgs $(10 * *-40$ erg-esu-cm/Gauss)

\begin{tabular}{rrrrr} 
state & \multicolumn{1}{c}{$\mathrm{XX}$} & \multicolumn{1}{c}{$\mathrm{YY}$} & \multicolumn{1}{c}{$\mathrm{ZZ}$} & \multicolumn{1}{c}{ R(length) } \\
1 & 0.0546 & -3.0072 & 4.3065 & 0.4513 \\
2 & -1.4786 & -76.1054 & 53.6402 & -7.9813 \\
3 & 58.5558 & -4.2650 & -111.5007 & -19.0700 \\
4 & -5.3281 & -18.8137 & 18.7492 & -1.7975 \\
5 & 66.5499 & -8.6811 & 1.3524 & 19.7404 \\
6 & 27.0422 & 2.6922 & -31.6728 & -0.6461 \\
7 & 19.7764 & -2.1968 & -7.6780 & 3.3005 \\
8 & -46.2331 & 61.8432 & 1.7019 & 5.7707 \\
9 & 45.9842 & -0.8850 & -12.0496 & 11.0165 \\
10 & -137.1471 & 0.1650 & -5.0095 & -47.3305 \\
11 & -4.4897 & 0.8733 & 5.3469 & 0.5768 \\
12 & 2.3732 & 5.0071 & -13.4971 & -2.0389 \\
13 & -49.8412 & 12.2761 & 14.9434 & -7.5406 \\
14 & 12.0320 & 10.7975 & -18.4343 & 1.4651 \\
15 & -0.0093 & 13.1174 & -57.2312 & -14.7077 \\
16 & 20.0886 & 16.3952 & 99.1225 & 45.2021 \\
17 & -277.4652 & -6.1047 & 3.3017 & -93.4227 \\
18 & 89.2772 & 34.0318 & 33.5792 & 52.2961 \\
19 & -47.4206 & 3.9994 & 1.8246 & -13.8655 \\
20 & -1.3688 & 3.6759 & 5.1480 & 2.4850 \\
21 & 16.1298 & 120.9571 & 39.5482 & 58.8784 \\
22 & -1.7809 & -4.3524 & -0.5135 & -2.2156 \\
23 & -1.4978 & -0.0296 & -8.6233 & -3.3836 \\
24 & 2.2910 & 22.6382 & 11.3637 & 12.0976 \\
25 & -73.9452 & 40.7699 & -8.7308 & -13.9687 \\
26 & 0.3309 & -0.5641 & -1.0216 & -0.4183 \\
27 & -19.6832 & -73.6900 & 62.2607 & -10.3708
\end{tabular}




$\begin{array}{rrrrr}28 & -65.3587 & 13.1947 & 69.4030 & 5.7463 \\ 29 & -443.9611 & 935.1155 & 317.0327 & 269.3957 \\ 30 & 0.1916 & 2.2157 & -18.9283 & -5.5070 \\ 31 & 13.4299 & 65.6174 & 13.5083 & 30.8519 \\ 32 & -90.5256 & 1.8248 & -38.5920 & -42.4309 \\ 33 & -62.6578 & 2.0417 & -27.8354 & -29.4838 \\ 34 & 1.8240 & 22.7607 & 1.2872 & 8.6240 \\ 35 & -240.7230 & 224.0092 & -93.2160 & -36.6433 \\ 36 & -123.1505 & 431.6988 & 57.7491 & 122.0991 \\ 37 & -515.8913 & 53.3844 & -264.3819 & -242.2963 \\ 38 & 55.3619 & 15.6121 & 0.5457 & 23.8399 \\ 39 & 1.3545 & 2.4180 & 0.4196 & 1.3974 \\ 40 & 14.9498 & -61.1141 & 128.3191 & 27.3850 \\ 41 & -19.2071 & 0.5615 & -48.1483 & -22.2646 \\ 42 & -60.5271 & -7.4427 & 98.5767 & 10.2023 \\ 43 & -0.8285 & 0.6181 & 0.1896 & -0.0069 \\ 44 & -10.2632 & 20.2313 & -48.7297 & -12.9205 \\ 45 & 45.9794 & 3.5248 & 8.8865 & 19.4636 \\ 46 & -10.7859 & 40.5000 & -32.1881 & -0.8247 \\ 47 & -28.3063 & 229.0530 & -119.7671 & 26.9932 \\ 48 & -183.0232 & 1275.6874 & -2371.0599 & -426.1319 \\ 49 & 93.5066 & -5.9965 & 157.0231 & 81.5110 \\ 50 & 8.7880 & 73.0594 & 5.9058 & 29.2511\end{array}$

\section{R-1 aB}

Rotatory Strengths $(R)$ in cgs $(10 * *-40$ erg-esu-cm/Gauss)

\begin{tabular}{rrrrr} 
state & \multicolumn{1}{c}{ XX } & \multicolumn{1}{c}{ YY } & \multicolumn{1}{c}{$\mathrm{ZZ}$} & \multicolumn{1}{c}{ R(length) } \\
1 & -0.0546 & 3.0072 & -4.3064 & -0.4513 \\
2 & 1.4786 & 76.1054 & -53.6402 & 7.9813 \\
3 & -58.5558 & 4.2650 & 111.5008 & 19.0700 \\
4 & 5.3281 & 18.8137 & -18.7492 & 1.7975 \\
5 & -66.5499 & 8.6811 & -1.3524 & -19.7404 \\
6 & -27.0422 & -2.6922 & 31.6728 & 0.6461 \\
7 & -19.7764 & 2.1968 & 7.6780 & -3.3005 \\
8 & 46.2331 & -61.8432 & -1.7020 & -5.7707 \\
9 & -45.9842 & 0.8850 & 12.0496 & -11.0165 \\
10 & 137.1472 & -0.1650 & 5.0095 & 47.3306 \\
11 & 4.4897 & -0.8733 & -5.3469 & -0.5768 \\
12 & -2.3731 & -5.0071 & 13.4971 & 2.0389 \\
13 & 49.8413 & -12.2761 & -14.9434 & 7.5406 \\
14 & -12.0320 & -10.7975 & 18.4343 & -1.4651 \\
15 & 0.0093 & -13.1174 & 57.2313 & 14.7077 \\
16 & -20.0885 & -16.3951 & -99.1227 & -45.2021 \\
17 & 277.4647 & 6.1047 & -3.3019 & 93.4225 \\
18 & -89.2767 & -34.0318 & -33.5790 & -52.2958 \\
19 & 47.4206 & -3.9994 & -1.8246 & 13.8656 \\
20 & 1.3688 & -3.6759 & -5.1480 & -2.4850 \\
21 & -16.1299 & -120.9571 & -39.5483 & -58.8784 \\
22 & 1.7809 & 4.3524 & 0.5135 & 2.2156 \\
23 & 1.4978 & 0.0296 & 8.6233 & 3.3836 \\
24 & -2.2910 & -22.6381 & -11.3637 & -12.0976 \\
25 & 73.9455 & -40.7700 & 8.7307 & 13.9687 \\
26 & -0.3311 & 0.5642 & 1.0216 & 0.4182 \\
27 & 19.6833 & 73.6900 & -62.2608 & 10.3708 \\
28 & 65.3587 & -13.1948 & -69.4030 & -5.7463 \\
29 & 443.9613 & -935.1153 & -317.0331 & -269.3957 \\
30 & -0.1916 & -2.2158 & 18.9283 & 5.5070 \\
31 & -13.4298 & -65.6170 & -13.5081 & -30.8516
\end{tabular}




$\begin{array}{lrrrr}32 & 90.5258 & -1.8248 & 38.5920 & 42.4310 \\ 33 & 62.6573 & -2.0417 & 27.8353 & 29.4836 \\ 34 & -1.8241 & -22.7606 & -1.2872 & -8.6240 \\ 35 & 240.7233 & -224.0090 & 93.2159 & 36.6434 \\ 36 & 123.1506 & -431.6985 & -57.7493 & -122.0991 \\ 37 & 515.8912 & -53.3844 & 264.3814 & 242.2961 \\ 38 & -55.3619 & -15.6122 & -0.5457 & -23.8399 \\ 39 & -1.3544 & -2.4180 & -0.4195 & -1.3973 \\ 40 & -14.9498 & 61.1142 & -128.3191 & -27.3849 \\ 41 & 19.2071 & -0.5615 & 48.1483 & 22.2646 \\ 42 & 60.5270 & 7.4428 & -98.5766 & -10.2023 \\ 43 & 0.8285 & -0.6181 & -0.1897 & 0.0069 \\ 44 & 10.2631 & -20.2314 & 48.7298 & 12.9205 \\ 45 & -45.9794 & -3.5248 & -8.8864 & -19.4635 \\ 46 & 10.7859 & -40.5000 & 32.1882 & 0.8247 \\ 47 & 28.3065 & -229.0540 & 119.7679 & -26.9932 \\ 48 & 183.0231 & -1275.6840 & 2371.0566 & 426.1319 \\ 49 & -93.5065 & 5.9968 & -157.0231 & -81.5109 \\ 50 & -8.7882 & -73.0592 & -5.9058 & -29.2511\end{array}$

\section{S-1bA}

Rotatory Strengths $(\mathrm{R})$ in cgs $(10 * *-40$ erg-esu-cm/Gauss)

\begin{tabular}{crrrr} 
state & \multicolumn{1}{c}{ XX } & \multicolumn{1}{c}{ YY } & \multicolumn{1}{c}{ R (length) } \\
1 & 0.6956 & -0.0591 & 0.9812 & 0.5392 \\
2 & 64.0358 & -91.2870 & 39.9864 & 4.2451 \\
3 & -13.3077 & -30.6084 & 2.2864 & -13.8766 \\
4 & 9.5089 & 30.5653 & -68.3024 & -9.4094 \\
5 & 65.0425 & 42.0359 & -42.2013 & 21.6257 \\
6 & 8.4335 & 4.7727 & -7.8168 & 1.7965 \\
7 & -0.2840 & -1.0777 & 4.5384 & 1.0589 \\
8 & 48.6257 & 67.8354 & -61.5200 & 18.3137 \\
9 & -14.8017 & 13.6878 & -89.3094 & -30.1411 \\
10 & -19.4425 & 53.0441 & -142.5855 & -36.3279 \\
11 & -48.7844 & 14.8050 & -14.5124 & -16.1639 \\
12 & 3.4696 & 13.0231 & 1.7163 & 6.0696 \\
13 & -27.5194 & 70.2914 & -51.6695 & -2.9658 \\
14 & 7.8139 & 49.6980 & -6.3276 & 17.0614 \\
15 & 20.8728 & 140.8170 & -56.6962 & 34.9979 \\
16 & -1.4970 & 36.9350 & -11.6923 & 7.9152 \\
17 & -46.2623 & 80.1299 & 15.5619 & 16.4765 \\
18 & 3.0065 & -0.3348 & -31.5917 & -9.6400 \\
19 & 17.6682 & -0.2659 & -63.8067 & -15.4681 \\
20 & 0.2381 & 1.0491 & -11.8322 & -3.5150 \\
21 & -5.0215 & 9.2628 & -26.6699 & -7.4762 \\
22 & 9.8461 & 1.7299 & 2.1918 & 4.5893 \\
23 & -13.3514 & 54.9690 & 14.0212 & 18.5463 \\
24 & 6.5579 & -3.4598 & 4.0219 & 2.3733 \\
25 & -0.1711 & 0.9605 & -3.8505 & -1.0204 \\
26 & 6.7790 & 8.9604 & -22.0464 & -2.1023 \\
27 & -1.6324 & 16.4612 & -26.1871 & -3.7861 \\
28 & 1.2807 & 92.1262 & -94.8960 & -0.4963 \\
29 & -17.2258 & 64.8689 & -292.4797 & -81.6122 \\
30 & 0.6365 & 2.9409 & -7.9778 & -1.4668 \\
31 & 0.0250 & 3.2474 & -0.0270 & 1.0818 \\
32 & 1.9083 & 10.0315 & -25.7797 & -4.6133 \\
33 & -35.4518 & -0.7632 & -0.4476 & -12.2209 \\
34 & -31.2817 & 109.4601 & -538.9196 & -153.5804 \\
35 & 2.1542 & 221.2694 & 3.2131 & 75.5456
\end{tabular}




$\begin{array}{rrrrr}36 & 167.4442 & 585.3511 & -2131.3942 & -459.5330 \\ 37 & 82.9637 & 29.9098 & -462.0832 & -116.4032 \\ 38 & -140.5379 & 1307.5050 & 346.7345 & 504.5672 \\ 39 & 3.1783 & 15.1403 & -265.1027 & -82.2614 \\ 40 & 380.0752 & 369.9128 & -119.0886 & 210.2998 \\ 41 & -2.9510 & 156.9990 & -42.9014 & 37.0489 \\ 42 & -5.4210 & 65.7937 & 12.2261 & 24.1996 \\ 43 & -0.2793 & 1.4703 & -13.9138 & -4.2410 \\ 44 & 2.0671 & -2.1535 & -199.2690 & -66.4518 \\ 45 & -71.3845 & 151.0469 & -144.2315 & -21.5230\end{array}$

\section{R-1bA}

\begin{tabular}{crrrr} 
Rotatory Strengths $(\mathrm{R})$ in & cgs & $(10 * *-40$ & rg-esu-cm/Gauss $)$ \\
State & $\mathrm{XX}$ & $\mathrm{YY}$ & $\mathrm{ZZ}$ & \multicolumn{1}{c}{$\mathrm{R}($ length $)$} \\
1 & -0.6956 & 0.0591 & -0.9811 & -0.5392 \\
2 & -64.0307 & 91.2829 & -39.9857 & -4.2445 \\
3 & 13.3052 & 30.6093 & -2.2898 & 13.8749 \\
4 & -9.5088 & -30.5661 & 68.3064 & 9.4105 \\
5 & -65.0421 & -42.0342 & 42.1984 & -21.6260 \\
6 & -8.4324 & -4.7721 & 7.8160 & -1.7962 \\
7 & 0.2841 & 1.0798 & -4.5383 & -1.0581 \\
8 & -48.6260 & -67.8409 & 61.5263 & -18.3135 \\
9 & 14.7999 & -13.6841 & 89.2943 & 30.1367 \\
10 & 19.4419 & -53.0458 & 142.5889 & 36.3283 \\
11 & 48.7869 & -14.8052 & 14.5153 & 16.1656 \\
12 & -3.4691 & -13.0214 & -1.7154 & -6.0686 \\
13 & 27.5178 & -70.2890 & 51.6706 & 2.9665 \\
14 & -7.8128 & -49.7037 & 6.3249 & -17.0639 \\
15 & -20.8732 & -140.8071 & 56.6929 & -34.9958 \\
16 & 1.4973 & -36.9425 & 11.6943 & -7.9170 \\
17 & 46.2630 & -80.1230 & -15.5632 & -16.4744 \\
18 & -3.0044 & 0.3347 & 31.5803 & 9.6369 \\
19 & -17.6692 & 0.2657 & 63.8189 & 15.4718 \\
20 & -0.2385 & -1.0483 & 11.8365 & 3.5166 \\
21 & 5.0213 & -9.2618 & 26.6634 & 7.4743 \\
22 & -9.8459 & -1.7320 & -2.1891 & -4.5890 \\
23 & 13.3514 & -54.9672 & -14.0238 & -18.5465 \\
24 & -6.5581 & 3.4602 & -4.0213 & -2.3731 \\
25 & 0.1709 & -0.9600 & 3.8501 & 1.0203 \\
26 & -6.7781 & -8.9591 & 22.0446 & 2.1025 \\
27 & 1.6326 & -16.4570 & 26.1825 & 3.7861 \\
28 & -1.2809 & -92.1284 & 94.8974 & 0.4960 \\
29 & 17.2246 & -64.8653 & 292.4650 & 81.6081 \\
30 & -0.6365 & -2.9397 & 7.9763 & 1.4667 \\
31 & -0.0248 & -3.2497 & 0.0263 & -1.0827 \\
32 & -1.9085 & -10.0301 & 25.7786 & 4.6133 \\
33 & 35.4393 & 0.7616 & 0.4439 & 12.2149 \\
34 & 31.2923 & -109.4610 & 538.9297 & 153.5870 \\
35 & -2.1551 & -221.2800 & -3.2107 & -75.5486 \\
36 & -167.4546 & -585.3752 & 2131.4146 & 459.5283 \\
37 & -82.9714 & -29.8705 & 462.1553 & 116.4378 \\
38 & 140.5234 & -1307.4828 & -346.7073 & -504.5556 \\
39 & -3.1565 & -15.1703 & 265.0356 & 82.2363 \\
40 & -380.0530 & -369.9316 & 119.0405 & -210.3147 \\
41 & 2.9518 & -156.9866 & 42.9106 & -37.0414 \\
42 & 5.4195 & -65.7863 & -12.2245 & -24.1971 \\
43 & 0.2776 & -1.4700 & 13.9379 & 4.2485 \\
44 & -2.0662 & 2.1523 & 199.2399 & 66.4420
\end{tabular}




\section{Archive for DFT calculations}

\section{$S-1 a A$}

$1 \backslash 1 \backslash G I N C-L O C A L H O S T \backslash F O p t \backslash U B 3 L Y P \backslash \operatorname{def} 2 S V P \backslash C 29 H 20 N 3$ ( 2) \PIOTR \23-Mar-2021 $\backslash \backslash \# \mathrm{P}$ UB3LYP/Def2SVP FOpt(tight) Geom=(NoDistance, NoAngle) fcheck \\naph thalene-1-(3-Ph-benzotrizin-1-yl)-8-Ph, S isomer $\backslash \backslash 0,2 \backslash \mathrm{C}, 2.3850213091$, $-2.0653649206,-4.4073410291 \backslash \mathrm{C}, 1.514347509,-1.6268161742,-3.4165419869 \backslash$ $C, 1.8299647371,-1.9148564336,-2.0376937433 \backslash C, 2.9639991794,-2.768109332$ $9,-1.7629014183 \backslash \mathrm{C}, 3.8005608068,-3.2043597351,-2.8270929334 \backslash \mathrm{C}, 3.5356632$ $957,-2.8329287421,-4.1238061288 \backslash \mathrm{C}, 1.1237354112,-1.4122174345,-0.890653$ $8844 \backslash \mathrm{C}, 3.2531727569,-3.1739771077,-0.4308997631 \backslash \mathrm{C}, 2.4833435044,-2.7455$ $941589,0.6262176834 \backslash \mathrm{C}, 1.4285242294,-1.8406263579,0.3895179661 \backslash \mathrm{H}, 2.1355$ $746495,-1.8465894929,-5.4480755584 \backslash \mathrm{H}, 4.6582706598,-3.8390233771,-2.590$ $2228073 \backslash \mathrm{H}, 4.1839002653,-3.1592493975,-4.9406569167 \backslash \mathrm{H}, 4.1062245125,-3.8$ $36727857,-0.264315606 \backslash \mathrm{H}, 2.7033890384,-3.068328535,1.6463096849 \backslash \mathrm{H}, 0.845$ $1259006,-1.4416115275,1.2209460891 \backslash \mathrm{C}, 0.3999826696,0.9266247706,-1.2594$ $390699 \backslash \mathrm{C}, 1.6924260035,1.3894224777,-1.5526391971 \backslash \mathrm{C},-0.7002573755,1.835$ $2197308,-1.2037717732 \backslash \mathrm{C},-2.0851815791,0.126530214,-0.5320083055 \backslash \mathrm{C}, 1.89$ $43721183,2.7424123252,-1.825320852 \backslash \mathrm{C},-0.4598557965,3.1967685037,-1.492$ $1770585 \backslash \mathrm{C}, 0.8184728126,3.6450637968,-1.8031114501 \backslash \mathrm{H}, 2.5325498625,0.695$ $6830657,-1.5683016506 \backslash \mathrm{H}, 2.9020359192,3.0972704032,-2.0545502196 \backslash \mathrm{H},-1.3$ $142699633,3.8747322047,-1.4490665468 \backslash \mathrm{H}, 0.9888748451,4.7021116178,-2.02$ $11472144 \backslash \mathrm{C}, 0.2550972909,-0.9693095904,-3.8842037366 \backslash \mathrm{C},-0.9985241705,-1$ $.5514701966,-3.6256887456 \backslash \mathrm{C},-2.1644146309,-1.0015737837,-4.1624576619 \backslash$ $\mathrm{C},-0.8599195264,0.7248108504,-5.2371763813 \backslash \mathrm{N},-1.1236205108,-0.80118268$ $91,-0.5671944939 \backslash \mathrm{N},-1.9513439615,1.4147633311,-0.8548733044 \backslash \mathrm{C},-2.09993$ $96016,0.1390389291,-4.9689195938 \backslash \mathrm{C}, 0.3071837868,0.1727096466,-4.702959$ $0691 \backslash \mathrm{H},-0.7989316606,1.6196515641,-5.86188821 \backslash \mathrm{H},-1.0595909489,-2.44376$ $65404,-2.9992415563 \backslash \mathrm{H},-3.1292581805,-1.4672442319,-3.9468722653 \backslash \mathrm{H},-3.0$ $141456344,0.5704217201,-5.3842508095 \backslash \mathrm{H}, 1.27339169,0.6391215738,-4.9095$ $421444 \backslash \mathrm{C},-3.4270509759,-0.3478345373,-0.0875462573 \backslash \mathrm{C},-4.495087125,0.56$ $17480875,-0.006701898 \backslash \mathrm{C},-3.6489774725,-1.6932651177,0.2558269357 \backslash \mathrm{C},-5$. $7576696311,0.1346643701,0.4079371499 \backslash C,-4.9126944497,-2.1165741016,0.6$ $699221891 \backslash \mathrm{C},-5.9716406777,-1.2051662929,0.7475771679 \backslash \mathrm{H},-4.3106351682,1$ $.6025426429,-0.2752755018 \backslash \mathrm{H},-2.8186955236,-2.3976202792,0.1935066798 \backslash \mathrm{H}$ $,-6.5803870743,0.8522210869,0.4668105906 \backslash \mathrm{H},-5.0731014199,-3.1651515387$ $, 0.9345230763 \backslash \mathrm{H},-6.9607544123,-1.5389258995,1.0724311329 \backslash \mathrm{N}, 0.099768156$ $8,-0.4093295091,-0.9916089734 \backslash \backslash$ Version=ES64L-G09RevD .01 \State=2-A \HF=$1280.4476115 \backslash \mathrm{S} 2=0.767213 \backslash \mathrm{S} 2-1=0 . \backslash \mathrm{S} 2 \mathrm{~A}=0.75017 \backslash \mathrm{RMSD}=3.207 \mathrm{e}-09 \backslash \mathrm{RMSF}=1.031$ e-06\Dipole $=1.1545611,-0.3164027,-0.2473488 \backslash$ Quadrupole $=4.8123307,-0.62$ $84905,-4.1838402,-2.5024791,-0.2509008,-4.964137 \backslash \mathrm{PG}=\mathrm{C} 01[\mathrm{X}(\mathrm{C} 29 \mathrm{H} 20 \mathrm{~N} 3)] \backslash$ $\backslash$ a

\section{$R-1$ aA}

$1 \backslash 1 \backslash G I N C-L O C A L H O S T \backslash F O p t \backslash U B 3 L Y P \backslash \operatorname{def} 2 \mathrm{SVP} \backslash C 29 H 20 \mathrm{~N} 3$ ( 2) $\backslash \mathrm{PIOTR} \backslash 23-\mathrm{Mar}-2021 \backslash 0$ $\backslash \backslash \# P$ UB3LYP/Def2SVP FOpt(tight) Geom=(NoDistance, NoAngle) fcheck \\naph thalene-1-(3-Ph-benzodiazen-1-yl)-8-Ph \\0,2\C, 3.7871370394,0.210134227 $4,1.6362607251 \backslash \mathrm{C}, 2.5464759932,0.0154631392,1.0404888235 \backslash \mathrm{C}, 2.4037868211$ $,-1.0354680197,0.0612097592 \backslash \mathrm{C}, 3.5225959468,-1.926304713,-0.1491728061 \backslash$ $C, 4.7579979433,-1.6856654341,0.5130421521 \backslash C, 4.8990766767,-0.6169572342$ $, 1.3660112109 \backslash \mathrm{C}, 1.2425300658,-1.2752400968,-0.7518684806 \backslash \mathrm{C}, 3.398517207$ $6,-3.0443885934,-1.0192710668 \backslash \mathrm{C}, 2.2279526966,-3.2895402893,-1.69995205$ $86 \backslash \mathrm{C}, 1.1560911674,-2.3817950524,-1.5785094114 \backslash \mathrm{H}, 3.8843485816,1.0048529$ $685,2.3793535721 \backslash \mathrm{H}, 5.5914744069,-2.3677718949,0.3269799436 \backslash \mathrm{H}, 5.8510163$ $968,-0.4255389474,1.8671213205 \backslash \mathrm{H}, 4.2590396772,-3.7079682644,-1.1369533$ $266 \backslash \mathrm{H}, 2.1342626645,-4.1554061644,-2.3592422096 \backslash \mathrm{H}, 0.2418377019,-2.52505$ $47108,-2.1568315401 \backslash \mathrm{C}, 0.2034005541,0.8602636579,-1.4517512887 \backslash \mathrm{C}, 1.3797$ $823259,1.36267364,-2.0299101341 \backslash \mathrm{C},-1.0149226083,1.6014273975,-1.526162$ 
$5394 \backslash \mathrm{C},-2.1367728131,-0.1287912949,-0.5079787892 \backslash \mathrm{C}, 1.3632826434,2.6115$ $691106,-2.6509637815 \backslash \mathrm{C},-0.9927756342,2.8651446247,-2.1564913438 \backslash \mathrm{C}, 0.18$ $03125195,3.3666618382,-2.707960218 \backslash \mathrm{H}, 2.3004747389,0.7810674384,-1.9926$ $604954 \backslash \mathrm{H}, 2.2819954403,2.9988130858,-3.0980269527 \backslash \mathrm{H},-1.932778361,3.4183$ $978282,-2.1991809319 \backslash \mathrm{H}, 0.1806703229,4.3448772381,-3.1948084246 \backslash \mathrm{C}, 1.425$ $8808671,0.8648213904,1.5499900439 \backslash \mathrm{C}, 0.3233587515,0.284669826,2.2020466$ $184 \backslash \mathrm{C},-0.6641570796,1.0840848262,2.7813183524 \backslash \mathrm{C}, 0.5247079106,3.0671586$ $628,2.0804973497 \backslash \mathrm{N},-1.0474635905,-0.8926934681,-0.3801330591 \backslash \mathrm{N},-2.1829$ $550272,1.0993242554,-1.0288455225 \backslash \mathrm{C},-0.5681518353,2.4779171226,2.72173$ $99923 \backslash \mathrm{C}, 1.5147218197,2.267409109,1.5037761086 \backslash \mathrm{H}, 0.606622457,4.15563318$ $34,2.0235984086 \backslash \mathrm{H}, 0.2401923089,-0.8027558126,2.2563307169 \backslash \mathrm{H},-1.5147739$ $517,0.6135786887,3.2806417545 \backslash \mathrm{H},-1.3445192729,3.1016620292,3.171806108$ $1 \backslash \mathrm{H}, 2.3631999902,2.733201754,0.9969264085 \backslash \mathrm{C},-3.4095110095,-0.727386823$ $,-0.0130018297 \backslash \mathrm{C},-4.6078036544,-0.0012444906,-0.1197203865 \backslash \mathrm{C},-3.438063$ $0623,-2.0108446819,0.5608106068 \backslash C,-5.8082964213,-0.5467891188,0.338142$ $9128 \backslash \mathrm{C},-4.6402209404,-2.5529742998,1.0174920576 \backslash \mathrm{C},-5.8295235197,-1.823$ $7970068,0.908305496 \backslash \mathrm{H},-4.5730663175,0.992897304,-0.5668031076 \backslash \mathrm{H},-2.507$ $3119942,-2.573424019,0.6418967515 \backslash \mathrm{H},-6.7338485499,0.0282465276,0.24923$ $3076 \backslash \mathrm{H},-4.6500016051,-3.5519197074,1.4616441457 \backslash \mathrm{H},-6.7701843939,-2.250$ $5290907,1.2665350318 \backslash \mathrm{N}, 0.1286780054,-0.3686366452,-0.7953547428 \backslash \backslash$ Versi on=ES6 $4 \mathrm{~L}-\mathrm{G} 09$ RevD.01 $\mathbf{\text { State }}=2-\mathrm{A} \backslash \mathrm{HF}=-1280.4476115 \backslash \mathrm{S} 2=0.767213 \backslash \mathrm{S} 2-1=0 . \backslash \mathrm{S} 2 \mathrm{~A}$ $=0.75017 \backslash \mathrm{RMSD}=4.801 \mathrm{e}-09 \backslash \mathrm{RMSF}=1.045 \mathrm{e}-06 \backslash \mathrm{Dipole}=1.2060089,-0.151047,-0.1$ $305194 \backslash$ Quadrupole $=3.7838909,2.9959064,-6.7797973,-1.8424531,-3.6132424$ $0.646579 \backslash \mathrm{PG}=\mathrm{C} 01[\mathrm{X}(\mathrm{C} 29 \mathrm{H} 20 \mathrm{~N} 3)] \backslash \backslash$

\section{S-1aB}

$1 \backslash 1 \backslash G I N C-L O C A L H O S T \backslash F O p t \backslash U B 3 L Y P \backslash \operatorname{def} 2 \mathrm{SVP} \backslash \mathrm{C} 33 \mathrm{H} 28 \mathrm{~N} 3$ ( 2) $\backslash \mathrm{PIOTR} \backslash 24-\mathrm{Mar}-2021 \backslash 0$ $\backslash \backslash \# P$ UB3LYP/Def2SVP FOpt(tight) Geom=(NoDistance, NoAngle) fcheck \\naph thalene-1-(3-Ph-benzoTriazin-1-yl)-8-Ph-Bu opt in vac isomer $S \backslash \backslash 0,2 \backslash C$ , 3.7912198874,0.1821963189,-1.6842824909\C,2.5552331524,-0.0124334448, $-1.0787750873 \backslash \mathrm{C}, 2.4312366202,-1.0360488312,-0.0680710032 \backslash \mathrm{C}, 3.560292298$ $4,-1.9094733661,0.1587130718 \backslash \mathrm{C}, 4.7893925338,-1.6723622186,-0.516172676$ $1 \backslash \mathrm{C}, 4.9142519163,-0.6237212957,-1.3965207984 \backslash \mathrm{C}, 1.2787896717,-1.2634224$ $164,0.7621698323 \backslash \mathrm{C}, 3.45198016,-3.0067270312,1.0573185743 \backslash \mathrm{C}, 2.288368319$ $8,-3.2449552176,1.7522054492 \backslash \mathrm{C}, 1.2080049357,-2.3490260095,1.6175241633$ $\backslash \mathrm{H}, 3.8751916878,0.957224549,-2.4495441346 \backslash \mathrm{H}, 5.6312962932,-2.340492969$, $-0.3176806612 \backslash \mathrm{H}, 5.8618227815,-0.4344638837,-1.9067365287 \backslash \mathrm{H}, 4.319228535$ $5,-3.6595739517,1.1855141862 \backslash \mathrm{H}, 2.2072289398,-4.0947839601,2.4336801493$ $\backslash \mathrm{H}, 0.3004404424,-2.4835229548,2.2083096255 \backslash \mathrm{C}, 0.2441672541,0.896071433$, $1.3920274747 \backslash \mathrm{C}, 1.4225854727,1.4141656831,1.952128441 \backslash \mathrm{C},-0.9671887045,1$ $.6513763617,1.4252988623 \backslash \mathrm{C},-2.1035482441,-0.1238357666,0.5050085858 \backslash \mathrm{C}$, $1.4156325871,2.6918267897,2.5114623464 \backslash \mathrm{C},-0.9355122064,2.9441265858,1$. $9928749916 \backslash \mathrm{C}, 0.2401354665,3.4604821733,2.5249596155 \backslash \mathrm{H}, 2.337796849,0.82$ $2865691,1.9472986904 \backslash \mathrm{H}, 2.3359242052,3.0913068434,2.9442645897 \backslash \mathrm{H},-1.870$ $0411107,3.5079880323,2.0062720552 \backslash \mathrm{H}, 0.2481563125,4.461260159,2.9634934$ $112 \backslash \mathrm{C}, 1.4175431365,0.801601415,-1.6025075463 \backslash \mathrm{C}, 0.3121153647,0.19283805$ $24,-2.2136560741 \backslash \mathrm{C},-0.7092258659,0.9558983153,-2.7851970127 \backslash \mathrm{C}, 0.445607$ $5981,2.9624267645,-2.1733630048 \backslash \mathrm{N},-1.0206779325,-0.9017917263,0.419326$ $8713 \backslash \mathrm{N},-2.1380677293,1.1361243351,0.9465704792 \backslash \mathrm{C},-0.6760289441,2.35942$ $68036,-2.7723834462 \backslash \mathrm{C}, 1.4703811083,2.2062243396,-1.606174372 \backslash \mathrm{H}, 0.52300$ $60297,4.0513973381,-2.1327320675 \backslash \mathrm{H}, 0.2430089591,-0.8967546597,-2.24333$ $61944 \backslash \mathrm{H},-1.5474735237,0.4280981971,-3.2398233266 \backslash \mathrm{H}, 2.3178062805,2.7127$ $402476,-1.1377727293 \backslash \mathrm{C},-3.3824601216,-0.7423873525,0.0514761597 \backslash \mathrm{C},-4.5$ $817051339,-0.0159685747,0.1483549844 \backslash \mathrm{C},-3.4158879624,-2.0471954556,-0$. $4719402417 \backslash \mathrm{C},-5.7868641457,-0.5811660764,-0.2727333294 \backslash \mathrm{C},-4.6226179627$ $,-2.6090116407,-0.8912267949 \backslash \mathrm{C},-5.812242706,-1.8787101857,-0.794154129$ $5 \backslash \mathrm{H},-4.5456444512,0.9926305933,0.5615793501 \backslash \mathrm{H},-2.4846711248,-2.6100882$ $881,-0.5446914654 \backslash \mathrm{H},-6.7129646345,-0.0058800453,-0.1916128933 \backslash \mathrm{H},-4.635$ 
$6092022,-3.6239876777,-1.2972637025 \backslash \mathrm{H},-6.756493667,-2.3205780239,-1.12$ $33886798 \backslash \mathrm{N}, 0.1608491553,-0.3616361384,0.7943315738 \backslash \mathrm{C},-1.8074555867,3.2$ $297266969,-3.3513252107 \backslash \mathrm{C},-2.9240662561,2.3828812588,-3.9885250425 \backslash \mathrm{C},-$ $2.4287492055,4.0674728547,-2.2088042856 \backslash \mathrm{C},-1.2371827189,4.1730040759,-$ $4.4351695941 \backslash \mathrm{H},-2.5483979679,1.7663555507,-4.8204386496 \backslash \mathrm{H},-3.403031317$ $5,1.7157037656,-3.2554214007 \backslash \mathrm{H},-3.7065537099,3.0437503788,-4.393972759$ $8 \backslash \mathrm{H},-1.6912166312,4.7447602042,-1.751363906 \backslash \mathrm{H},-3.2586035521,4.68522825$ $61,-2.590780717 \backslash \mathrm{H},-2.8206085959,3.4143159987,-1.4133339404 \backslash \mathrm{H},-2.036838$ $0327,4.8071135592,-4.8524407284 \backslash \mathrm{H},-0.4600315524,4.8411375575,-4.033579$ $3188 \backslash \mathrm{H},-0.7911868055,3.5996811831,-5.2637519499 \backslash \backslash$ Version=ES64L-G09RevD $.01 \backslash$ State $=2-A \backslash H F=-1437.5884562 \backslash \mathrm{S} 2=0.766954 \backslash \mathrm{S} 2-1=0 . \backslash \mathrm{S} 2 \mathrm{~A}=0.750166 \backslash \mathrm{RMSD}=3$ $.005 e-09 \backslash \mathrm{RMSF}=9.176 \mathrm{e}-07 \backslash \mathrm{Dipole}=1.0716333,-0.0970197,0.1289794 \backslash$ Quadrupo $l e=4.6898285,2.5197957,-7.2096242,-2.9221643,4.8636504,-1.2265251 \backslash P G=C$ $01[\mathrm{X}(\mathrm{C} 33 \mathrm{H} 28 \mathrm{~N} 3)] \backslash \backslash$

\section{$R-1$ aB}

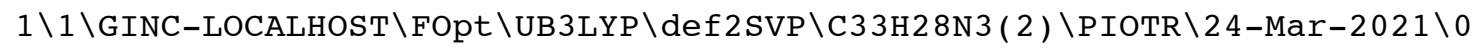
$\backslash \backslash \# P$ UB3LYP/Def2SVP FOpt(tight) Geom=(NoDistance, NoAngle) fcheck \\naph thalene-1-(3-Ph-benzoTriazin-1-yl)-8-Ph-Bu opt at Def2SVP in vac $\backslash \backslash 0,2 \backslash$ C, $3.791176666,0.1820582953,1.6843979278 \backslash C, 2.5552057995,-0.0125148173,1$ $.0788399788 \backslash \mathrm{C}, 2.431217778,-1.0360853685,0.0680894788 \backslash \mathrm{C}, 3.5602587823,-1$ $.9095296188,-0.1586916572 \backslash \mathrm{C}, 4.7893418675,-1.672477825,0.5162461601 \backslash \mathrm{C}, 4$ $.9141978847,-0.6238763245,1.3966417126 \backslash \mathrm{C}, 1.2787936076,-1.2633950813,-0$ $.7622004492 \backslash \mathrm{C}, 3.4519493485,-3.006743535,-1.0573460186 \backslash \mathrm{C}, 2.2883553044,-$ $3.2449131814,-1.7522827642 \backslash \mathrm{C}, 1.2080103611,-2.3489616602,-1.6176018694 \backslash$ $\mathrm{H}, 3.8751420167,0.9570528589,2.4496943563 \backslash \mathrm{H}, 5.6312352989,-2.3406220399$, $0.3177556633 \backslash \mathrm{H}, 5.8617560558,-0.4346642535,1.9068978244 \backslash \mathrm{H}, 4.3191853349$, $-3.6596075089,-1.1855386113 \backslash \mathrm{H}, 2.2072175064,-4.0947118092,-2.43379522 \backslash \mathrm{H}$ $, 0.3004627785,-2.4834108889,-2.2084241838 \backslash \mathrm{C}, 0.2442488491,0.8961513764$, $-1.3920051877 \backslash \mathrm{C}, 1.4226998626,1.4142381241,-1.9520440454 \backslash \mathrm{C},-0.967086430$ $9,1.6514889768,-1.4252876259 \backslash \mathrm{C},-2.1035237663,-0.1237315451,-0.50510952$ $48 \backslash \mathrm{C}, 1.4157993807,2.6919223266,-2.5113258125 \backslash \mathrm{C},-0.9353568576,2.9442616$ $373,-1.9928096696 \backslash \mathrm{C}, 0.2403226047,3.4606086385,-2.5248323609 \backslash \mathrm{H}, 2.337895$ $7822,0.8229142973,-1.9472067903 \backslash \mathrm{H}, 2.3361163226,3.0913963395,-2.9440797$ $543 \backslash \mathrm{H},-1.869870728,3.5081477847,-2.0062160476 \backslash \mathrm{H}, 0.2483845232,4.4614043$ $753,-2.9633248735 \backslash \mathrm{C}, 1.4175185802,0.8015275485,1.6025667993 \backslash \mathrm{C}, 0.3120542$ $154,0.1927672076,2.2136521162 \backslash \mathrm{C},-0.7092871601,0.9558299678,2.785189440$ $2 \backslash \mathrm{C}, 0.4456187022,2.9623541604,2.173478114 \backslash \mathrm{N},-1.0206765116,-0.901718997$ $9,-0.4194221598 \backslash \mathrm{N},-2.1379953965,1.136247571,-0.9466209725 \backslash \mathrm{C},-0.6760538$ $95,2.3593581497,2.7724350458 \backslash \mathrm{C}, 1.470392364,2.2061489595,1.6062934725 \backslash \mathrm{H}$ $, 0.5230463994,4.0513244391,2.1328948817 \backslash \mathrm{H}, 0.2429189359,-0.896824957,2$. $2432848667 \backslash \mathrm{H},-1.5475639503,0.4280324942,3.2397651364 \backslash \mathrm{H}, 2.317846637,2.7$ $126625159,1.1379419667 \backslash \mathrm{C},-3.3824673467,-0.74226866,-0.0516467621 \backslash \mathrm{C},-4$. $5816902928,-0.0158150261,-0.1485375911 \backslash \mathrm{C},-3.4159470059,-2.047097269,0$. $4717152249 \backslash \mathrm{C},-5.7868785022,-0.5809986783,0.272485752 \backslash \mathrm{C},-4.6227060466,-$ $2.6088994697,0.8909369093 \backslash \mathrm{C},-5.8123086028,-1.8785634133,0.7938527017 \backslash \mathrm{H}$ $,-4.545589285,0.9928000968,-0.5617195325 \backslash \mathrm{H},-2.4847471939,-2.6100170557$ $, 0.5444758357 \backslash \mathrm{H},-6.7129613557,-0.0056854811,0.1913566007 \backslash \mathrm{H},-4.63573754$ $22,-3.6238917382,1.2969319348 \backslash \mathrm{H},-6.7565823856,-2.3204203657,1.12303639$ $09 \backslash \mathrm{N}, 0.160877524,-0.3615785525,-0.7943637531 \backslash \mathrm{C},-1.8074781209,3.2296630$ $442,3.351373996 \backslash \mathrm{C},-2.4287109404,4.0674725763,2.2088664522 \backslash \mathrm{C},-2.9241324$ $325,2.382819829,3.9885003012 \backslash \mathrm{C},-1.237218312,4.1728808458,4.4352771425 \backslash$ $\mathrm{H},-1.6911452563,4.7447600518,1.7514796319 \backslash \mathrm{H},-2.8205596461,3.4143587989$ $, 1.4133554569 \backslash \mathrm{H},-3.2585626235,4.6852333491,2.590839981 \backslash \mathrm{H},-2.5485085584$ $, 1.7662499214,4.8204012073 \backslash \mathrm{H},-3.7066168391,3.0436922286,4.3939485538 \backslash \mathrm{H}$ $,-3.4030894561,1.7156850746,3.2553524952 \backslash \mathrm{H},-2.0368716946,4.8069936463$, $4.8525469342 \backslash \mathrm{H},-0.7912657805,3.5995121289,5.2638511454 \backslash \mathrm{H},-0.460036058$, $4.8410109057,4.0337413378 \backslash \backslash$ Version=ES64L-G09RevD.01 \State=2-A $\backslash \mathrm{HF}=-1437$ 
$.5884562 \backslash \mathrm{S} 2=0.766954 \backslash \mathrm{S} 2-1=0 . \backslash \mathrm{S} 2 \mathrm{~A}=0.750166 \backslash \mathrm{RMSD}=2.828 \mathrm{e}-09 \backslash \mathrm{RMSF}=9.175 \mathrm{e}-0$ $7 \backslash$ Dipole $=1.071635,-0.0970422,-0.1289462 \backslash$ Quadrupole $=4.6900142,2.5198432$ $,-7.2098574,-2.9220625,-4.8633283,1.22695 \backslash \mathrm{PG}=\mathrm{C} 01[\mathrm{X}(\mathrm{C} 33 \mathrm{H} 28 \mathrm{~N} 3)] \backslash$

\section{S-1bA}

$1 \backslash 1 \backslash G I N C-L O C A L H O S T \backslash F O p t \backslash U B 3 L Y P \backslash \operatorname{def} 2 \mathrm{SVP} \backslash C 27 \mathrm{H} 24 \mathrm{~N} 3$ ( 2) $\backslash P I O T R \backslash 24-M a r-2021 \backslash 0$ $\backslash \backslash \# P$ UB3LYP/Def2SVP FOpt(tight) Geom=(NoDistance, NoAngle) fcheck \\naph thalene-1-(3-tBu-benzoTriazin-1-yl)-8-Ph opt in vac $\backslash \backslash 0,2 \backslash N,-0.26317277$ $59,-0.8640481569,-0.6847128834 \backslash \mathrm{N},-2.5997748409,0.5737328331,-0.8229142$ $361 \backslash \mathrm{C},-2.4695825804,-0.5578829578,-0.1247260552 \backslash \mathrm{N},-1.3668824891,-1.292$ $8257606,-0.0167343628 \backslash \mathrm{C}, 0.856682456,2.1337400688,-2.5852277776 \backslash \mathrm{C}, 0.929$ $7008971,0.914153555,-1.913364575 \backslash C,-0.2327639051,0.3590617826,-1.35297$ $16209 \backslash \mathrm{C},-1.4769784322,1.056271611,-1.4310962966 \backslash \mathrm{C},-1.5150561122,2.2852$ $723713,-2.1274225966 \backslash \mathrm{C},-0.3664156094,2.8154795638,-2.7014687465 \backslash \mathrm{H},-2.4$ $770669122,2.798411499,-2.1804533099 \backslash \mathrm{H},-0.4109847408,3.768617766,-3.233$ $9785418 \backslash \mathrm{H}, 1.7638954897,2.5594529455,-3.0207730612 \backslash \mathrm{H}, 1.8826768402,0.393$ $3612715,-1.8257148871 \backslash \mathrm{C}, 0.9319127993,-1.609570572,-0.4060437072 \backslash \mathrm{C}, 1.68$ $2974274,-2.2849852604,-1.4296443805 \backslash C, 1.3536980654,-1.6082010421,0.912$ $6344592 \backslash \mathrm{C}, 1.273725713,-2.4556749248,-2.8032368461 \backslash \mathrm{C}, 2.9662287527,-2.81$ $84536735,-1.0317519742 \backslash \mathrm{C}, 2.5658707559,-2.2173688299,1.2949526471 \backslash \mathrm{H}, 0.7$ $329467101,-1.1005079594,1.6523955852 \backslash C, 2.1797122622,-2.9938815483,-3.7$ $097205846 \backslash \mathrm{C}, 3.836013634,-3.3816046044,-2.0059951398 \backslash \mathrm{C}, 3.3692662041,-2$. $7830788927,0.3314915775 \backslash \mathrm{H}, 2.8745891233,-2.2014276681,2.342667014 \backslash \mathrm{C}, 3.4$ $64476116,-3.4380867022,-3.3281832844 \backslash \mathrm{H}, 1.8594995451,-3.1232421138,-4.7$ $460311256 \backslash \mathrm{H}, 4.8056121368,-3.7663180527,-1.6796919264 \backslash \mathrm{H}, 4.3366106749,-3$ $.2164577025,0.5980857042 \backslash \mathrm{H}, 4.1365241542,-3.8610458532,-4.0787705994 \backslash \mathrm{C}$, $-0.103999984,-2.1933038261,-3.3215985595 \backslash C,-1.2104981285,-2.8869706015$ $,-2.8006528093 \backslash \mathrm{C},-0.3029200619,-1.3506694726,-4.4297166481 \backslash \mathrm{C},-2.476403$ $4655,-2.7391793122,-3.3710357754 \backslash \mathrm{H},-1.0749840877,-3.5529514203,-1.9458$ $275126 \backslash \mathrm{C},-1.5715653838,-1.1963461356,-4.9944398755 \backslash \mathrm{H}, 0.5458787963,-0.8$ $003690683,-4.8424075306 \backslash \mathrm{C},-2.6630382831,-1.8921002433,-4.4680353686 \backslash \mathrm{H}$, $-3.3222433819,-3.294994827,-2.9584313832 \backslash \mathrm{H},-1.7067466206,-0.5272654019$ $,-5.8480813917 \backslash \mathrm{H},-3.6559017515,-1.7750112447,-4.9094507708 \backslash \mathrm{C},-3.706014$ $1215,-1.0432197679,0.6462191867 \backslash C,-3.4638244466,-2.4034704887,1.317742$ $5541 \backslash \mathrm{C},-4.0337269659,0.0158704708,1.7230402792 \backslash \mathrm{C},-4.8895946741,-1.1518$ $052052,-0.3379609098 \backslash \mathrm{H},-3.2176907866,-3.1798548794,0.5781652789 \backslash \mathrm{H},-2.6$ $308667785,-2.3604369779,2.0339184571 \backslash \mathrm{H},-4.3711207958,-2.7170786408,1.8$ $58814816 \backslash \mathrm{H},-4.1958338496,1.0017823409,1.2634598686 \backslash \mathrm{H},-4.944592886,-0.2$ $687279654,2.2747274072 \backslash \mathrm{H},-3.2117568675,0.1079440787,2.4518777401 \backslash \mathrm{H},-5$. $8074066593,-1.437675683,0.2011972985 \backslash \mathrm{H},-5.0621385439,-0.1935833571,-0$. $8476291434 \backslash \mathrm{H},-4.6948624681,-1.916036824,-1.1071401461 \backslash \backslash$ Version=ES64L-G 09 RevD. $01 \backslash$ State $=2-A \backslash H F=-1206.6960057 \backslash S 2=0.765122 \backslash \mathrm{S} 2-1=0 . \backslash \mathrm{S} 2 \mathrm{~A}=0.750145 \backslash$ $\mathrm{RMSD}=5.240 \mathrm{e}-09 \backslash \mathrm{RMSF}=7.322 \mathrm{e}-07 \backslash \mathrm{Dipole}=1.1431731,-0.1474806,-0.2662631 \backslash \mathrm{Q}$ uadrupole $=3.3129541,-4.4013141,1.08836,-1.1791148,1.9081413,-2.7590704$ $\backslash \mathrm{PG}=\mathrm{C} 01 \quad[\mathrm{X}(\mathrm{C} 27 \mathrm{H} 24 \mathrm{~N} 3)] \backslash \backslash$

\section{$R-1 \mathrm{bA}$}

$1 \backslash 1 \backslash$ GINC-LOCALHOST $\backslash F O p t \backslash U B 3 L Y P \backslash \operatorname{def} 2 \mathrm{SVP} \backslash \mathrm{C} 27 \mathrm{H} 24 \mathrm{~N} 3$ ( 2) $\backslash P I O T R \backslash 24-M a r-2021 \backslash 0$ $\backslash \backslash \# \mathrm{P}$ UB3LYP/Def2SVP FOpt(tight) Geom=(NoDistance, NoAngle) fcheck \\naph thalene-1-(3-tBu-benzoTriazin-1-yl)-8-Ph opt in $\operatorname{vac} \backslash \backslash 0,2 \backslash \mathrm{N}, 0.743186327$ $4,1.5307766481,-0.5587825749 \backslash \mathrm{N}, 3.4367982174,1.253267972,-0.0967673734 \backslash$ $\mathrm{C}, 2.8560212465,2.4175492617,-0.4002839117 \backslash \mathrm{N}, 1.5625657831,2.6126789274$, $-0.638289164 \backslash \mathrm{C}, 1.0286843371,-2.1636042793,-0.2083361523 \backslash \mathrm{C}, 0.4482177599$ $,-0.9174277042,-0.4412023283 \backslash \mathrm{C}, 1.238006308,0.2418761615,-0.3654403677 \backslash$ C, $2.6370933389,0.1469853566,-0.0937254439 \backslash C, 3.1890334487,-1.1315690213$ , $0.1459082071 \backslash \mathrm{C}, 2.3964280707,-2.2713901292,0.0948276842 \backslash \mathrm{H}, 4.2587566302$ $,-1.180871111,0.3576878208 \backslash \mathrm{H}, 2.8383665947,-3.2536044579,0.2791403038 \backslash \mathrm{H}$ $, 0.4087910146,-3.0615437643,-0.2666771146 \backslash \mathrm{H},-0.6126354715,-0.843067953$ $4,-0.6781226695 \backslash \mathrm{C},-0.6092561164,1.7727309529,-0.9759778463 \backslash \mathrm{C},-1.738844$ 
$7442,1.5612676181,-0.1114853529 \backslash C,-0.7746674973,2.1849598098,-2.287283$ $5923 \backslash \mathrm{C},-1.67770255,1.2556210764,1.29784596 \backslash \mathrm{C},-3.0416597858,1.650354337$ $3,-0.7314735846 \backslash \mathrm{C},-2.0575754697,2.3564277332,-2.8452815899 \backslash \mathrm{H}, 0.1178763$ $045,2.3533554257,-2.8917171821 \backslash \mathrm{C},-2.8525770812,0.9236405754,1.96241353$ $23 \backslash \mathrm{C},-4.208253882,1.3229813136,0.013308305 \backslash \mathrm{C},-3.1674311361,2.062503752$ $6,-2.0866261585 \backslash \mathrm{H},-2.1590424963,2.6826219822,-3.8828596855 \backslash \mathrm{C},-4.113943$ $0409,0.9332691628,1.3280862977 \backslash \mathrm{H},-2.7970033919,0.6981074457,3.02977299$ $\backslash \mathrm{H},-5.179601066,1.3868962072,-0.4836816 \backslash \mathrm{H},-4.1701815247,2.1399970551$, $2.5145648461 \backslash \mathrm{H},-5.0088563376,0.6715192954,1.8977718815 \backslash \mathrm{C},-0.449182311$, $1.3687581131,2.1425970675 \backslash \mathrm{C}, 0.2171942034,2.5993913577,2.2781688048 \backslash \mathrm{C},-$ $0.0159023505,0.2828618043,2.9240208983 \backslash \mathrm{C}, 1.2851071686,2.7366395323,3.1$ $672247136 \backslash \mathrm{H},-0.1098579797,3.4570723835,1.686526729 \backslash \mathrm{C}, 1.0584705693,0.41$ $84669481,3.8069273176 \backslash \mathrm{H},-0.5197988313,-0.6815291199,2.8258263936 \backslash \mathrm{C}, 1.7$ $118122537,1.6471594341,3.933213824 \backslash \mathrm{H}, 1.783685759,3.7042315783,3.266235$ $5972 \backslash \mathrm{H}, 1.3869819979,-0.4413128079,4.3964236786 \backslash \mathrm{H}, 2.5508500798,1.756485$ $4464,4.6248776249 \backslash \mathrm{C}, 3.7747126371,3.6435647083,-0.5078101624 \backslash \mathrm{C}, 2.979227$ $5081,4.9346067855,-0.7533616728 \backslash \mathrm{C}, 4.5826116586,3.770708495,0.800774594$ $1 \backslash \mathrm{C}, 4.7459962953,3.4008466052,-1.685228281 \backslash \mathrm{H}, 2.3972257892,4.8823249843$ $,-1.6845534657 \backslash \mathrm{H}, 2.2694643526,5.1321669368,0.0636675853 \backslash \mathrm{H}, 3.6712644819$ , $5.7892413547,-0.8239317698 \backslash \mathrm{H}, 5.1392878799,2.8458422472,1.006821445 \backslash \mathrm{H}$, $5.2973302391,4.6064587004,0.7266749162 \backslash \mathrm{H}, 3.91838591,3.9660599365,1.657$ $65831 \backslash \mathrm{H}, 5.457279597,4.2383251212,-1.7731921402 \backslash \mathrm{H}, 5.3151131983,2.471703$ $7002,-1.5358469528 \backslash \mathrm{H}, 4.1999729334,3.3192004147,-2.6394340588 \backslash \backslash$ Version= ES64L-G09RevD. $01 \backslash \mathrm{State}=2-\mathrm{A} \backslash \mathrm{HF}=-1206.6960057 \backslash \mathrm{S} 2=0.765122 \backslash \mathrm{S} 2-1=0 . \backslash \mathrm{S} 2 \mathrm{~A}=0$. $750145 \backslash \mathrm{RMSD}=5.155 \mathrm{e}-09 \backslash \mathrm{RMSF}=7.386 \mathrm{e}-07 \backslash \mathrm{Dipole}=-1.085578,-0.4578361,-0.10$ $67894 \backslash$ Quadrupole $=1.4266966,-1.5679419,0.1412453,1.2988195,4.1127601,-2$ $.7479019 \backslash \mathrm{PG}=\mathrm{C} 01 \quad[\mathrm{X}(\mathrm{C} 27 \mathrm{H} 24 \mathrm{~N} 3)] \backslash \backslash$

\section{References}

(1) Fulmer, G. R.; Miller, A. J. M.; Sherden, N. H.; Gottlieb, H. E.; Nudelman, A.; Stoltz, B. M.; Bercaw, J. E.; Goldberg, K. I. NMR chemical shifts of trace impurities: Common laboratory solvents, organics, and gases in deuterated solvents relevant to the organometallic chemist, Organometallics 2010, 29, 2176-2179.

(2) Constantinides, C. P.; Obijalska, E.; Kaszyński, P. Access to 1,4dihydrobenzo[e][1,2,4]triazin-4-yl derivatives, Org. Lett. 2016, 18, 916-919.

(3) Zhou, Y.; Zhang, Z.; Jiang, Y.; Pan, X.; Ma, D. Synthesis of 1,2,4-benzotriazines via copper(I) iodide/1H-pyrrole-2-carboxylic acid catalyzed coupling of o-haloacetanilides and N-Boc hydrazine, Synlett 2015, 1586-1590.

(4) Berezin, A. A.; Zissimou, G.; Constantinides, C. P.; Beldjoudi, Y.; Rawson, J. M.; Koutentis, P. A. Route to benzo- and pyrido-fused 1,2,4-triazinyl radicals via N'-(het)aryl-N'-[2nitro(het)aryl]hydrazides, J. Org. Chem. 2014, 79, 314-327.

(5) Dominguez, Z.; Lopez-Rodriguez, R.; Alvarez, E.; Abbate, S.; Longhi, G.; Pischel, U.; Ros, A. Azabora[5]helicene charge-transfer dyes show efficient and spectrally variable circularly polarized luminescence, Chem. Eur. J. 2018, 24, 12660-12668. 
(6) Romero-Nieto, C.; López-Andarias, A.; Egler-Lucas, C.; Gebert, F.; Neus, J.-P.; Pilgram, O. Paving the way to novel phosphorus-based architectures: A noncatalyzed protocol to access sixmembered heterocycles, Angew. Chem. Int. Ed. 2015, 54, 15872-15875.

(7) PK, Rigaku Oxford Diffraction Ltd, Yarnton, Oxfordshire, England, 2018.

(8) Sheldrick, G. M. SHELXT - Integrated space-group and crystal- structure determination, Acta Cryst., Sect. A 2015, A71, 3-8.

(9) Sheldrick, G. M. Crystal structure refinement with SHELXL, Acta Cryst., Sect. C 2015, C71, 3-8.

(10) Neugebauer, F. A.; Rimmler, G. ENDOR and triple resonance studies of 1,4-dihydro-1,2,4benzotriazinyl radicals and 1,4-dihydro-1,2,4-benzotriazine radical cations, Magn. Reson. Chem 1988, 26, 595-600.

(11) Hande, A. A.; Darrigan, C.; Bartos, P.; Baylère, P.; Pietrzak, A.; Kaszyński, P.; Chrostowska, A. UV-Photoelectron spectroscopy of stable radicals: The electronic structure of planar Blatter radicals as materials for organic electronics, Phys. Chem. Chem. Phys. 2020, 22, $23637-23644$.

(12) Connelly, N. G.; Geiger, W. E. Chemical redox agents for organometallic chemistry, Chem. Rev. 1996, 96, 877-910.

(13) Reist, M.; Testa, B.; Carrupt, P.-A.; Jung, M.; Schurig, V. Racemization, enantiomerization, diastereomerization, and epimerization: Their meaning and pharmacological significance, Chirality 1995, 7, 396-400.

(14) Gaussian 09, Revision A.02, M. J. Frisch, G. W. Trucks, H. B. Schlegel, G. E. Scuseria, M. A. Robb, J. R. Cheeseman, G. Scalmani, V. Barone, B. Mennucci, G. A. Petersson, H. Nakatsuji, M. Caricato, X. Li, H. P. Hratchian, A. F. Izmaylov, J. Bloino, G. Zheng, J. L. Sonnenberg, M. Hada, M. Ehara, K. Toyota, R. Fukuda, J. Hasegawa, M. Ishida, T. Nakajima, Y. Honda, O. Kitao, H. Nakai, T. Vreven, J. A. Montgomery, Jr., J. E. Peralta, F. Ogliaro, M. Bearpark, J. J. Heyd, E. Brothers, K. N. Kudin, V. N. Staroverov, R. Kobayashi, J. Normand, K. Raghavachari, A. Rendell, J. C. Burant, S. S. Iyengar, J. Tomasi, M. Cossi, N. Rega, J. M. Millam, M. Klene, J. E. Knox, J. B. Cross, V. Bakken, C. Adamo, J. Jaramillo, R. Gomperts, R. E. Stratmann, O. Yazyev, A. J. Austin, R. Cammi, C. Pomelli, J. W. Ochterski, R. L. Martin, K. Morokuma, V. G. Zakrzewski, G. A. Voth, P. Salvador, J. J. Dannenberg, S. Dapprich, A. D. Daniels, O. Farkas, J. B. Foresman, J. V. Ortiz, J. Cioslowski, and D. J. Fox, Gaussian, Inc., Wallingford CT, 2009. 